\title{
Can remittances influence the tenure and quality of housing in Uganda?
}

Citation for published version (APA):

Rugadya, M. A. (2014). Can remittances influence the tenure and quality of housing in Uganda? [Doctoral Thesis, Maastricht University]. Boekenplan. https://doi.org/10.26481/dis.20140626mr

Document status and date:

Published: 01/01/2014

DOI:

10.26481/dis.20140626mr

Document Version:

Publisher's PDF, also known as Version of record

\section{Please check the document version of this publication:}

- A submitted manuscript is the version of the article upon submission and before peer-review. There can be important differences between the submitted version and the official published version of record.

People interested in the research are advised to contact the author for the final version of the publication, or visit the DOI to the publisher's website.

- The final author version and the galley proof are versions of the publication after peer review.

- The final published version features the final layout of the paper including the volume, issue and page numbers.

Link to publication

\footnotetext{
General rights rights.

- You may freely distribute the URL identifying the publication in the public portal. please follow below link for the End User Agreement:

www.umlib.nl/taverne-license

Take down policy

If you believe that this document breaches copyright please contact us at:

repository@maastrichtuniversity.nl

providing details and we will investigate your claim.
}

Copyright and moral rights for the publications made accessible in the public portal are retained by the authors and/or other copyright owners and it is a condition of accessing publications that users recognise and abide by the legal requirements associated with these

- Users may download and print one copy of any publication from the public portal for the purpose of private study or research.

- You may not further distribute the material or use it for any profit-making activity or commercial gain

If the publication is distributed under the terms of Article $25 \mathrm{fa}$ of the Dutch Copyright Act, indicated by the "Taverne" license above, 


\section{Can Remittances influence the Tenure and Quality of Housing in Uganda?}


(C) 2014 Margaret A. Rugadya, Maastricht

ISBN 9789086663309

Publishing: Boekenplan, Maastricht

www.boekenplan.nl

All rights reserved. No part of this publication may be reproduced, stored in a retrieval system, or transmitted in any form, or by any means, electronic, mechanical, photocopying, recording or otherwise, without the prior permission in writing, from the author. 


\section{Can Remittances influence the Tenure and Quality of Housing in Uganda?}

\section{DISSERTATION}

to obtain the degree of Doctor at the Maastricht University, on the authority of the Rector Magnificus Prof. dr. L.L.G. Soete, in accordance with the decision of the Board of Deans, to be defended in public on $26^{\text {th }}$ June 2014, at 12.00 hours

by

Margaret Agaba Rugadya 


\title{
Supervisor
}

Prof. dr. Chris de Neubourg

\section{Co-supervisors}

Prof. dr. Edward Kirumira (Makerere University)

Dr. James Mackie (ECDPM)

\author{
Assessment Committee \\ Prof. dr. Luc Soete (UN Merit, Maastricht University) \\ Prof. dr. Ben White (Erasmus University, Rotterdam) \\ Dr. Melissa Siegel (UN Merit / MSoG, Maastricht University) \\ Dr. Paul Engel (ECDPM)
}




\section{Declaration}

I hereby declare that this thesis is my own work and effort and that it has not been submitted anywhere for any award. Where other sources of information have been used, they have been acknowledged.

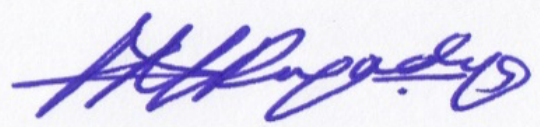

$26^{\text {th }}$ June 2014 



\section{Acknowledgements}

I take this opportunity to express my profound gratitude, first to my lead supervisor Prof. dr. Chris de Neubourg for his exemplary guidance, monitoring and constant encouragement throughout the course of writing this thesis. I also express my sincere gratitude to my co-supervisors, Prof. Dr. Edward Kirumira of Makerere University and Dr. James Mackie of the European Centre for Development Policy Management. The blessing, help and guidance given by you from time to time shall carry me a long way in the journey of my life.

I also take this opportunity to express a deep sense of gratitude to Dr. Mindel van de Laar, the PhD Coordinator for her cordial support, valuable information and guidance, which helped me in completing this task through its various stages.

I am obliged to the European Centre for Development Policy and Management for their scholarship, which supported three years of my study at Maastricht University. Furthermore, I am also grateful for a year of support from the Maastricht School of Governance.

Finally, I thank my family and friends for their constant encouragement, without which this thesis would have been impossible to complete. I am grateful for your love and cooperation during the period of writing my thesis.

Margaret A. Rugadya 



\section{Table of Contents}

List of Tables and Figures $\quad 12$

$\begin{array}{ll}\text { Thesis Abstract } & 14\end{array}$

Chapter One: Introduction $\quad 15$

$\begin{array}{lll}1.1 & \text { Introduction } & 15\end{array}$

1.2 Migration and Remittances 15

1.3 Remittance Flows to Sub-Saharan Africa 16

1.4 Remittance Flows to Uganda 19

$1.5 \quad$ Problem Statement 22

1.6 Research Questions and Sub Questions 23

$\begin{array}{lll}1.7 & \text { Outline of Dissertation } & 24\end{array}$

Chapter 2: Review of Literature $\quad 26$

2.1 Introduction 26

2.2 Theories of Migration 26

$2.3 \quad$ Theories of Remittances 31

2.3.1 Remittance Transfers 31

2.3.2 Remittance Use 36

$2.4 \quad$ Conclusions from the Literature $\quad 42$

2.4.1 Theoretical Implications for the thesis from the Literature $\quad 42$

2.4.2 Empirical Implications for the thesis from the Literature 43

2.4.3 Methodological Challenges for the thesis 44

Chapter 3: Housing in Uganda $\quad 47$

$\begin{array}{lll}3.1 & \text { Introduction } & 47\end{array}$

3.2 Methods $\quad 47$

3.3 Status of Housing in Uganda 48

3.4 Real Estate Market in Uganda $\quad 50$

3.5 Financing Housing in Uganda 53

3.6 Remittances and their Potential 55

$\begin{array}{lll}3.7 & \text { Conclusions } & 58\end{array}$ 
Chapter 4: Methodology $\quad 60$

$\begin{array}{lll}4.1 & \text { Introduction } & 60\end{array}$

4.2 Research Variables and their Measures 60

4.3 Research Questions and Hypothesis 63

4.4 Data Description 64

4.5 Reliability of Data Reported on Income / Expenditure 66

4.6 Data Analysis Method 67

$\begin{array}{lll}4.7 & \text { Endogeneity in Analysis } & 70\end{array}$

$\begin{array}{lll}4.8 & \text { Fungibility of Income } & 72\end{array}$

$\begin{array}{lll}4.9 & \text { Conclusion } & 74\end{array}$

Chapter 5: Remittances and Housing Tenure in Uganda 75

$\begin{array}{lll}5.1 & \text { Introduction } & 75\end{array}$

5.2 Theory and Evidence from Other Studies 75

$\begin{array}{lll}5.3 & \text { Household Size } & 78\end{array}$

$\begin{array}{lll}5.4 & \text { Household Distribution } & 79\end{array}$

5.5 Relations: Remittances and Housing Tenure 81

5.6 Logistic Regressions for Hypothesis Testing 89

5.7 Summary of Findings 90

$\begin{array}{lll}5.8 & \text { Discussion and Conclusions } & 92\end{array}$

Chapter 6: Remittance and Housing Quality in Uganda 95

$\begin{array}{lll}6.1 & \text { Introduction } & 95\end{array}$

6.2 Theory and Evidence from other Studies 96

6.3 Status of Housing Quality 98

6.3.1 Access to Welfare Amenities by Households 98

6.3.2 Physical Conditions of Housing 102

6.4 Relations: Remittances and Housing Quality 105

6.4.1 Remittances and Household Welfare Amenities 105

6.4.2 Remittances and Physical Conditions of Housing 112

6.4.3 Correlation Matrix: Remittances and Housing Quality 118

6.5 Logistic Regressions for Hypothesis Testing 119

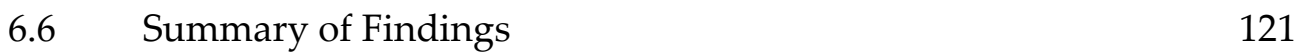

$\begin{array}{lll}6.7 & \text { Discussion and Conclusions } & 124\end{array}$ 
Chapter 7: Thesis Conclusions

7.1 Introduction

7.2 Overall Conclusion

7.3 Theoretical Base

128

7.4 Household Incomes and Remittances

129

7.5 Remittances and Housing Tenure

7.6 Remittances and Housing Quality

7.7 Remittances and Gradual Improvements in Housing

131

7.8 Financing Housing Tenure and Quality

131

7.9 Remittances in the Real Estate Market

7.10 Limitations

References 


\section{List of Tables and Figures}

Figure 1.1: Remittances and Other Resource Flows to Africa 1990 - 2010

Figure 1.2: Capital Flows to Sub-Saharan Africa 1990 -2010 17

Figure 1.3: Flow of Remittances to Sub-Saharan Africa, 1990-2010 17

Figure 1.4: Remittance inflows to Uganda, 1996 - $2008 \quad 20$

Figure 1.5: Remittance Flows compared to FDI and NGO inflows to Uganda 20

Table 1.6: Use of Cash Remittances in Uganda, 2007

Table 3.1: Services Offered by Real Estate Firms 52

Table 3.2: Migrants/ Remittances in the Clientele of Firms 57

Figure 5.1: Distribution of households by household size $\quad 79$

Figure 5.2: Household Distribution in Rural and Urban Areas - 2005 to $2010 \quad 80$

Figure 5.3: Distribution of households by remittances and Location in 2005/2006 80

Figure 5.4: Distribution of households by remittances and location in 2009/2010 81

Table 5.5: Value of Total Remittances at Household Level in 2005/2006 82

Table: 5.6: Value of Total Remittances at Household Level in 2009/2010 82

Table 5.7: Cash Value of Remittances Received 83

Table 5.8: Housing Structure between 2005/2006 and 2009/2010 85

Figure 5.9: Status of Tenure in 2005/2006 85

Figure 5.10: Status of Tenure in 2009/2010 86

Figure 5.11: Remittances and status of housing tenure in 2005/2006 87

Table 5.12: Remittances and status of Housing Tenure in 2005/2006 88

Figure 5.13: Remittances and status of housing tenure in 2009/2010 88

Table 5.14: Remittances and status of Housing Tenure in 2009/2010 89

Table 5.15: Correlation matrix for receipt of remittances and status of housing tenure $\quad 89$

Table 5.16: Regression of Remittances with Housing Tenure in 2005/2006 90

Table 5.17: Regression of Remittances with Housing Tenure in 2009/2010 90

Table 5.18: Overall Influence of Remittances on Housing Tenure 90

Figure 6.1: Status of access to drinking Water in 2005/2006 98

Figure 6.2: Status of access to drinking water in 2009/2010 99

Table 6.3: Type of Toilet used by Households 100

Table 6.4: Status of Household's Access to Lighting Source 101

Table 6.5: Status of Households' access to Cooking Fuel 102

Table 6.6: Construction Materials of Roof of Houses 103

Table 6.7: Material of External Wall of House 104 
Table 6.8: Material of Floor of Houses

Table 6.9: Cash value of Remittances and source of Lighting in 2005/2006

Table 6.10: Cash value of remittances and source of lighting in 2009/2010

Table 6.11: Cash value of Remittances and cooking fuel in 2005/2006

Table 6.12: Cash value of Remittances and cooking fuel in 2009/2010

Table 6.13: Cash value of Remittances and type of toilet used in 2005/2006 108

Table 6.14: Cash value of Remittances and type of toilet used in 2009/2010 109

Table 6.15: Remittances and Source of drinking water in 2005/2006 111

Table 6.16: Remittances and Source of drinking water in 2009/2010 111

Table 6.17: Remittances and Roof Materials in 2005/2005 113

Table 6.18: Remittances and Roof Materials in 2009/2010 113

Table 6.19: Remittances and Material of External Wall in 2005/2006 114

Table 6.20: Remittances and Material of External Wall in 2009/2010 115

Table 6.21: Remittances and Floor Material in 2005/2005 116

Table 6.22: Remittances and Floor Material in 2009/2010 117

Table 6.23: Spearman's Correlation Matrix for 2005/2006 118

Table 6.24: Spearman's Correlation Matrix for 2009/2010 119

Table 6.25: Regression of Remittance on Housing Quality Variables 120

Table 6.26: Overall Influence of Remittances on Housing Quality 121 


\section{Thesis Abstract}

Remittances have increasingly become an important source of foreign capital, exceeding the inflow of foreign aid and other private capital inflows to many countries in Africa. Remittances are now an acknowledged source of additional income for households, given that they are private funds whose use does not only rely on one user but rather two users, the households and migrants themselves, with no intermediary. Theoretically remittances constitute one such explanatory factor for migrants to maintain attachment with their home countries, which is adequately described by trans-nationalism theorists. The demand for housing in Uganda far exceeds the supply, with the housing shortage estimated to reach close to 8 million units in 2020. Significant proportions of remittances, approximately 25 per cent are absorbed by housing, which is one of the major beneficiary sectors in Uganda. Faced with this growth, some governments have attempted to regulate the use of such inflows through policy, albeit without success. However, for the housing sector it is possible to create incentives for the targeted use of remittances for advancement of tenure and quality of housing. The findings of this thesis from a pooled-cross section analysis on sample survey data from the Uganda National Household Survey 2005/2006 (UNHS III) and 2009/2010 (UNHS IV), show that due to significant positive correlations between remittances and the attributes of housing tenure (own and rent) and housing quality (access to utilities and physical condition of housing), remittances can be conditioned. Cross-tabulation and correlation matrices confirm the independence of remittances and their influence as an explanatory variable for the changes in housing tenure and quality. The logistic regression results place higher odds on households receiving remittances to advance their housing tenure and finance improvements in housing quality for both utilities and physical conditions than those that do not. The conclusion is that remittances can serve as a tool for improved housing tenure and quality for households. 


\section{Chapter One: Introduction}

\subsection{Introduction}

This chapter introduces the research area by highlighting trends in the inflow of remittances to sub-Saharan Africa, justifying the choice of Uganda as a case study area in providing micro level data on the impact of remittances on the housing sector in recipient countries. It also details the relationships under investigation in the subsequent chapters, and defines the study variables and their measures. The research questions and sub-questions are also defined.

\subsection{Migration and Remittances}

Remittances have increasingly become an important source of foreign capital, exceeding the inflow of foreign aid and other private capital inflows to many countries. Indeed, they currently represent around one-third of total financial flows to the developing world, having experienced a tremendous growth in recent years. However, there has been a limited amount of research on remittances in sub-Saharan Africa. While several empirical studies have analysed the impact of remittances on economic growth in recipient countries, the results remain largely inconclusive. Ratha et al (2011) notes that "migration from Africa has increased substantially over the past few decades, however the migration rate (the ratio of emigrants to the total population of the country of origin) remains low on average", albeit with marked variation across countries.

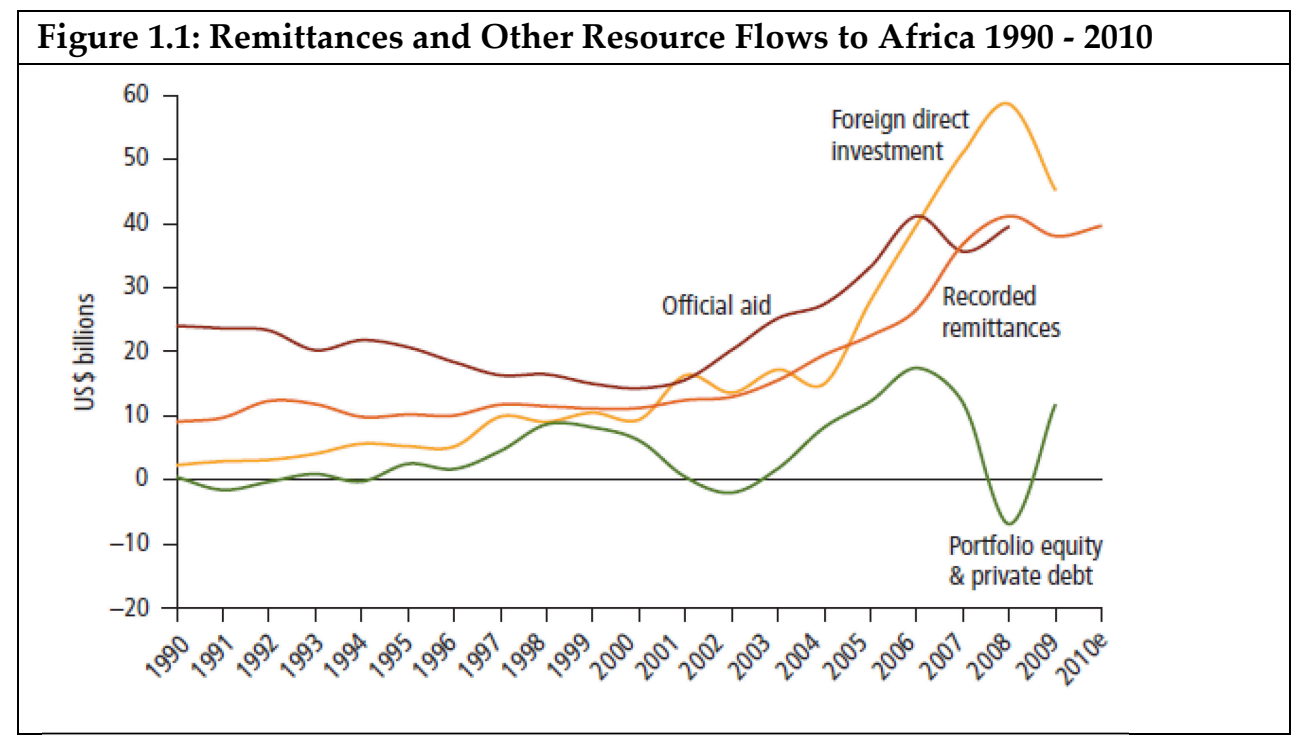

Source: Mohapatra and Ratha (2011), Remittance Markets in Africa, World Bank 
According to Julca (2012), international migrant remittance flows to developing countries were estimated at $\$ 351$ billion in 2011, up 8 per cent over 2010 and are projected to reach $\$ 414$ billion by 2014. According to Plaza et al (2011), officially recorded remittance flows to Africa are estimated to have reached $\$ 40$ billion in 2010 (divided roughly equally between North Africa and Sub-Saharan Africa) almost twice the amount received in 2005 and more than four times the $\$ 9.1$ billion received in 1990 as shown in figure 1.1 above. Remittances to Africa equalled 2.6 per cent of GDP in 2009, somewhat more than the 1.9 per cent average for all developing countries. Remittance flows to Africa are equal in size to aid inflows and in some instances may be larger than official aid. In other instances, remittances do exceed private capital flows such as foreign direct investments, portfolio debt and equity flows (Ratha et al, 2011).

According to Ratha (2011), migrant remittances contribute to international reserves, help finance imports, and improve the current account position of recipient countries. Ratha further asserts that they are associated with reductions in poverty, improved health and education outcomes, increased household resources devoted to investment and increased business investments. Similarly, Plaza et al (2011) points out that a significant part of remittances is spent on human and physical capital investments, such as education, health, land and housing, starting a business, improving farms and purchasing agricultural equipment (Plaza et al, 2011). Although the targeted use of remittances for specified sector growth such as land and housing has been noted in various studies (Yeboah 2003, Smith and Mazzucato 2003, Vertovec 2004, Doyle 2006, Ndubueze 2009), it is yet to be advanced based on empirical evidence co-relating improved housing with the receipt of remittances, which is the subject of this thesis.

\subsection{Remittance Flows to Sub-Saharan Africa}

Sub-Saharan Africa received on average around 6 per cent of total remittance flows to developing countries between 2005 and 2009, attaining a high of around seven (7) per cent in 2009, based on estimates of workers' remittances and compensation of employees received from the World Bank's World Development Indicators (2010). 


\section{Figure 1.2: Capital Flows to Sub-Saharan Africa 1990 -2010}

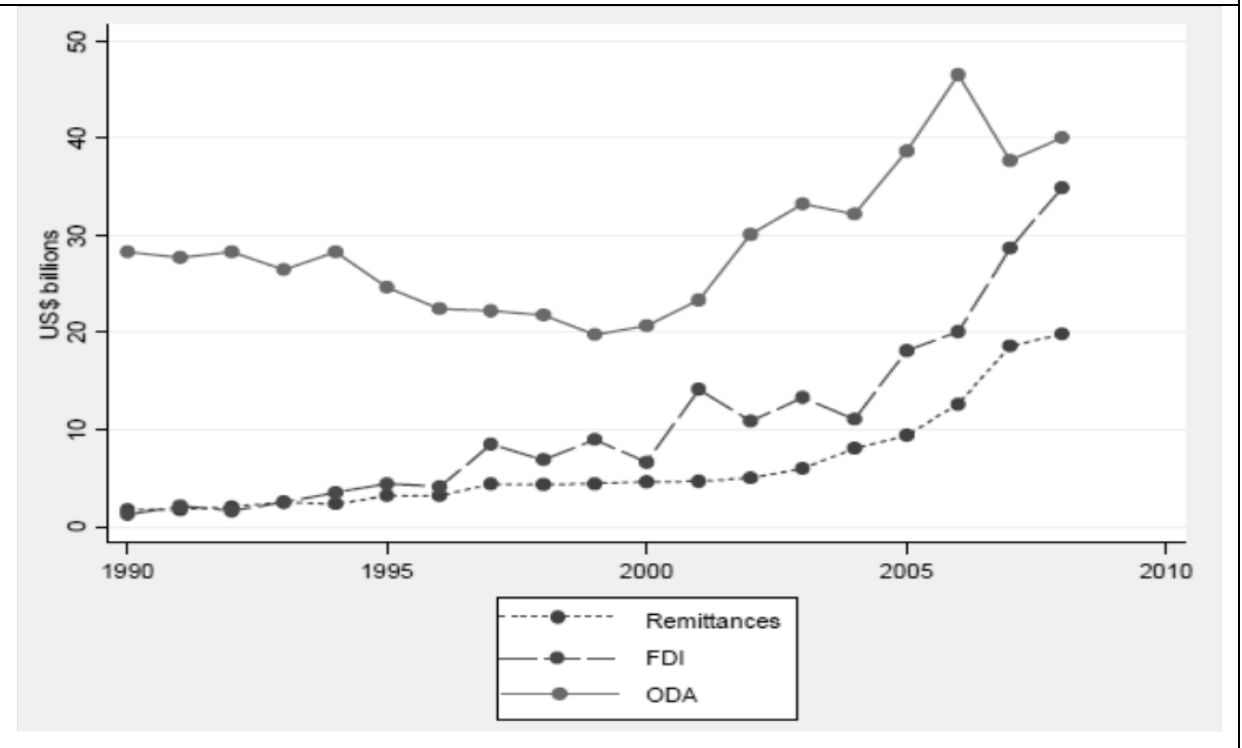

Source: Mohapatra and Ratha (2011), Remittance Markets in Africa, World Bank

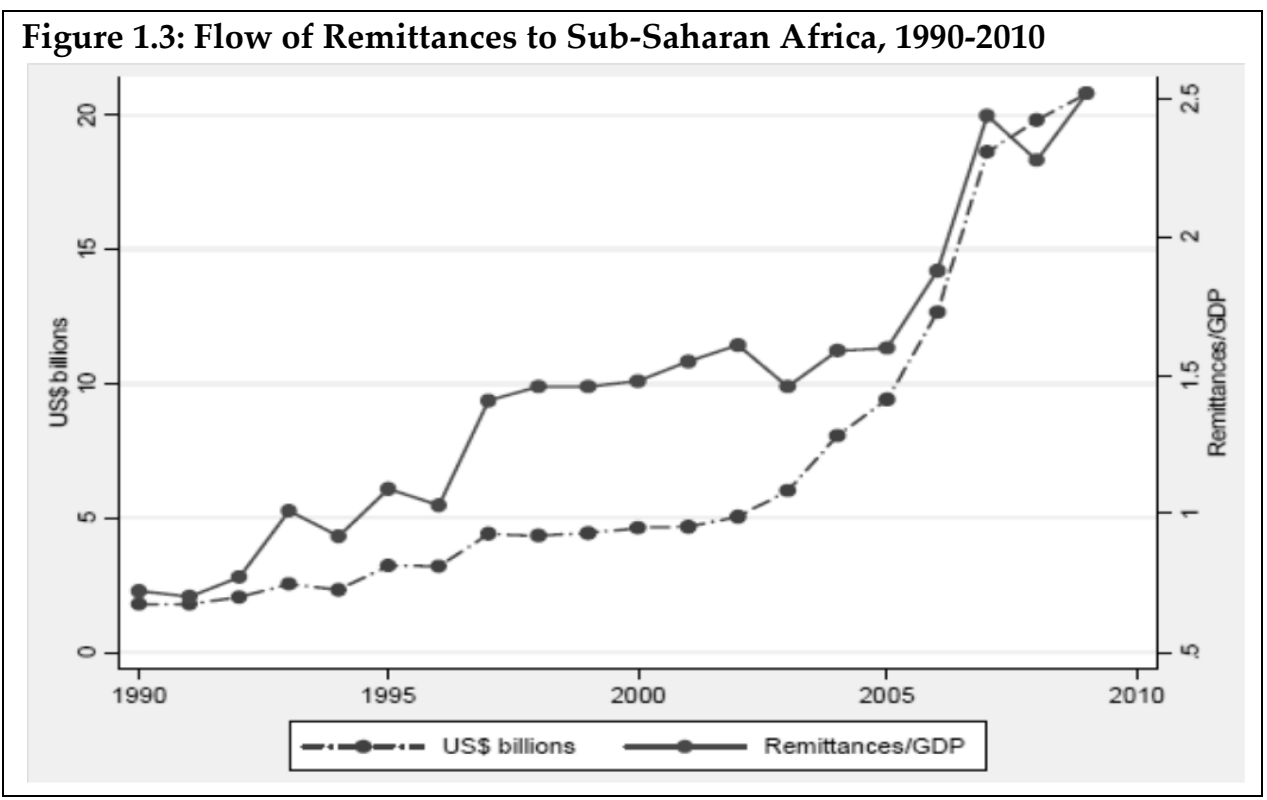

Source: Mohapatra and Ratha (2011), Remittance Markets in Africa, World Bank

Figure 1.2 compares remittances as a share of GDP for sub-Saharan Africa showing that it has been higher for the sub-region since 2007. Figure 1.3 shows the consistent 
increase in the flow of remittances to sub-Saharan Africa, both in relation to GDP and in absolute currency units. As depicted by the figure, in absolute terms, the steepest increase in remittances occurred between 2005 and 2007. When measured as a percentage of GDP, remittances have generally exhibited an upward trend since 1990, peaking at 2.5 per cent in 2009, based on estimates by Lartey (2010) with computations using data from World Development Indicators for 2010. While this is a relatively small share in absolute terms, many countries are attracting around the same level of remittances as GDP, and in several cases, even higher remittances than some major recipient countries in Asia and Latin America.

In Ratha et al's (2011) view, a few countries account for a substantial share of remittances to Sub-Saharan Africa and North Africa. It is further observed that "Nigeria's $\$ 10$ billion equalled about half of all officially recorded remittances to Sub-Saharan Africa in 2010. Other large remittance recipients in dollar terms include Sudan, Kenya, Senegal, South Africa, and Uganda". However, Mohapatra and Ratha (2011) find that as a share of GDP, "the largest recipients are Lesotho (28.5 per cent), Togo (10.7 per cent), Cape Verde (9.4 per cent), Senegal (9.3 per cent), and the Gambia (8.2 per cent)". In Ratha et al's, 2011 view, Egypt and Morocco, the two largest recipients in North Africa in terms of both absolute flows and share of GDP, account for three-quarters of flows to North Africa, followed by Algeria and Tunisia. Such estimates based on official data by the International Monetary Fund are likely to underreport the actual volume of remittances received by Africa countries compared to self-reported data compiled by the countries themselves.

In Plaza et al's (2011) view, the example of Ghana's central bank, which reported $\$ 1.6$ billion in remittance inflows in 2009, a figure that was more than 10 times more than the $\$ 114$ million reported by the IMF balance of payments statistics. According to Mohapatra and Ratha (2011), these discrepancies are in part related to the misreporting of migrant remittances with other types of current transfers, such as transfers to nongovernmental organizations and embassies and payments related to small-value-trade transactions. According to Mohapatra and Ratha (2011), surveys of migrants and remittance recipients and other secondary sources suggest that informal remittance flows, which are not included in the IMF estimates, could be equal to or exceed official figures for Sub - Saharan Africa (Page and Plaza 2006; IFAD 2009). Mohapatra and Ratha (2011) recognize efforts by central banks in African countries in collecting and estimating remittance inflows through household data collection and surveys of amongst remittance receiving households such as in Uganda, but even then such efforts are limited to a few countries.

Orozco (2002) observes that 'the links established through remittances suggest radical changes are remaking the outlook of countries' economies.' According to Adams and Page (2003), a 10\% increase in international remittances as a share of the 
country's GDP may reduce the share of households living in poverty by $1.6 \%$. Referring to Mishra (2005), Ratha et al assert that an increase of $1 \%$ in remittances in 13 Caribbean countries led to an increase in domestic private investment by $0.6 \%$. Baldé (2011) quotes Pelletier and Rocher (2008), to observe that migrant remittances have two advantages over foreign aid in the context of developing countries: (i) they are a source of more stable external financing; and (ii) by supporting private consumption, they have a stabilizing effect on the recipient countries' economies, acting as a mitigating mechanism for shocks. Baldé (2011) finds that remittances may have indirect positive effects on growth through savings and investment. Contrary to foreign aid, remittances are directly received by poor households and people in need, and not by governments as intermediaries. It can be assumed that this is the reason why remittances would be an effective means than foreign aid to allocate resources, to households' interest and to favour economic development.

\subsection{Remittance Flows to Uganda}

According to Endo et al (2010), remittances to Uganda are mainly from the US, the UK, Iraq and the United Arab Emirates (Dubai). Furthermore, remittance inflows increased from $\$ 546.36$ in $2007 / 08$ to $\$ 745.85$ million in 2008/09, representing an increase of 36.5 per cent, with this increment placing remittances almost at par with FDI in 2008/2009. Figure 1.4 shows remittance inflows to Uganda from 1996 to 2008. In 2008, remittance inflows and outflows accounted for 5 per cent and 2.2 per cent of GDP in Uganda, respectively. Net flows of 2.8 per cent of GDP are well above the sub-Saharan African net flows (1.2 per cent) and the developing countries net flows of 1.5 per cent (World Bank, 2009).

In 2008, remittances inflows to Uganda were US\$ 723.52 million in the balance of payments, equivalent to around 5 per cent of GDP. The balance of payment estimates of remittances for 2000 to 2008 averaged US\$ 386.1 million per annum, whereas between 1996 and 2000, remittance inflows averaged US\$ 175.4 (Endo et al, 2010). When compared to Uganda's budget for the fiscal year 2008/2009, this figure is equivalent to around 23 per cent of the budget. Put differently, it is bigger than the largest allocation to any one sector in the country (New Vision, 2010). 


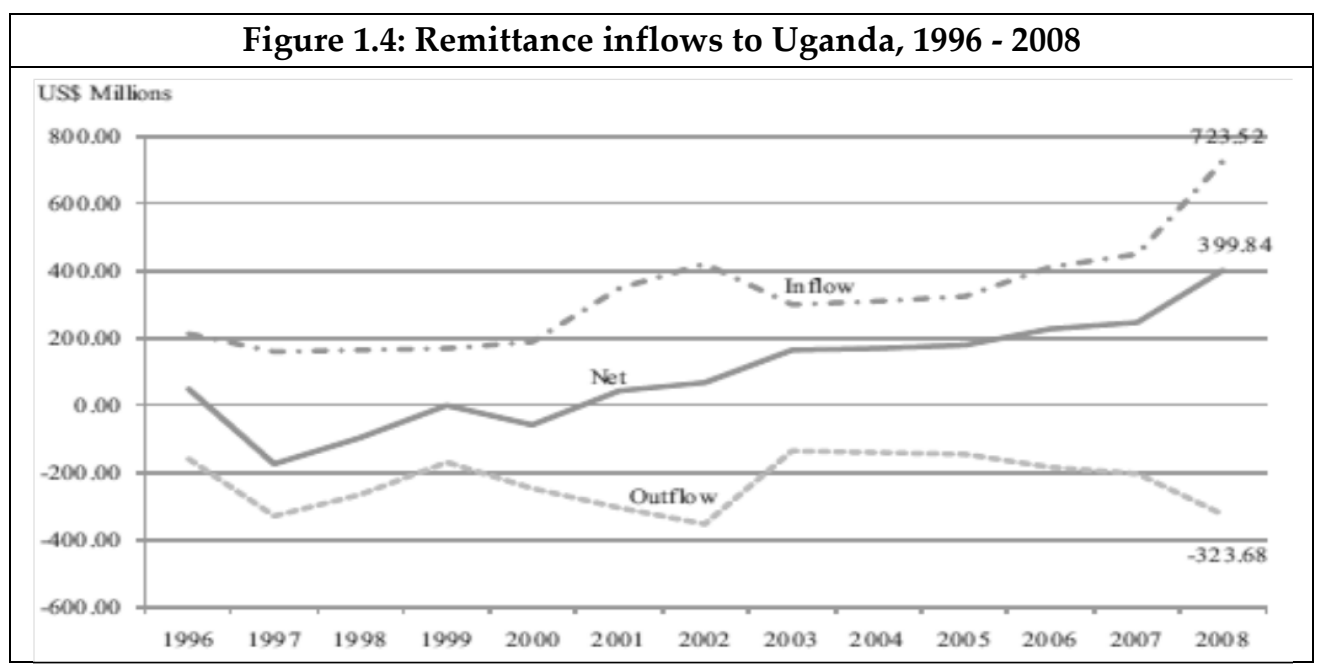

Source: Bank of Uganda, Balance of Payments, 2009

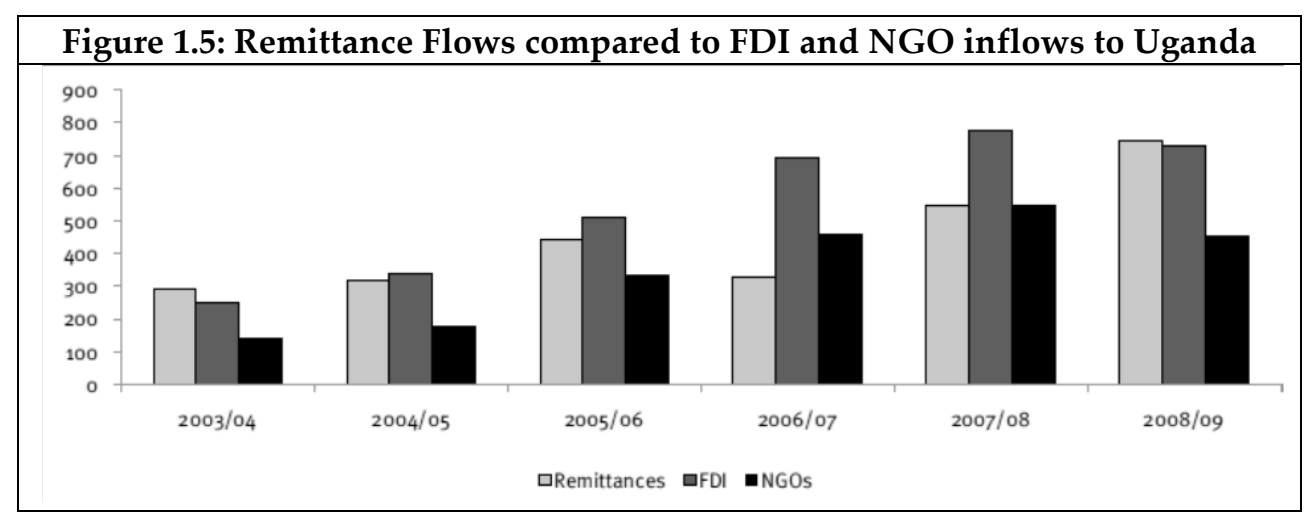

Source: Ssewanyana and Bategeka, 2010

Figure 1.5 shows, that there was no reduction in remittance flows when the crisis in world markets crisis happened, with Ugandans working abroad continuing to remit money home. This according to Ssewanyana and Bategeka is because: 1) such monies are a small share of the migrant's total earnings; 2) migrants in anticipation of a bigger disaster due to the crisis maintained the levels of remittances; or 3) migrants were employed in sectors whose nature was not affected by the crisis (Ssewanyana and Bategeka, 2010). Remittances to Uganda during the second quarter of 2009 declined by 11.4 per cent compared with same period in 2008. Ssewanyana and Bategeka's (2010) analysis shows that workers' remittances in the third quarter of 2009 were slightly lower than the corresponding period in 2008, with this reduction partly explaining the slowdown in investment in the construction sector 
during that period (Ministry of Finance, Planning and Economic Development, 2009).

Table 1.6 specifically analyses the use of cash remittances based on the 2007 remittance survey data by the Uganda Bureau of Statistics, with the findings showing that 52.2 per cent of the total remittances received in cash by households in Uganda were used for consumption; 27.4 per cent for education, 22 per cent for household expenditure and 2.7 per cent for health. Apart from consumption, a significant proportion of cash remittances (41.1 per cent) were spent on savings and investment, with building works accounting for 21.2 per cent and land purchase accounting for 6.9 per cent. Estimates in the last four years indicate that workers' remittances have exhibited a good record in performance, increasing every year. North America (US and Canada) have remained the major sources of remittances. According to the Bank of Uganda, the country received US\$ 732.4 million in 2008, which increased to US\$753.6 million in 2009. Furthermore, in 2010, the country (Uganda) realised US\$ 772 million and US\$ 813 million in 2011 (Daily Monitor, 2012). These figures as reported slightly differ from the figures recorded by the World Bank.

\begin{tabular}{|lc|}
\hline \multicolumn{2}{|l|}{ Table 1.6: Use of Cash Remittances in Uganda, 2007 } \\
\hline Use & Per cent \\
\hline 1. Consumption & $\mathbf{5 2 . 2}$ \\
Education & 27.4 \\
Household Expenditure & 22.0 \\
Health & 2.7 \\
\hline 2. Savings and Investment & $\mathbf{4 1 . 1}$ \\
\hline Building & 21.2 \\
Land Purchase & 6.9 \\
Business & 6.6 \\
Savings & 5.0 \\
Farming & 0.8 \\
Vehicle Purchase & 0.6 \\
Livestock & 0.0 \\
\hline 3. Personal and Community Service & $\mathbf{4 . 9}$ \\
Ceremony & 4.0 \\
Church & 0.8 \\
Visa Fees & 0.0 \\
\hline 4. Others & 2.9 \\
\cline { 2 - 2 } & $\mathbf{1 0 0}$ \\
\hline
\end{tabular}

Source: UBoS, 2007 
The Uganda National Household Survey (UNHS) of 2005/2006 reveals that median monthly nominal wages in Uganda averaged between US\$ 14.40 and US\$ 153.14. Comparing this with Endo et al's (2010) finding of an average monthly remittance of US\$ 500 from an undocumented migrant in the United States and US\$1,000 from a documented migrant in the United States, this shows that remittances have the potential to enhance the welfare gains of recipient families in Uganda. The choice of housing as the sector within which the impact of remittances is examined in this thesis, is justified by the sheer volume of remittances that the housing and construction account for which is approximately 28 per cent of remittances received in 2007 based on the Remittance Survey data for 2007 (Uganda Bureau of Statistics, 2007). Accordingly, this thesis questions whether such remittances can influence tenure of housing and quality of housing in Uganda. In pursuing the potential presented by remittances in the housing sector, this thesis is interested in drawing conclusions that are public policy focused on the prospects of harnessing migrants' investments. My core interest and focus in this thesis, therefore is extricating the influencing ability of remittances on households to improve quality of their housing or invest in more secure tenure of their housing.

\subsection{Problem Statement}

Despite the magnitude of remittances, the impact of these transfers on the economies of developing nations is only beginning to be ascertained. The interest for analysing remittances in the housing sector derives from the collective acceptance of the role of remittances and migrant-built houses, which have attracted the attention of comparative scholars who seek to, understand the relationship between transnational migration and "home" (Mazzucato, 2008). In this context, housing increments are partially accounted for by houses sold to migrants abroad (Maloney, 2004), the international transfer of monies into the housing sector (Yeboah, 2000), increases in housing stocks financed by migrants (Cohen, 2007) and 'long-distance house building' by diaspora wage earners (Diko and Tipple, 1992; Pellow, 2003; Mazzucato, 2008). It is suggested that by acquiring a house, the migrant turns capital flows into equity (Ndubueze 2009, Amuedo \& Pozo 2008, World Bank 1993).

Migrant inflows not only increase the size of the housing market, but also help to develop local capital markets. Similarly, Osili (2004) also finds that a large proportion of remittance income in Nigeria is spent on housing. In Ghana, Kabki et al (2003) finds that the majority of the migrants invested in housing for their family, and most of those who had not yet, hoped to do so in the future. In the Todgha oasis valley in Southern Morocco, remittances enabled families to move out of the traditional village and build new houses (de Haas, 2003). Theorists have indexed houses as powerful symbols of emigrants' continuing efforts to lay claim to local and national belonging (Pellow, 2003) and accrue social capital (Yeboah, 2000). However, 
as Fiadzo (2004) points out that very few housing quality and tenure studies have been undertaken in developing countries, yet remittances present a micro level potential for financing the improvement of housing stocks.

\subsection{Research Questions and Sub Questions}

In this thesis, I examine how remittances influence tenure and quality of housing by constructing relations between remittances and characteristics of migrant and nonmigrant households regarding housing tenure (specifically on rent or ownership) and quality of housing (state of physical structure and access to amenities). By analysing these variables, I determine the extent, structure and nature of relations between remittances and housing quality or tenure. With this analysis I contribute to the growing debate on use of remittances at household level, albeit within a sector such as housing in a developing economy such as Uganda. Accordingly, the overall research question therefore is: Can remittances (as a share of household income) influence the tenure and quality of housing at household level in Uganda? This overall research question is answered in three sub-questions:

Sub-Question One: What is the relationship between remittances and housing tenure at household level in Uganda? This question investigates the relationship between household income and tenure of housing in terms of ownership and rental status, measuring the status of migrant and non-migrant households in housing, whether (owned or rented) in relation to income from remittances. The dependent variable is housing tenure for migrant and non-migrant households, while the explanatory variable is remittances as a share of household income.

Sub-Question Two: What is the relationship between remittances and housing quality at the household level in Uganda? This question examines variations in housing quality between migrant and non-migrant households based on household income singling out remittances. In this respect, the dependent variable is quality of housing, while the explanatory variable is remittances as a share of household income.

Sub-Question Three: Is the use of remittances evident in Kampala's (Uganda) housing market? The dependent variable is housing services of construction, maintenance, operation, occupancy, use or appearance of dwelling units undertaken by real estate agents in Kampala, Uganda, licensed to negotiate and arrange sales (of either land or housing) as intermediaries for owners or owners of real estate property. Meanwhile, the explanatory variable is remittances received as payment for real estate services. This question is addressed through an assessment of the situation of the housing market in Kampala, based on a mini-survey conducted by author and the review of existing literature on housing finance. 


\subsection{Outline of Dissertation}

The first chapter sets the context for this research by highlighting trends in the flow of remittances to sub-Saharan Africa and Uganda. It introduces the research area, justifying the choice of Uganda as a case study area in providing micro level data on the impact of remittances on the housing sector in recipient countries. It also details the relationships under investigation in the subsequent chapters, and defines the study variables and their measures. The research questions and sub-questions are also defined.

The second chapter places the area of study within the theoretical developments that have shaped the debate on migration and remittances as a starting point. Indeed, this understanding is critical to suggestions at the conclusion of analysis, given that they are drawn in relation to migration and remittances, and hence the need for this grounding as a starting point. Additionally, the chapter also summarizes the findings of existing studies on remittances, underscoring their known contribution to the field of migration and remittances. As part of the conclusion to the literature review, contributions from empirical studies are highlighted and the implications of theory to the analysis proposed in this thesis are emphasized including the methodological caveats that need to be upheld.

The third chapter investigates the financing of housing through a summary narrative on the situation of the housing market and the variance likely to occur due to the inflow of remittances. This narrative, based on a review of three key studies, contextualizes the subsequent conclusions and research sub-questions in the broader socio-economic context of Uganda's housing market. The literature review was complemented by extracts from semi-structured qualitative interview questionnaires administered through face-to-face interviews with 37 real estate firms in Kampala, who were tasked with considering the inflow of remittances into their operations over the last 2 years. This is necessary to contextualize conclusions at the national level in the real estate and housing sectors.

The fourth chapter of this thesis builds on the conclusions of the second chapter and third chapter, to frame the investigation on remittances and housing tenure and quality. First by defining the research variables, sub-variables, and their measures, based on the research questions. The data sets applied in the analysis are also described showing how they were collected and the reliability of variables and their attributes. Specifically, the measures undertaken during data collection to ensure that income and expenditure reported by households was reliable. The data analysis method is also detailed and the hypotheses to be tested are also articled. The chapter ends with explanations on how endogeneity and fungibility of income are dealt with in the analysis. 
In the fifth chapter, the influence of remittances on housing tenure is analysed at three levels: (a) the descriptive data, followed by cross-tabulations showing the status of relationships between variables; (b) the Pearson's chi-square and Spearman's correlation matrices to prove the independence of variables; and (c) subsequently logistic regression to ascertain the structure of relations established. Of specific interest are the odds for a household to improve its ownership or rent of housing. The analysis is premised on models developed by housing economists who emphasize income as the major explanatory variable accounting for tenure change and disparities between migrant and non-migrant households. In addition, there is the argument that remittances serve more than simply to bridge wage differentials between locations, as articulated by the neo-classical economists, but rather are a source of additional household income that can aid migrant households to attain secure housing tenure (ownership and rental).

The sixth chapter determines whether households that receive remittances have a better prospect of improved physical conditions and access to welfare amenities than those that do not using a comparative approach and considered differentials in housing quality for migrant and non-migrant households. The assumption is that households that receive remittances have a second line of income that enables them to make improvements in their housing situation. By aggregating the various attributes of housing quality into a compound measure, a housing quality index is constructed to compare the status of housing quality at two different points in time (2005/2006 and 2009/2010), for households receiving remittances and those not receiving.

The seventh chapter offers a conclusion regarding all emerging findings, aggregating them to offer an opinion based on empirical findings presented in the preceding chapters on the influence of remittance on housing in a developing country at household level. 


\section{Chapter 2: Review of Literature}

\section{$2.1 \quad$ Introduction}

This chapter places the area of study within the theoretical developments that have shaped the debate on migration and remittances as a starting point. Indeed, this understanding is critical to suggestions at the conclusion of analysis, given that they are drawn in relation to migration and remittances, and hence the need for this grounding as a starting point. Additionally, the chapter also summarizes the findings of existing studies on remittances, underscoring their known contribution to the field of migration and remittances. To conclude the review, contributions from empirical studies are highlighted and the implication of theory to the analysis, in this thesis is emphasized including the methodological caveats that need to be upheld.

\subsection{Theories of Migration}

Economic motivation is the underlying premise of most neo-classical theories of migration, beginning with the expected income hypothesis advanced by Todaro (1969), who hypothesized that rural-to-urban migration is a response to expected urban income. This theory modelled the unemployment problem based on an individual's choice to migrate to the urban sector when the expected urban sector wage - calculated as the probability that a migrant is hired in the urban sector multiplied by the sector's real wage - is larger than the real wage of the rural sector. However, given that the expected urban wage increases by either an increase in available jobs or a boost in the urban wage, or alternatively a decline in rural wages, more migrants leave the rural sector and swell the labour supply in the urban causing higher unemployment (Rosen, 2007). In advancing his theory, Todaro (1969) recommended the equalization of the expected urban wage with the actual rural wage, or forcibly preventing individuals from migrating other than increasing the available jobs as the solution unemployment in urban areas resulting from migration. The Todaro (1969) model having dominated migration thinking in developing countries and it's suggested solutions to address unemployment in urban areas have proved imperfect over time, owing to the failure to account for changes in the welfare of the rural sector after migration.

Given the perfections in the Todaro (1969) model, the Harris and Todaro (1970) model emerged to advance the basics, but also provide a solution by suggesting a fixed urban wage to balance out the wage differentials between urban and rural areas. Despite the urban sector remaining the major pull for migration in this model, it further hypothesised that reverse migration from the urban sector to the 
agriculture sector is also possible. The model's use of shadow pricing suggests that an optimal wage subsidy would allow an economy to produce at the optimal production possibilities frontier and boost production in both the urban and rural sector. Therefore, as a solution, Harris and Todaro (1970) suggested a combination of both subsidies and migration restrictions for optimality in the choice of production.

Stiglitz (1974) and Bhagwati and Srinvasan (1974) do not ascribe to optimality in the choice of production, as concluded by Harris and Todaro (1970). Accordingly, their point of departure is on restrictions imposed on migrants, where wage subsidies are allocated to both the modern and rural sector as a possible way of preventing migration without restrictions. The allocation of wage subsides would allow optimal production without causing social unrest from migration restrictions. Todaro (1976) agreed with their results, providing further theoretical proof that increasing job opportunities in the urban sector causes an increase in migration.

Migrants not only consider the probability of finding a job in the urban sector, but also that of finding any informal job in the short-run in urban areas. If there is a high probability that a migrant can find a low paying job in the urban sector, there is less risk associated with migrating, thus inducing further migration. Barnum and Sabot (1977) and Lucas (1985) provided the first empirical proof of the Harris and Todaro model, with Barnum and Sabot evaluating two possibilities of why individuals migrated to the urban sector in Tanzania: 1) the expected wage differentials led to migration; and 2) education influenced mobility. Both possibilities are not mutually exclusive, and indeed the data confirmed both. De Haas (2007) concludes that while the classic Harris - Todaro models was not wrong in terms of predicting a transfer of labour from rural to urban areas, they may have been optimistic, at least implicitly, about the speed with which this would occur, and almost certainly wrong in the assumption that the migration process amounts to a lottery.

Credit for placing the behaviour of individual migrants in a wider societal context and consideration not of the individual, but rather the family or household as the most appropriate decision-making unit in migration is due to Stark (1980). This alternative view formed the basis for several strands of theories or approaches known as the 'new economics of labour migration'. De Haas (2010) acknowledges that the new economics of labour migration emerged as a critical response to neoclassical migration theory during the 1980s and 1990s, and has strong conceptual parallels with other "pluralist" strands in development thinking - the so-called livelihood approaches - and sociological or anthropological research on migrants' trans-nationalism. It rejects neo-classical models, which ignore constraints and are evaluated, as too rigid to deal with the diverse realities. 
Katz and Stark (1986) believed that many individuals had a strong desire for higher income and the higher social status accorded to them by wealth, to the extent that theoretically, an individual will take the high risk to migrate if the utility function to be derived from migration fits the desire of being rank high in socially and in wealth terms. Therefore the prospect of greater wealth and status, increase the utility function such that the risk levels are seen as low, even when the decision to migrant is a gamble at a chance of greater wealth and status likely to arise out of the migration decision. In brief, the Katz and Stark (1986) theoretical model raises the possibility that migration in developing countries involves a more complex decision making than suggested income differentials.

Stark and Levhari (1982) argue that households are better able to diversify their resources, such as labour, in order to minimize income risks than individuals. The assumption is that people, households and families act not only to maximize income but also to minimize and spread risks. Internal and international migration can subsequently be perceived as a household response to income risk, given that migrant remittances provide income insurance for households of origin. Indeed, this risk spreading motive can even explain the occurrence of migration in the absence of (expected) wage differentials. The idea is that it may be a pareto-superior strategy for households as a whole to have members migrate elsewhere, either as a means of risk sharing and / or an investment in access to higher earnings streams (Lucas and Stark, 1985). Not only is migration perceived as a household risk spreading strategy, it is also as a way to overcome various market constraints.

The new economics of labour migration places the household in imperfect credit (capital) and risk (insurance) markets that prevail in most developing countries (Stark and Levhari 1982, Taylor 1999), which are often weakly developed or difficult to access for non-elite groups. Particularly through international remittances, migration can represent a household strategy to overcome such market constraints by enabling households to invest in productive activities and improve their welfare (Stark, 1980). Stark and Lucas (1988) moved the theoretical debate to the household level as a decision-making unit, supported by Hoddinott (1994), who introduced remittances into the migration decision making process. According to Hoddinott (1994), the decision to migrate occurs at the household level and includes the potential migrant, whereby the household maximizes a joint utility function between the migrant and household in which the income budget constraint includes the migrant remitting a portion of their earnings back to the household. A minimum remittance level is agreed upon by the two parties before migration can proceed. Previously, remittances were never considered an essential reason for a migrant to leave, and were thus treated as separate decisions. 
Ellis (1998) and Taylor (1999) agree that remittances have diversification and riskneutralizing effects on a household's consumption. While remittances are ignored in neo-classical migration theory, they are perceived within new economics labour of migration as one of the most essential motives for migrating. Accordingly, migration is recognized as one of the strategies or forms of portfolio diversification by families, in which 'inter-temporal contractual arrangements' are made to diversify, secure, and potentially improve livelihoods. Moreover, they provide a radically different conceptualization of migration as a household strategy to diversify risk and overcome market constraints.

Trans-nationalism theory emerged to describe a process by which migrants build and sustain social relations that bind together their societies of origin and settlement (Vertovec 2004). Migrants are designated as "trans-migrants" when they develop and maintain multiple relations - social, economic, political, organizational and religious - that span borders. Taking a transnational approach shifts the analytical focus from a fixed place to a mobile process and from 'place of origin and place of destination' to the movements involved in sustaining cross-border livelihoods (Sorensen and Olvig 2002). The transnational migration describes a situation in which remittance sending and receiving societies are understood to constitute a single field of analysis (Levitt and Nyberg-Sorenson 2004). Mazzucato (2008) asserts that trans-nationalism has been significant in understanding the impact of migration and remittances as far from straightforward, depending on which dimensions of socioeconomic change are considered and the level of analysis, whether micro or macro.

De Haas (2010) proposes a combination of insights from the new labour economics, livelihood approaches and trans-nationalism studies, emphasizing the need to recognise limitations, namely that: the direct link drawn by new economic of labour migration between motives of migration and the act of remitting is often more unsettled in practice (Lindley, 2007); despite household approaches seeming the best compromise to harmonize agency and structure approaches, this involves the risk of reifying the household as monolithic, altruistic units taking unanimous decisions to the advantage of the whole group (Carling, 2005); and case study based empirical work on trans-nationalism often pays insufficient attention to counterfactual cases of migrants, following a more classical path of assimilation and fading of transnational ties (Guarnizo et al, 2003).

De Haas (2010) further observes that despite an increasing body of empirical research on the development impacts of migration, such findings are clearly contradictory. Moreover, he asserts that this contradiction cannot simply pertain to differences in paradigmatic orientation - leading to different interpretations of similar empirical data - political ideology or methodology, but rather also relate to 
real, existing differences. He contends that new economics of labour migration has striking - though as yet unobserved - conceptual parallels with livelihood approaches, which has prompted a departure from rather rigid and theoretically deductive historical-structuralism views towards more empirical approaches. Haan and Yaqub (2009) observe that these theories remain grounded in a functionalistic and individualistic framework, within which migration is primarily seen in terms of contractual arrangements within the household, and also as solutions to market failures, whereas little attention is paid to the "non-economic" factors driving such decisions.

McKenzie and Rapoport (2004) introduce the concept of migration networks, as a way of financing migration since it is a costly undertaking. They argue that networks serve as a source of information and therefore reduce costs associated with search and opportunities forgone while in transition and before a migrant settles down to a job. They are supported by Massey (1988), who points out the value of networks to households that are not able to afford a direct financing of migration due to liquidity constraints. He thus concludes that poor households in large migration networks have a higher chance of migrating or receiving remittances than household with a smaller migration network. In this sense therefore network serve to lower the cost of migration, which influences an individual's decision to migrate and consequently improves benefits and income to a migrant household in the longer term, as more member of household migrant under the safety provided by the network.

In cumulative causation theory (Massey 1990), individuals migrate as a result of a growing web of social ties connecting origin and destination regions (or other changes created by past migration), facilitating movement through information dissemination (Winters et al. 2001; Curran et al. 2005; Garip 2008), imitation or contagion (Kandel and Massey 2002). By contrast, in wealthy households with productive assets (e.g. land or cattle in a rural setting), a migrant's departure is likely to bring about a loss in labour force for economic activities. While households sending migrants to reach household goals (NELM) may recover from that loss and prosper through remittances, those losing migrants to achieve personal goals (neoclassical or cumulative causation) may face losses in their existing assets. If migration costs are sizeable, migrants will initially be primarily drawn from households at the upper-middle of the community wealth distribution, causing inequality to initially increase with such households becoming richer from income earned abroad. By contrast, if migration costs are low or liquidity constraints do not bind, the lower part of the distribution is also able to migrate, resulting in a more neutral or even inequality-reducing effect of migration income (Garip, 2008).

Migration theories reviewed above, provide this thesis with the basic understanding of how remittances arise and for what purpose. The theory of trans-nationalism is 
the most relevant for understanding the actions of migrants as individuals, while the new economics of labour migration shifts the focus of migration theory from individual independence to mutual interdependence, moving from the individual to the level of the family or the household. In this sense, this theory assists this thesis in placing the unit of analysis at household level, because remittances become part of a household's strategy aimed at diversifying the resources in order to compensate for risks associated with inefficient markets. The new economics of labour migration places the household in an imperfect credit (capital) and risk (insurance) market that prevails in most developing countries (Stark and Levhari 1982, Taylor, 1999). Migration is recognized as one of the strategies, or a form of portfolio diversification, in which 'inter-temporal contractual arrangements' are made to diversify, secure, and, potentially improve families' livelihoods. This argument is essential in analysing collective trends within household data that show similarities in occurrences between household receiving remittances and those that do not receive remittances.

\subsection{Theories of Remittances}

\subsubsection{Remittance Transfers}

The theories of remittance transfers have been developed around individual motives as to why migrants remit, which include altruism, exchange, inheritance or strategic motive and family agreements in which remittances are viewed as insurance and investment. Funkhouser (1995) analysed the reasons underlying remittances and concluded that there is no one reason why a migrant remits, but rather each migrant has individual response and thus no one specific theory can account for remittance transfers. However, two main approaches have been developed to explain why remittances are sent: the first, is premised on the thinking that households act as an altruistic unit to ensure the highest welfare for all members; while the second is that individual members transfer money based on their self-interest to ensure an exchange of services equal to the transfer's value (Lucas and Stark, 1985). Within these two approaches, there are many case-specific reasons for remitting, including: strategic exchanges, shared risk and insurance, inheritance, and implicit family loans.

According to Chami et al (2008), "the remittance-determination process has three aspects that jointly influence whether a migrant remits, and if he or she does so, the timing and quantity of the remittances he or she makes". Chami et al (2008) emphasises the utility of the individual remitting, in determining the motivation to remit, which they defined within altruism and self-interested exchange. Altruism motivates the individual to remit because of the utility derived from consumption, while exchange enables the remitter to view the remitted resources as his or hers 
even though they may be exchanged for goods and services that provide utility. The second aspect is the intended use of remitted resources that a migrant plans ahead of remitting. In Chami et al's (2008) view, intended uses include: "risk sharing (insuring) and altering the inter-temporal path of consumption (consuming, saving, and investing). In addition, some (and perhaps many) households use a portion of the remittances received from the migrant to purchase services to replace the migrant's labour contributions to the household". The third aspect is implementing the remitters plan, which Chami et al (2008) refer to as "end uses", such as "purchase of final goods and services (for consumption), of financial assets (including being held as cash), or of real assets (including human capital)".

The idea of describing inter-family transfers as purely altruistic was first developed in 1974 by Becker. Becker theorized a household with a 'head' who transfers purchasing power to any member within the family. The 'head's' utility encompassed the utility of all other members of the household, and accordingly any change in the welfare of others would directly affect the head's utility. Furthermore, the head would not make a choice based on their own preferences without taking into account the other members' welfare. Using a migration decision example, Becker illustrated that if the head was debating about migrating and the head's spouse obtained a high utility from companionship, then before the head would migrate, not only would the wage compensating differential have to be higher in the urban sector, but it would also need to be at a level that compensates for the spouse's loss of utility. The head would subsequently "pay" the spouse through an inter-family transfer. Not only does the head make decisions based on the family members' welfare, but there is also a monetary transfer at the end of the head's life to their children, in the form of a bequest.

Tomes (1981) provided empirical content in support of Becker's altruistic theory, using data from intergenerational transfers to show that parents decided bequests based upon their children's ability to earn income, and indeed may provide their children with large amounts of human capital. As the child's earning power increases, the parent feels less liable for the child's welfare, which leads to a smaller bequest. Conversely, in families where the children have lesser amounts of human capital and a lower earnings capability, the parent will forgo their own consumption and bequest a larger amount. Bernheim and Stark (1988) believed that a true test of altruism involves evaluating whether it arises within a family endogenously. If it doesn't, then, according to Becker's definition, no head of household exists and the decisions are made through the negotiations of self-interested members. Andreoni (1989) showed that individuals can transfer wealth that may appear altruistic, yet the individual actually receives a "warm glow" feeling in exchange for the transfer, whereas a purely altruistic transfer would not result in any increase of the individual's utility. 
Bernheim et al (1985) believed the altruistic model was fallible, with people motivated by self-interest, and bequests, transferred as an exchange for services rendered. There is a strategic game played out by a household member and a beneficiary, whereby the former will intentionally attempt to manipulate the beneficiary's behaviour by offering different levels of bequests. For example, a parent who enjoys the company of their grandchildren will use the possibility of a bequest to pressure the beneficiary to visit more often. The bequest would subsequently pay for the time the grandchildren subsequently spend with the individual. Bernheim et al. did not use any underlying assumptions for bequests, and the model explicitly tests the strategic choices of a parent, including altruism. The authors concluded that exchange reflected a major factor in monetarily dividing up bequests. Another possibility is the parent using their bequests to coerce their migrant children into sending larger remittances. According to de la Briere et al. (2003), migrants who remit more have a greater probability of receiving a larger bequest, while the sibling migrants are strategically played against each other in a competition for favouritism by their parents. At the end of the parent's lifetime, the most favoured child would subsequently receive the largest bequest.

Lucas and Stark (1985) showed that migrants in Botswana are motivated to remit through a combination of exchange and altruism. Lucas and Stark (1985) noticed a surprising empirical trend in Botswana, in which migrants with higher education remit a larger portion of their income than their less-educated counterparts. However, this may not support either pure altruism or exchange. Lucas and Stark (1985) believed that these migrants used remittances to pay back their family for income spent on the migrants' education prior to migrating. The education was not obtained by the migrant through altruistic means from their parents, but rather was a loan from the household, with the expectation of repayment. Altonji et al. (1992) and Altonji et al. (1997) rejected the altruism model using consumption data linking family members, by showing that the distribution of consumption was dependent upon the recipient's income, while Cox et al. (1998) showed that the exchange model provided motives for inter-family transfers in Peru.

Poirine (1997) believed that there was an internal, informal financial market between potential migrants and non-migrant family members. Non-migrant family members invest in the potential migrants' human capital, and the individual subsequently migrates to the modern sector and receives a higher wage. Remittances are transferred back to the non-migrant family members as repayment for the investment in human capital. If the remittance involved payment of a loan, the remittance should not be used for capital investment, but would rather be sent on a regular basis without delay and would depend on the value of the loan. Using data from the South Pacific, Poirine (1997) showed that it is more likely that migrants 
remit to pay back a loan for human capital rather than altruistic or exchange purposes.

Ilahi and Jafarey (1999) provided empirical confirmation of the theory of implicit loans, suggesting that large migration costs restrain the potential migrant and hinder the possibility of migrating. Members of a household loan the migrant money to offset these costs, with the migrant subsequently repaying the loan through remittances. Furthermore, when the loan is paid off, remittances quickly drop. Using data from Pakistan, evidence supported the hypothesis that remittances decline when loans are paid off. In other circumstances in South Asia remittances were primarily used to repay debts and migration costs incurred by future migrants, while Stark (1995) believed that remittances may be used to prevent potential migrants from migrating.

Another theory considers the use of remittances as insurance against rural sector shocks. In many agrarian societies, formal insurance is neither practical nor available, and the key to a successful insurance arrangement is to have many uncorrelated sources of income. Fafchamps (1992) showed that agricultural households will insure each other by transferring income to households that did not have successful production, thus enabling households to specialize in high risk products without the worry that production will fail and they will not earn enough to live. Social networks include household members that have migrated to the urban sector. The migrant's remittances are generally uncorrelated with the income received by a household in the rural sector, and could be used to offset a major drought or other calamity that would cause the total rural income to drop.

Moreover, remittances are not necessarily limited to insurance against rural sector failure, but can also be used to insure household savings. If a household earns enough to build savings over time, a slight downturn in production may not be sufficient for the social network to provide insurance. Fafchamps and Lund (2003) show that a household's total net worth is taken into account before a transfer is made, whereby if a household has a large enough pool of savings, members of the social network may not remit. By contrast, only once a household's savings are used will the social network provide insurance relief through remittances.

Grieco (2003) emphasises that remittances are exchanged within relationships of immediate kin that are either spouses, parents, children or siblings. In such situations the kinship ties form the basis for decision to remit by a migrant, and therefore remittance transfer will continue as long as the kinship relations are functional or are maintained across time. In this sense therefore Porte's $(1995,1998)$ view remittances serve the purposes of building and maintaining social capital within a social network finds support, in that the existing relationship define the 
motivation for remitting resources, without then the remittances would not exist. In such networks therefore, Porte (1998) asserts that "both migrants and non-migrants act as donors and recipients of social capital, making their resources available to network members while simultaneously accessing the resources of others". In Massey et al. (1987), networks are thought to reduce costs and disruptions in the migration process by providing connections between those who send remittances and those who receive them. In Massey et al (1987) opinion, "kin groups tend to be the dominant social organisations present in migrant networks which guarantees continuity through new members".

In contrast, Grieco (2004), views potential family reunification as "the underlying social process that determines the remittance behaviour of migrant households, whereby remittance levels increase as the migrant household works to support dependent family members in the country of origin and assist in their eventual emigration". Therefore remittance level plummets as soon as the family is reunited. With this observation Grieco (2004) suggest that "households with a history or in the middle of the family reunification process are the most active remitters", thus the potential for family reunification influences remittances positively. Menjivar et al (1998) also supports the kin argument by pointing that "the presence of the migrant's siblings and, particularly, mother back home positively influences the decision to remit, while owning a home in the host country appears to have a negative effect on the amount remitted to the home country".

Given the social basis on which remittance behaviour is based - namely, strong kin ties - it is highly unlikely that this behaviour will be continued by the children or grandchildren of immigrants. The reason is simple: immediate kin, including parents, spouses, children and siblings, are the most likely of all social ties to exchange financial resources, such as remittances. The second and third generation (and even many of the "1.5 generation" who immigrated as children) would have most or all of their strong ties in the country of destination, and thus it is unlikely that they would be willing to directly support distant, often unknown relatives in an ancestral origin country whose weak social ties lack a financial exchange component (Grieco, 1998).

This review of the theories of remittances shows that the focus on the migrant and the non-migrant relationship as suggested by (Grieco, 2004) in which remittances are exchanged provides additional insights, while the existence of relationships helps to explain why remittances exist, why they continue across time, and also why they end. In this sense, recognition of relationships "backs up the causal chain" and incorporates the cause (i.e. migrant and non-migrant relationship), the event (i.e. exchange of remittances) and the effect (i.e. amount and frequency) of remittance 
behaviour into a single framework, that is useful in analysing household decisions on whether housing is an area of investment or not.

\subsubsection{Remittance Use}

In literature, the end use of remittances has been discussed based on observations of recipients or recipient households. Three important observations have been documented in literature. First, is that a larger percentage of remittances are used to increase consumption rather than for productive investment or entrepreneurial undertakings. Second, is that not all remittances are used for consumption, there is evidence to support the assertion that remittances are saved or invested even though this accounts for smaller portions compared to consumption. Lastly, a household's use of remittances for savings or investment in items such as land or housing may not be reflected in the overall productive activities of a country, even though they may be reflected in expenditures of a household. This is one area that has been problematic for researchers, as such activities are often reflected as expenditure rather than saving or investment in the economy.

Chami et al (2008) further introduces a progressive dimension in analysing the use of remittances by connecting three aspects of the remittance process, motivation, intended function and end use of remittances along a continuum. It is further argued that this distinction potentially allows for distinction of theories based on end use or intended functions of remittance whether they are used for consumption or asset accumulation. In their view, "theories can be distinguished from one another only by specifying the complete path from motivation to end use. In short, the "insurance" or "inheritance" theories of remittance determination that appear in the literature are not complete theories but only parts (in this case, dealing with the intended function) of complete theories".

Such a distinction would readily eliminate the existing confusion in current literature, about the causes of remitting behaviour and the uses of remittances. Chami et al (2008) further asserts, "this confusion has resulted because remitting is a deceptively simple activity whose true complexity research has gradually revealed". This does not however set aside the fact that limitations in data used also contributes to the resultant confusion on conclusions drawn from analysis. Chami et al (2008) is however emphatic that, "the lack of a universally accepted framework for characterizing and interpreting the research on remittance determination" reduces the chances of attaining consensus amongst scholars and researcher either theoretically or empirically. Chami et al (2008) in their profound understanding of remittances therefore recommend, "cross-country longitudinal studies following cohorts of migrants and their families over time as they experience migration, remittances and repatriation in order to address the theoretical and empirical issues 
associated with research on remittance use". This in their view would not only resolve the persistent questions regarding motivation for remitting, intended use of remittance and end use of remittance but would also ensure the collection of data that is accurate on remittances and their end uses.

\section{(a) Remittances for Consumption}

In support of remittance use for consumption, the work of Glytsos (1996) shows that rural households in Greece increased their consumption to the level of a typical urban household by purchasing luxuries such as expensive clothing, beverages, and consumer durables. This is supported by Ahlburg (1991) using data from Tonga and Western Samoa, who confirmed that remittances were not saved but only used to fund immediate consumption. Djajić (1986) and Quibria (1997) theorised that a sufficiently large amount of remittances would not only benefit the receiving households but also enhance the welfare for households without remittances receipts. What needs to recognised in these arguments is the fact that the volume of transactions supported by remittances in the economy boost and support welfare for households without remittances. Regmi and Tisdell (2002) noticed that the level of remittances to households in Nepal totalled around $4 \%$ of households' income. It is common to find arguments asserting that remittances of this size cannot foster much capital development in rural areas, and are rather used to provide additional consumption for the households.

Mazzucato (2008) asserts that those who consider remittances as non-productive offer a too simplistic perspective. First, it assumes that remittances can be divided into two categories, namely 'consumptive remittances' and 'productive remittances', which fails to take cognizance of the institutional embedding of transactions necessary to understand how remittances have not only an economic but also a social and cultural meaning. Second, remittances constitute one kind of investment in relationships between migrants and actors in the country of origin. These investments often precede or are followed with other investments, and thus sustain relationships within their country of origin. Third, the consumption-production divide fails to acknowledge multiplier effects, i.e. the indirect effects of remittances on other sectors and actors within a local economy.

This argument is complimented by Vertovec's (2004) thinking that differing proportions of remittances are spent on consumer goods and 'productive' investments, if one is to accurately analyse the use of remittance, then they have to consider a whole household and the community economy within which the household is located. He therefore cautions that care must be taken not to paint a misleading picture, without losing the fundamental understanding that migrants sometimes channel remittances directly into investment. In a survey article, Chami 
et al (2003) states that while some remittances are saved and invested; the investments are not productive in terms of the overall economy. The end use of remittances from literature according to Chami et al (2008), is compensatory to family members for "bad economic conditions, it is reasonable to expect that the bad conditions are associated with depressed consumption levels, including a lack of consumer durables such as good-quality housing. Therefore, remittance recipients use the funds to bring the family closer to its desired standard of living through the purchase of consumption goods, services, and consumer durables".

In support of the consumption argument, Elseoud (2014) underscores studies that "claim migrants spend most of their remittances on consumption goods (such as food and consumer goods) by asserting that such patterns of expenditure tend to have little positive development effect on local economies. Even though there are other studies that show results of migrants spending their remittance earnings on investment goods (like education, housing and business). It is clear that these patterns of expenditure support the build-up of human and physical capital". Elseoud (2014) therefore concludes that, "patterns of remittance-inspired expenditure on housing can create both better living conditions for migrants and new income and new employment opportunities for local people who are working in construction sector". Kapur's (2005) research findings show that migrant households have higher quality homes and home ownership rates than those not receiving remittances, while Doyle (2006) confirms that remittances in housing are more likely to be used for home improvements than for home purchases. Moreover, Adams (1998) asserts that the accumulation of land by the migrant households was vastly greater than households that did not receive remittances.

\section{(b) Remittances for Investment}

In support of investment and savings, as the end use of remittances, Adams (1991) analysed the consumption and investment spending of households in rural Egypt, he found that migrant households had a larger marginal propensity to invest than non-migrant households. These households invested their remittances by purchasing land and housing. Using survey data collected from the poorest regions of Pakistan, Adams (1998) showed that migrant households tended to invest their remittances by purchasing land and housing, and the accumulation of land by the migrant households was vastly greater than households that did not receive remittances. According to Chami et al (2003), land in itself is not an economy wide producible asset, given that a country cannot increase its size. Indeed, when households purchase land, it merely changes hands, and thus there is no increase in productivity. Only when new capital is purchased and implemented will productivity increase. In my view, Chami skips one important aspect in land 
economics that occurs when transactions on land are effected, namely capital gains, which increases land values as transactions take place.

Lucas (1987) reviewed the agricultural output and productivity of migrant households, noting that remittance receiving households invested in new agricultural technology. While agricultural output decreased due to the loss of migrant workers' labour in the short run, Lucas argued that agricultural productivity increased in the long run. Migrant households used remittances to purchase agricultural capital and cattle to enhance productivity, thus providing access to capital markets that were prohibitively expensive prior to the migration. Using the same fundamental model as Lucas, Rozelle et al. (1999) evaluated agricultural output and productivity in China. Indeed, agricultural output dropped as migration increased in the short run due to the loss of the migrants' productivity. Remittances partially offset the loss in production by giving the migrant household access to capital, which in turn increased productivity through hired labour and investment in agricultural capital.

Edwards and Ureta (2003) observed that remittances increased school retention in El Salvador, and therefore concluded that the hazards of leaving school are lessened with remittances, allowing children access to higher education and attainment in human capital. Remittances from abroad increase total income and allow children the opportunity to stay in school longer, and such effects are larger for girls than boys and for older than younger children in Mexico (Hanson, 2002). Ilahi (1999) observed migrants' savings were a significant factor in deciding on self-employment in India, namely that the more money saved while away, the more likely the migrant was to start a business. Many households have the opportunity to invest in selfbusiness ventures. In the Philippines, Yang (2004) showed that an increase in remittances increased a household's likelihood of forming a business.

Osili (2006) in his analysis of households in Ghana introduced an additional dimension, and asserts that the use of remittances also depends on "the origin family and its economic resources", mainly two asset resources "size of landholdings measured in hectares and the number of buildings owned". He finds that "the migrant's origin household's economic position is positively related to the migrant's origin savings" and the decision whether to invest remittances or not. This is not different from Taylor's (1992) assessment, which found remittances to be associated with increased holding of land and cattle in a sample survey of 55 farms in Mexico. However remittances were applied to the direct purchase of cattle rather than land. The reason advanced for investing in cattle was that, all land in the area was "reform land" and was out of the land market or not open for sale. Woodruff and Zenteno (2001) also found a positive correlation between migration and small business investment in Mexico. In both Taylor (1992) and Woodruff and Zenteno 
(2001), it is clear that the migrant family's stock of wealth or well-being is a key determinant of what remittances are used for or where they are invested.

\section{(c) Remittances for Housing}

Results from empirical studies show a mixed picture. According to Doyle (2006) remittances should cushion poor households to access resources for housing. In reality most household engaged through housing improvement rather than outright purchases due to extra income from remittances. Even with housing improvements, remittances are still the ideal resource for improving family assets and overall quality of life. However, the review of literature show a limited application of housing mortgages based on receipt of remittance. Doyle (2006) emphasizes the use of remittances in progressive house building, as opposed to the purchase of complete homes. However, Doyle also warns that remittances alone cannot solve endemic problems in the housing sector, and rather that they must be seen mainly as an alternative means of payment (Doyle 2006). Indeed, in Latin America and the Caribbean, efforts have been made to introduce housing products based on remittances from the US (Bendixen Associates, 2006), these are however seen to have a limited impact on overall housing investments based on UNDP (2005) figures for El Salvador, where remittances have only serviced the purchase of 0.7 per cent of investments in housing.

Smith and Mazzucato (2003) acknowledge the widespread negative perception among researchers and practitioners of the migrants' construction of "luxury" houses, which is considered as driven by prestige and status considerations and subtracting resources from "productive" investment. Firstly, they argue that a spacious, functional and hygienic house is a legitimate aspiration, particularly because it may enable households to become more independent from the extended family (de Haas, 2007). Secondly, house building generates positive "multiplier effects", given that bricklayers and other workers use their wages for consumption or investment. Thirdly, in contexts characterized by few investment opportunities and high inflation, housing reflects a sound way of protecting savings, and housing may also generate income, particularly by renting out the house or part of it.

Moreover, they indicate that consumptive expenses and so-called "non-productive investments" such as on housing can have highly positive multiplier effects in local and regional economies, which generate employment and income for non-migrants and can contribute to poverty reduction. Rempel and Lobdell (1978) conducted twelve remittance usage studies in the 1970s and concluded that a large majority of people tended to use remittance for pure consumption. Indeed, research of this nature has generated the common idea that migrants do not use their money 
"productively". However, such research has been criticized for serious deficiencies in its methodological design (Özden and Schiff 2005).

Additionally, Stark (1991) asserts that investing in housing also reflects limitations in the menu of investment choices available to migrants in the country of origin, given that houses present unique advantages in that they are durable, highly visible and associated with low risk and monitoring requirements. Mazzucato's (2008) study of returned Ghanaian migrants reveals the importance of house building and house ownership, which many reported conferred status or prestige, and defined "manhood", particularly in Ashanti culture. In Turkey, the 1970 "Abadan Survey" found that 49 per cent of remittances were spent on housing (quoted in Russell, 1986). Furthermore, similar results were reported in Ghana, where Kabki et al (2003) found that the majority of the migrants interviewed were investing in a house for their family, and most that had not yet done so hoped to do in the future. In the Todgha oasis valley in Southern Morocco, remittances enable families to move out of the traditional village and build new houses (de Haas, 2008). Moreover, a study of eleven Mexican villages found that between 71 per cent and 89 per cent of migrant households expanded or repaired their house, or built a new one (Basok, 2003).

Durand et al (1999) showed a majority of households in Mexico were unable to invest remittances due to lacking access to necessary asset markets, while those households with access to education, land, businesses and housing often invested a portion of their remittances in productive investments. However, Durand et al (1999) offer an alternative reason, arguing that the high risk of business failure and possible legal issues with land accumulation prevents migrant households from using remittances for productive investments. Additionally, whether remittances flow into housing or other uses is context specific and considered wasteful within some literature, despite de Haas's (2010) affirmation that remittance receiving households often have a higher propensity to invest than non-migrant households. Mazzucato (2008) reported house building and house ownership, as conferring status or prestige, and defined "manhood", particularly in Ashanti culture, as one of the key motivations for migrant household to invest in housing. The more appealing preposition that speaks to my area of study is that offered by Stark (1991), who reasons that investing in housing is a reflection of limitations in the menu of investment choices available to migrants. Ultimately, what makes the difference in my opinion is the extra marginal propensity or additional purchasing power that a migrant household attains as a result of receiving remittances.

Ratha et al (2011) argues that dual-citizenship is a relevant factor for diasporas' participation in trade, investment, and technology transfer, while it makes easier to travel to, remit and own land in the origin country. Uganda is one of the countries that has ceded to dual citizenship as a deliberate policy to encourage close links 
between migrants and their home country, and therefore support the continuous flow of remittances. However, the pursuit of sector specific policies such one to support remittances into the housing is currently not evident due to lack of analysis and research such as the one advanced in this thesis to inform policy decisions.

\section{(d) Remittance Policies}

Julca (2012) develops a typology of remittance policies and argues for a variety of policies including but not limited to fiscal, financial, and institutional policies. Julca's (2012) argument is that financial and institutional policies have been the most attractive for policy makers to work with because of their straight forward nature of what is needed to support continuance flow of remittance, a factor that has left the resultant application or use of remittance to individual remitters or receipt households. Indeed, the instruments Julca (2012) lists as commonly applied include "development bonds, various kinds of tax incentives to import fixed capital or remit through the banking system as well as preferential interest rates, exchange rates, and the set-up of foreign currency accounts, electronic transfers, microfinance, various types of insurance as well as the establishment of regulatory frameworks for remittances transfer and their use; financial literacy programmes, and training for start-up businesses".

\subsection{Conclusions from the Literature}

\subsubsection{Theoretical Implications for the thesis from the Literature}

From the literature remittances are the most tangible consequence of migration for households in sub-Saharan Africa. A resource that does not need middleman to apportion out, nor require special knowledge to understand how the funds are accessed, or impose conditions for their use, by any entity outside of the family or the migrant and his/her household. In this sense therefore, remittances have subsequently played a big role in family budgets and in improving housing through autonomous and informal methods.

Neo-classical economists have argued that people move permanently to raise and maximize their wages in receiving countries, new economics of labour migration contends that people move on a temporary basis to achieve their goals or targets, and thus migration goes "beyond a response to negative wage differential". The neoclassical theories are based on the notion of wage differentials between receiving and sending areas, as well as the migrant's expectations for higher earnings. In other words, unlike the new economics of labour migration, which views migration as the logical outcome of a "calculated strategy", the neo-classical stance considers that an individual maximizes not only their earnings, but also the family is conceptualized 
as a coalition vis-à-vis the rest of the world, with family members sharing the costs and rewards of migration. Accordingly, the neo-classical and new economics of labour migration approaches differ from each other in positing contrasting sets of interpretations regarding the purpose and use of remittances.

The theory of trans-nationalism, which partially address the reasons why individual remit, is also beneficial in analysing the use of remittance because it increases possibilities for investigating migrants and their families as persons or units that live trans-nationally and adopt transnational identities, through which multiple relations - social, economic, political, organizational and religious - that span borders are developed and maintained. These are significant to understanding the impact of remittances, which is far from straightforward yet better understood as the result of logically intertwined outcome of personal agendas, persons and places. When pushed further, remittances constitute one explanatory factor for maintaining attachment to the home country that trans-nationalism theorists appropriately capture. This understanding of remittances as a trans-national resource is explored with specificity to the housing sector and housing of households that receive remittances in this thesis.

\subsubsection{Empirical Implications for the thesis from the Literature}

From the literature, it is also clear that there are empirical implications that this thesis has to consider in its analysis. First, is the recognition that evidence presented by different authors has led to varied and conflicting conclusions on the decision of placing remittance resources on housing improvement of purchase of housing. This could turn out to be one of the shortcomings of the analysis in this thesis. According to Julca, (2012) literature on the remittance policy has "made progress on assessing different aspects of remittances such as a) the implementation of regulatory frameworks to reduce transfer costs in different corridors; b) the support to financial inclusion; c) the support to investment motivations of diasporas". It has however not progressed in terms of specific policies that can increase the possibility of home ownership and improved housing quality for households that receive a second source of income as pointed out by Carter' (2007). This indeed is one of the key questions for which this thesis will propose additional perspectives.

Secondly, even as remittances have diversification and risk-neutralizing effects on a household's consumption, there are varied reasons for remitting and the effects are similarly varied depending on households. Therefore the context of remittance receiving and remittance sending is a factor that influences the use of remittance, which is not captured in cross-section data sets to be used in the analysis in this thesis. There are varied sources of income within a household, apart from and in addition to remittances and to what extent these also determine, whether 
remittances are applied in housing improvement will be an important consideration. However, the wealth status of the receiving household or its net worth has to also be taken into account. These motives are not mutually exclusive but many studies have tried to disentangle them empirically. It is impossible to aim for disentangling such motives in this thesis, because such motives are not captured in the data.

As the author of this thesis, it is important for me to heed Doyle's (2006) advice that remittances alone cannot solve endemic problems in the housing sector, and rather must be seen mainly as an alternative means of payment. However, as de Haas (2010) warns, the resulting micro-empirical evidence from my analysis of the role of migration and remittances in households' livelihoods will not be taken as evidence that migration stimulates development in more general terms and on the macrolevel. Accordingly, it would be inaccurate to argue that "migration and remittances durably improve households' living standards" to "migration stimulates national development", in any case it would be a situation of making inferences made at a micro- scale of analysis and attempting to transposed them to a macro-level scale of analysis. As indicated by Ratha (2010), there is a significant problem in generalizing findings for specific countries and households as valid for all households across the globe. Indeed, this conjecture is not plausible in the long run, given that households, regions or countries differ, and thus one must be cautious of all empirical findings regarding household usage of remittances.

\subsubsection{Methodological Challenges for the thesis}

From the review of literature, it is also clear that this thesis will encounter methodological challenges. In this section, the following challenges are recognized. The first is recognition that literature tends to view remittance as non-productive but consumptive resources. According to Mazucatto (2008) who concurs with scholars such as Vertovec (2004) and Taylor (1999), this perspective is too simplistic. First, it assumes that remittances can be divided into two categories, namely 'consumptive remittances' and 'productive remittances', which fails to acknowledge the necessary institutional embedding of transactions to understand how remittances have not only an economic but also a social and cultural meaning.

The second challenge is the fungibility of money or remittances. Stark (1980) recognises that researchers cannot simply obtain information concerning if or how households budget their remittances differently from the rest of their income. Instead, researchers have to rely on econometric techniques for sorting remittance households from non-remittance households, subsequently comparing spending habits. Such techniques need to take account of the fact that only successful migration counts. Second, data on remittances do not take account of reverse flows of initial investment. Because remittances affect total income, the effect can best be 
understood through study of the entire household investment portfolio rather than through the study of separate investment options.

Thirdly, Taylor (1999) observes that many studies of migration impacts disregard income fungibility and the indirect, community-wide impacts of migration, which is often missed by traditional research approaches. De Haas (2007) contends that migration optimists tend to ignore evidence on first-round effects looking for second- and third-order effects. However, the optimist and pessimist conclusions are not necessarily incompatible: the point is that conditions and context appear crucial for the chances that migration and remittances end up stimulating development in areas of origin. Additionally, discussion of whether remittances flow into housing or other uses is context-specific and thus considered wasteful in some literature, despite de Haas's (2010) affirmation that remittance receiving households often have a higher propensity to invest than non-migrant households.

De Haas (2010) points out that household approaches often seem the best compromise to harmonise actor and structure approaches. Criticism of household approaches has focused on the underlying assumption of a household as a monolithic, altruistic unit taking unanimous decisions to the whole group's advantage, which may mask intra-household age, gender and other inequalities. A strict household approach would disguise the importance of migration-relevant social bonds with non-household family, community members and friends, and would also rule out the agency of individual household members and consequently their potential ability to revolt against the will of powerful household members by, for instance, migrating without consent. De Haas (2010) concludes that the choice of the household as the primary unit of analysis can be considered a kind of optimum strategy or compromise between agency and structure approaches, acknowledging that the forms of households vary across time, space and social groups, which is particularly applicable in developing countries.

In this analysis, I agree with Stark's (1980) affirmation that researchers cannot simply obtain information on how households budget their remittances differently from the rest of their income, due to the fungibility of money. I support the philosophy that a focus on migrant and non-migrant households should principally make it easier to incorporate findings from household-level analysis. Furthermore, I support Haan and Yaqub's (2009) recommended use of households rather than places as the unit of analysis, given that this better takes account of the fact that much, if not most, migration is "circular", with continued interactions involving areas of origins rather than a one-way and one-off move. Carter's (2007), segregates household income by considering earnings of spouses as second lines of income, with remittances considered a second line of income that influences home tenure (ownership and rental) and housing quality. When household income is disaggregated in such a 
manner, each component is shown to have its own significant effect on housing tenure and quality. Moreover, he also asserts that most work on this kind of analysis has been derived from cross-sectional analysis, which is applied by this thesis.

The transnational approach to migration research and analysis delivers best by better disaggregating and characterizing types and levels of transnational activity. More still, a focus on households should, in principle, make it easier to incorporate findings from household-level analysis. It is also valuable for this thesis to split households, as Rosen (2007) does in work on Pakistan, into three groups: households receiving remittances from abroad, households receiving remittances from within the country, and non-remittance households. This is considered a more accurate approach because it focuses on a household's complete investment portfolio.

Ratha (2010) highlights a significant problem in generalizing findings for specific countries and households as valid for all households across the globe. Indeed, this conjecture is not plausible in the long-run given households, regions or countries differ, and thus caution must be maintained with all empirical findings regarding household usage of remittances. Therefore, it is important that the results are evaluated in the context of the household's geographic location. In this respect, this thesis will only evaluate results in the context of the household's geographic location, given that households, regions or countries differ, and thus one must be cautious of all empirical findings regarding household usage of remittances, pointing out that the implications of migration and remittances vary according to level of analysis, from individual to community, nation or state.

Overall, the review of literature shows that micro-empirical evidence highlighting the often positive role of migration and remittances in households' livelihoods is often inaccurately assumed as evidence that migration stimulates development is in more general terms and on the macro-level. Assertions must have limitations and avoid committing a classical ecological fallacy by transferring inferences made on a micro to a macro level. Theoretical underpinnings play a critical role in defining the unit of analysis and the variables in a thesis of this nature. For this case, transnationalism is the major theory to understanding remittances and their application to housing tenure and security. Above all methodological challenges in disentangling the dollar of remittances that goes to improvements in housing tenure or quality at household level have to be dealt with depending on the quality of data applied in the analysis. 


\section{Chapter 3: Housing in Uganda}

\subsection{Introduction}

In this chapter I examine the financing of housing through a summary narrative on the situation of the housing market and the variance likely to occur due to the inflow of remittances in Uganda. This narrative is based on review of three key studies; these include Endo, Namaaji and Kulathunga (2010), Uganda's Remittance Corridors from United Kingdom, United States, and South Africa: Challenges to Linking Remittances to the Use of Formal Services. Kalema and Kayiira (2008), Access to Housing Finance in Africa: Exploring the Issues. No. 4: Overview of the Housing Finance Sector in Uganda and Giddings (2009), the Land Market in Kampala, Uganda and its Effect on Settlement Patterns. The review contextualizes the subsequent conclusions and research sub-questions in the broader socioeconomic situation of Uganda's housing market.

The motivation for this chapter is to retain the case study method, through a microanalysis of the housing market in Uganda. This chapter is considered necessary for a better understanding of the context in Uganda that is not captured in the review of literature at the start of this thesis that is concerned more with the fields of studymigration, remittance and housing - rather than the location of study - Uganda. In this chapter a detailed overview of the housing market in Uganda is posted, so that overall conclusions are made based on context and make meaning to policy makers within country, who may find the findings of this thesis useful or applicable to their policy work.

\subsection{Methods}

The review of literature was complemented by findings from a mini-survey conducted amongst 37 real estate firms in Kampala - Uganda, under their umbrella organization the Association of Real Estate Agents (AREA) in Kampala. The minisurvey was not in any way meant to take away from the main analysis of the thesis which is based on the Uganda National Household Survey of (2005/2006) UNHS III and $(2009 / 2010)$ UNHS IV. It was intended to compliment contextual understanding of the housing and real estate market from the literature, to which remittances might be a key source of financing. The mini- survey was undertaken using semistructured qualitative interview questionnaires administered through face to face interviews to the 37 real estate firms in the association. The interviews focused on nature of services offered by the firms', the extent of government regulation and the clientele of such institutions. 
The firms were tasked to consider the inflow of remittances into their operations over the last two years and to discern the extent to which remittances may be filtering into this sub-sector of the economy. Results from the interviews were transcribed, manually coded and assembled in a descriptive naming scheme, then constructed into "quasi-statistics", in which the trends or patterns are coded based on counts or number of times a particular response was mentioned in interviews as an estimate of frequency. In this way, the codes, according to Seidel and Kelle (1995) served both as "heuristic tools - primarily flags or signposts that point to things in the data" - and as objective codes - transparent representation of facts as captured in the interview process - "described in the data".

\subsection{Status of Housing in Uganda}

Housing is fixed in location, extremely durable (slowly depreciating), and can be viewed alternatively as a composite commodity yielding a flow of 'housing services', or as a set of individual characteristics. According to Malpezzi (2003), housing market analysis is complicated by several facts. First, the system of property rights implicit in any supply and demand diagram cannot be taken for granted. Second, housing is a composite commodity and may be examined in terms of its service flows or stock in some aggregate way, or in terms of individual characteristics. Third, supply in any given period comes from both new construction and modification of the existing stock. Fourth, the transaction costs of changing consumption are quite high. Fifth, housing consumption choices are bound up with tenure choices. Sixth, housing markets are a large part of the economy in general and the capital stock in particular; having strong linkages with it's the aggregate economy.

According to the Uganda National Household Survey (UNHS), the estimated national housing requirement stood at 426,000 in $2005 / 2006$, this has now risen to 550,000 units in 2009/2010. According to the UNHS III (2005/6), more than 65 per cent of the Kampala population rents housing, and over 53 per cent live in "tenements" of less than two rooms. Moreover, the fact that around 85 per cent of Kampala's population live in slum areas is testament that the formal land/housing market is not functioning as well as it should, and especially for low and moderate income families. Crowding is significant, with densities averaging more than 14,000 per square kilometre, in many of the poorer slum neighbourhoods of Kampala City.

According to the UNHS IV (2009/2010), growth in the housing sector in Uganda has averaged 7 per cent over the last few years, with the exception of 2000/01, when it recorded a 1.8 per cent growth rate. With a GDP growth averaging 6.5 per cent and a population growth average of 3.4 per cent per annum since 1995, the demand for decent and affordable housing has experienced an upward spiral, due to the drastic 
rise in people's living standards in relation to an increment in gross domestic product (GDP) and income per capita. It is estimated that the housing shortage will reach close to 8 million units by 2020, of which 2.5 million will be in urban centres and 1 million in Kampala city alone, if the current population growth rate is sustained (Uganda Bureau of Statistics, 2010).

Kalema and Kayiira (2008) observe that Uganda has not had a well-managed scheme for the supply of housing during the last 25 years, with the country's current housing supplies still basic and poorly managed. This is due to the fact that construction of new housing has significantly lagged behind population growth, with the demand for housing considerably outstripping supply. Giddings (2009) observes that there are two distinct land and housing markets in Kampala: (1) a formal sector market for land that is duly registered, where purchases and sales are recorded and formal legal agreements signed; and (2) an informal sector market where property and land use rights may be purchased and sold without being formally recorded. Both land markets are very active, with considerable buying and selling of properties and use rights. However, the two are not completely independent of each other because the extent to which the formal sector land market fails to function reasonably well affects the extent to which residents revert to the informal sector to meet their housing needs.

Kalema and Kayiira (2008) assert that Uganda's land tenure systems have also presented a major hurdle to the supply of decent housing stock, and especially in urban areas. Most land in urban areas is privately owned under mailo land tenure (the term is used in Uganda to describe a land tenure system that came into effect when the kingdom of Buganda signed an agreement with the British-administered Uganda Protectorate in 1900. The basic unit of the mailo system is a square mile, hence the derivation of mailo, which is also equivalent to 640 acres.), where houses are constructed either by landlords or by tenants who have occupancy rights using their own savings as opposed to gaining housing mortgage from banks. Over time, this has prompted the emergence of slums in areas such as Kisenyi, Katwe and Kalerwe within Kampala City.

According to Giddings (2009), homes in the upscale Kololo neighbourhood can sell for well over $\$ 1$ million, while a serviced housing unit in other neighbourhoods costs over $\$ 60,000$ on average. In 2002, land in the desirable Ntinda area, most of which is fairly well-serviced and leased by the Kampala City Council or Uganda Land Commission, sold on average for $\$ 30,000$ per $1 / 4$ acre. By 2008 , the average price had risen fourfold, to $\$ 120,000$ per $1 / 4$ acre. Moreover, in the Nsambya area, land selling for around $\$ 15,000$ per $1 / 4$ acre in 2002 is now selling for about $\$ 60,000$ in 2009 . In the less well-serviced Kisenyi and Bwaise areas, 1/4 acre parcels selling for around $\$ 10,000$ in 2002 are now fetching about $\$ 20,000$ in 2009. In the Muyega area, 
commonly termed as the "rich man's slum" due to its land use being extremely unorganized and not well serviced, yet upon which some substantial houses have been built, a $1 / 4$ acre plot sold for around $\$ 30,000$ in 2002 now sells for double that amount in 2009.

According to Giddings (2009), there has been steady annual growth of around 13 per cent in the construction industry, including the production of cement, reinforcing rods, corrugated roofing sheets and paint. Overall, fewer than 5,000 units are being produced by formal sector developers in the Kampala area per year-far short of the effective demand, and what is being produced through the formal sector is still too expensive for a "moderate" income family, even if one is able to secure a mortgage. To afford a $\$ 35,000$ apartment, with an 80 per cent, 20 year mortgage at the interest rates of $16-18$ per cent in 2009 , a family would have to earn over $\$ 1,300$ per month. Indeed, this type of housing is beyond the reach of the great majority of families living in the city (Giddings, 2009).

Most formal sector housing developers are building an average of 3-4 single-family houses per acre, resulting in a land cost of around $\$ 5,000$ per house. Providing adequate infrastructure to land adds approximately $35-40$ per cent to the cost of a house, making a serviced plot worth a minimum of $\$ 11,000$. Moreover, this would typically not include the cost of compensating existing owners of certificates of occupancy, which as noted above can add significantly to the cost of acquisition. With the average mid-level civil servant earning around $\$ 120$ per month, this effectively means that a person has to work and save the entirety of their salary for a minimum of four to five years in order to acquire a plot in even one of the poorer neighbourhoods of the city (Giddings, 2009). In such situations, households with a top-up income from remittances are better placed for the uptake of such housing.

\subsection{Real Estate Market in Uganda}

This thesis advances the argument that remittances can be directed to the housing sector or real estate market in Uganda. It is important to note two key trends that are evident in the literature, which would certainly affect the application of remittance to these sectors of the economy, i.e., the real estate market is in infancy and the level of compliance with professional and ethical standards in this market is low as elaborated below.

\section{(a) Real Estate Market is in Infancy}

Both Giddings (2009) and Kalema and Kayiira (2008), show clearly, that the housing sector in Uganda has a deficit in supply of housing that can be served well with the receipt of remittances and their investment in the housing sector. Due to high 
demand and low supply, the price of housing units is doubling in less than a decade, which makes housing an attractive option for investment of remittances, if they can be channelled there. Both Giddings (2009) and Kalema and Kayiira (2008), seem to imply that the players in the housing market are mainly private developers who are yet to think of organised mobilisation of resources in order to increase housing supply, given the demand that is nearly spiralling out of control. While it is admitted that the formal housing industry is still small, it has gradually grown from being largely controlled by the government to now being market and private sector driven, the real estate industry in Uganda remains in its infancy.

\section{(b) Non Professional Real Estate Services}

Kalema and Kayiira (2008) assert that Kampala has very few organized real estate developers and a number of individuals who play a relatively substantial role yet whose activities cannot be easily quantified. Real estate developers have recently formed a body for their own self-regulation, the Association of Real Estate Agents (AREA). In the third and fourth quarter of 2010, a survey was for this thesis under the auspices of AREA, where 37 of these firms provided views and observations on the filtration of remittances into the services they provide.

Table 3.1 shows that 31 of such firms were legally registered under the company laws of Uganda to undertake business of real estate services. However, only 5 of the 37 firms were registered under the Registration of Surveys Act 1974 (Cap 275) for upholding professional and ethical standards in the provision of services. Feeble as this may be, it is a signal of the absence of sufficient professional real estate services that migrants and their households can rely on to access services for housing ownership beyond their own savings. Nathan Behangana, the president, of the Institute of Surveyors of Uganda, acknowledged in a $2^{\text {nd }}$ August 2009 interview with the New Vision Newspaper that ethical conduct and adherence to professional standards is not possible if services providers are not registered as required under the Surveyors Registration Act. 


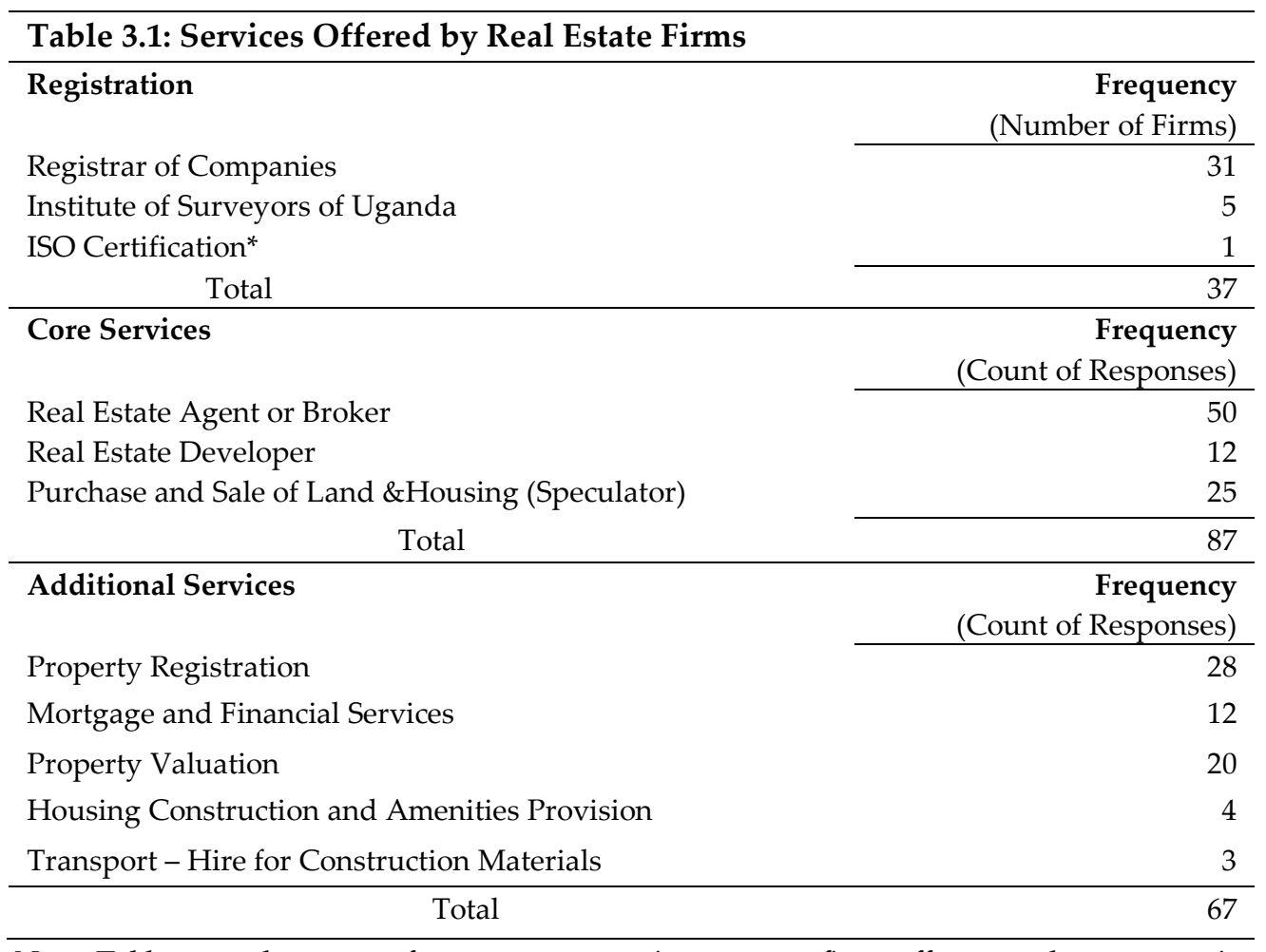

Note: Tables records counts of responses on services as some firms offer more than one service

Bageine (2010) asserts that developers in Kampala hardly observe laws that govern the industry, which has resulted in unprofessional and unregulated players or developers who disregard guidelines and defraud clients, and especially in land transactions.

\section{(c) Real Estate Services are Limited}

Real estate brokerage is the most important service offered by the 37 firms, followed by speculative purchase and sale of housing and land and lastly real estate development Findings from the coded interviews from the survey of 37 firms also show that the majority of real estate firms undertake real estate brokerage, accounting for approximately 50 of the 87 responses recorded in the survey (see table 3.1). Brokerage in this sector includes managing land and its fixed assets, especially residential and commercial buildings. This is followed by speculative purchase and sale of both housing and land, which accounts for 25 of the 87 responses of firms surveyed. Real estate development - the purchase and construction of housing - is apparently the least important service, accounting for 12 responses out of the 87 views offered by real estate firms. 


\subsection{Financing Housing in Uganda}

Housing must be financed, because of its high cost in relation to incomes. Because of its locational fixity, housing markets are profoundly affected by the operation of land markets, and by infrastructure. Housing is the largest asset owned by most households. Bertrand Renaud (1984) put it best: Housing is always financed, in the sense that virtually all owners of housing capital must pay for their units over several periods. Even households which own their units 'free and clear' finance the unit in the sense that holding such a large asset has a financial opportunity cost. But in most countries only a small share of this potential finance, roughly equal to the value of the underlying assets, is in the form of mortgages or other formal sector finance. Goldsmith (1985) shows that in both developing and developed countries formal sector finance is only a small part of the total.

\section{(a) Household Incomes:}

Uganda's large informal sector (over $80 \%$ of the population) renders it difficult to estimate the exact income levels of individuals, which is made even more challenging by the fact that many employed persons also engage in extra activities to supplement their incomes. Nevertheless, results from the 2005/6 National Household Survey estimated the combined monthly average household income at Uganda Shillings 170,891 (US\$ 98). The Capital City, Kampala recorded the highest monthly income per household of Uganda Shillings 347,918 (US\$200), while the central region (excluding Kampala) recorded a monthly household income of Uganda Shillings 209,369 (US\$ 120).

According to Kalema and Kayiira (2008), all commercial banks require an individual to have a monthly salary of at least Uganda shillings 1 million (US \$ 575) to access a mortgage loan. On this basis, less than one per cent of the country's households $(35,621$ households) can qualify for a mortgage loan. This is attributed to the unachievable conditions set by commercial banks for accessing loans; for example, many Ugandans are not in salaried jobs, while many earn below the required qualifying incomes for mortgage loans. In addition, collateral requirements by lending institutions, including commercial banks, reflects a major challenge to many would-be borrowers, making remittances a plausible alternative. Therefore, the input of remittances in the housing sector becomes even more crucial. Kalema and Kayiira (2008) observe that the most significant challenge for real estate development as a service within the housing sector is the high cost of mortgages.

(b) Limited Housing Mortgages 
Giddings (2009) asserts that the low quality of housing also mirrors the low income levels and use of own savings to incrementally undertake construction, given that most Ugandan's are unable to access housing finance to invest in house improvement, purchase or completion. Kalema and Kayiira (2008) assert that the lack of developer financing has crippled the formal private sector to such an extent that its contribution to housing delivery has been relatively insignificant. Furthermore, Endo et al (2010) observe that the development of the mortgage market has been stifled since 1971, when Uganda experienced economic instability and political turmoil. Banks have since been preoccupied with investment in high-yield government debt, large, high-quality corporate accounts, as well as customer loans with short-term maturities.

The industry faces a lack of long-term (shillings) funding in both the domestic banking system and capital markets, an inadequate stock of well-planned, good quality houses to support the development of a secondary mortgage market, delays in the land registry and associated risks, and inadequate infrastructural support to property developers. Giddings (2009) observes that developers of larger parcels of land in Kampala will typically seek to stage payments to the owners as they build and sell competed houses, they can use the proceeds to purchase more of the land besides the growing shortage of buildable land

Consequently, Endo et al (2010) recommend as a first step that banks recognize remittances as a stable source of income and innovatively develop remittancerelated products and instruments to finance housing purchase, construction and maintenance. However, most commercial banks do not appear to have the sufficient incentive to develop a tailored product for remittances, and particularly remittance products tailored to low-income people who depend on remittances. A lack of affordable and attractive basic financial products reflects an obstacle to triggering the economic impact from remittances. Instead, commercial banks have shown a preference for low-risk liquid assets, such as T-Bills, rather than providing loans to the private sector.

\section{(c) Limited Options for Private Developers}

One real estate firm, Jomayi Properties, is offering 300 serviced plots in a new development called the Mukono Estates near the Jinja Road to the east of the city for $\$ 2,500$ for $1 / 8$ of an acre and $\$ 5,000$ for $1 / 4$ acre plots, and another 300 plot estate around eight $\mathrm{km}$ south of the centre of Kampala for $\$ 6,250$ - $\$ 7,500$ for plots of a little more than $1 / 8$ of an acre. The National Social Security Fund (NSSF) purchased a large parcel of more than 400 un-serviced acres in Wakiso District around $13 \mathrm{~km}$ from Kampala for $\$ 15,000$ per acre, while a savings cooperative of a publishing company purchased 30 acres of land off the airport road to Entebbe around $20 \mathrm{~km}$ 
from Kampala for $\$ 25,000$ per acre. Indeed, prices have escalated so much during the past six years that the "standard" plot has shrunk from $1 / 4$ to $1 / 8$ an acre. Further out, there are still some larger tracts available some $15-20 \mathrm{~km}$ from the city centre, usually un-serviced mailo land, selling for $\$ 15,000-\$ 25,000$ per acre (Giddings, 2009).

Kalema and Kayiira (2008) conducting research in 2006 found that in the 5 years since the new condominium law passed in 2001, few developers had taken advantage of the possibility of developing apartment type buildings on smaller parcels, yet to date few developers has taken advantage of this to build flats that would be more affordable to more moderate-income families. One developer, Tirupati Developments, recently completed a 16 unit "moderate" income condominium project with two and three bedroom flats selling for between $\$ 84,000$ and $\$ 93,000$. Equally the National Housing and Construction Company (NHCC) are selling two bedrooms at 80.5 million Uganda Shillings flats in its Namugoona Apartments in the Kasubi section of the city for $\$ 51,000$. However, neither of these comes close to serving lower income families. Kalema and Kayiira (2008), thus conclude that the rapidly escalating price of land and high costs associated with providing adequate infrastructure, most new housing being built by developers in "housing estates" is well beyond the reach of low- and moderate-income families.

Another real estate developer, Akright Properties, is selling houses in a 3,000 unit planned community $18 \mathrm{~km}$ from the city for between $\$ 44,000$ for a shell 'starter' house and $\$ 110,000$ for a $260 \mathrm{~m}$ five bedroom house on a $1 / 4$ acre plot, marketed to "moderate income" families. Another large developer, PAN Africa Housing, is constructing a 2,000 unit development in the Kirinya suburb of Kampala of housing costing between $\$ 31,250$ and $\$ 46,900$ - again targeting so-called "low income" earners. While these may be more affordable to steady wage earners who can qualify for a mortgage, housing built at these densities remains unaffordable to the vast majority of Kampala's population (Kalema and Kayiira, 2008).

\subsection{Remittances and their Potential}

Two studies are particularly pertinent in understanding the use of remittances in the housing in Uganda. The first study examines the relationship between migration and wealth accumulation using Poisson regression analysis based upon sample survey data for 9,711 households, (UNHS data collected in 2001/2002 by the Bureau of Statistics of Uganda). Undertaken by Herrin et al (2008), this study empirically demonstrates Katz and Stark's (1986) hypothesis that a risk-averse migrant from a developing country would take an actuarially unfair gamble, with expectations of improved economic well-being from repeated migration moves, on average, not being realized. 
The second study is based on analysis of sample survey data from the 2007 and 2009 Remittances Household Survey by the Bureau of Statistics and the Bank of Uganda, undertaken by Endo et al (2010), despite concentrating on remittance transfer channels and policies for their improvement, it confirms that remittances do not seem to have contributed to the development of housing in Uganda. However, anecdotal information from Endo et al (2010), demonstrates that remittances are used to purchase and build houses in Uganda without being channelled through financial intermediaries.

Endo et al (2010) highlight that analysing remittance flows proves difficult due to the many undocumented migrants who typically use informal remittance transactions. Indeed, they assert that "quantifying the remittance flows is a challenging task due to lack of proper methodologies, accuracy of recorded data, and extensive use of informal mechanisms. Although balance of payments data on remittances are commonly used for this purpose, they could be misleading because informal remittance flows are not accounted for in these calculations. This problem is aggravated further by the difficulty in estimating the flow of migrants, especially undocumented migrants".

Endo et al (2010) argue that shifting remittance use to investment and wealth creation could improve financial services and services in the housing market in Uganda. This may not set aside the high cost of mortgages or the fact that less than $1 \%$ of the Uganda's households (35,621 households) can qualify for a mortgage loan. Nevertheless, it will improve the contribution of private sector to housing delivery significantly, an aspect that housing policy in Uganda needs to address. However, remittances tend to be used to finance short-term needs; indeed, almost 80.7 per cent of remittances to Uganda from abroad are used for short-term consumptions needs and services, education expenses, and health expenses (Uganda Bureau of Statistics, 2006). The purchase of building materials and land commonly requires the accumulation of remittances for mid-term financing, which only accounts for 5.4 per cent.

However, Endo et al (2010) also note that remittances from Ugandan expatriates flowing into the housing sector in Uganda seem to contribute to the increase of prices in housing supply, including materials. They see a potential threat in remittances creating two separate housing markets: one high-end market for migrants and another low-end market for the middle- and low-income population. Consequently, expatriates who purchase high-end, expensive housing in Uganda create a different market segment, and developers tend to concentrate on this demand at the expense of middle and low-income populations, who cannot afford such housing. 


\begin{tabular}{|c|c|}
\hline \multicolumn{2}{|c|}{ Table 3.2: Migrants/ Remittances in the Clientele of Firms } \\
\hline Migrants in Every Ten Clients & $\begin{array}{r}\text { Frequency } \\
\text { (Number of Firms) }\end{array}$ \\
\hline Very Few (1-2) & 4 \\
\hline Few $(3-4)$ & 7 \\
\hline Average (5-6) & 9 \\
\hline Above Average (7-8) & 12 \\
\hline Majority (9-10) & 5 \\
\hline Total & 37 \\
\hline Payment by Migrant Clients & $\begin{array}{r}\text { Frequency } \\
\text { (Count of Responses) }\end{array}$ \\
\hline Cash through friends/relatives & 24 \\
\hline Bank transfers/EFTs & 26 \\
\hline Money Transfer s (Western Union) & 6 \\
\hline Others & 1 \\
\hline Total & 57 \\
\hline
\end{tabular}

In the mini-survey of real estate firms, shown in table 3.2, 12 out of the 37 firms surveyed reported at least 7-8 out of ten clients being from abroad, while 9 firms stated at least 5-6 in every ten clients are from abroad. Overall, at least each firm in the survey had encountered clients from abroad, who were collectively interpreted in this analysis as meaning migrants or migrant households. To adduce evidence of transactions with clients from abroad, firms were asked to reveal the mode of payment in any transactions involving clientele from abroad. In this respect, most of the firms (26) received payment from overseas clients through bank transfers, while 24 firms received payment through friends/relatives of their clients, while 6 firms did so through money transfer agencies such as Western Union. The cases in table 3.2 indicate that more than half of the firms' surveyed reported served clients from abroad.

Endo et al (2010) observe that there is anecdotal information highlighting that remittances are used to obtain and build houses in Uganda without being channelled through financial intermediaries, and hence are missed by official statistical data. For example, the formal mortgage mechanism financed around 0.1 per cent of the total supply of housing in 2003. With such a financing gap, the potential for remittances to finance housing is enormous. Giddings (2009) observes that most of the housing in new "estates" sells quickly, with sales as such attributed to the inflow of remittances from the diaspora, which is unsurprising given the shortage of middle-income housing. 


\subsection{Conclusions}

The review in this chapter and the findings of the mini-survey reveal the following key aspects with regard to housing, which are essential in drawing conclusions to the subsequent analysis of remittances undertaken in the next chapters of this thesis.

From the literature and the mini-survey, housing as a product in Uganda's economy has very high demand with limited options of supply, because of a number of factors. There are limited financing opportunities and choices when it comes to input resources to either secure tenure of housing or to improve the quality of housing. This is because aggregate household incomes are low and wages/salaries for individuals are low. Moreover the unit cost of housing is way beyond the aggregate income of most Ugandan households. This effectively locks out individuals and household from accessing mortgages to finance housing purchase or construction and indeed any improvements in quality of pre-existing housing. The implication for remittances is that there is demand for remittances to become a visible part of the housing acquisition or improvement equation, especially for low income households in order to improve a household's chance at securing their tenure or improving the quality of their housing, thus making the contribution of this thesis timely.

In addition, housing supply is mainly driven by private capital through corporations, a few banks or individuals and households through self-construction. Inevitably the quality of housing is low because it is self-financed and without adequate regulatory supervision and compliance. In retrospect, remittances are private resources controlled by the migrant and his or her household that receives them. Therefore the principle of self-financing purchase or construction of housing and improvements in quality sits well with this type of resources that are free of formalities and intermediaries making them readily available to respond to demand, if only their volume and amounts are high enough to support investment in housing.

Furthermore, there is limited supply of housing as shown by the national housing requirements in Uganda estimated to reach 8 million units by the year 2020. Even if migrants and remittances receiving household made housing their number one option for investment, they might encounter limited options. This is because the housing and real estate sector is not adequately organized to managed or tap into the potential that remittances represent. There are no tailored products for migrants nor are there financing choices that use remittances as investment capital. The banking sector that is supposed to lead the way in developing such innovative financing mechanisms, is yet to respond to remittances in a manner necessary to plough them into the housing finance market. Real Estate Developers under their 
professional association (AREA) are just beginning to re-align their services to required professional standards and enforce/adhere to ethical conduct.

Additionally, the housing products in the market have tended to be of low quality because they are built for a market that receives low incomes, yet migrants may want to focus on high-end quality products of housing. However, the government of Uganda might find it useful to consider increasing its role in regulation so as to encourage agents to professionalise and improve the services they can offer as this might place real estate developers in a position to respond to growing demand for diversified housing options by migrant households. For instance in Kampala city alone, 85 per cent of population resides in slums, a factor that is driven by the low rate of construction compared to the rate of population growth. The place of remittances in such a situation would ideally, be to provide extra resources that raise the volume and rate of construction of new units of better quality. This is easier said than done, as most families that receive remittances may not have the professional skills to deliver product of this nature in housing but would be in position to invest in such a sector if guided by professionals.

Lastly, both the literature review and the mini-survey show, that in Uganda, the formal and the informal housing markets are functioning in parallel, and both are utilizing private capital as the main form of financing. The place of remittances in such a scenario is therefore guaranteed. Remittances fit the bill of inclusion in such a market. 


\section{Chapter 4: Methodology}

\subsection{Introduction}

This chapter builds on the conclusions of the second chapter, to frame an investigation on remittances and housing tenure and quality. First by defining the research variables and sub-variables and their measures, based on the research questions articulated in the first chapter. Secondly, it describes the data sets applied in the analysis showing how they were collected and reliability of variables and the attributes contained therein. Specifically, this chapter discloses the measures undertaken during data collection and analysis to ensure that income and expenditure reported by households was reliable. The data analysis method is also detailed and the hypotheses to be tested are spelt out. The chapter ends with explanations on how endogeneity and fungibility of income are dealt with in this thesis.

\subsection{Research Variables and their Measures}

There is a sizeable body of literature exploring the empirical determinants of remittances and housing. I have been guided by theory in choosing explanatory variables and determining the form of the relationship under investigation. The explanatory variable in this thesis is remittances, which refers to both domestic and international remittances. The analysis is based on national sample survey data collected at household level, with remittances segregated from overall household income in the analysis. Household income is the sum of income that accrues from economic activities performed by household members on a regular basis, and is taken as a gross aggregate of income from: agricultural activities; non-agricultural activities, wage and salaries, and from transfer earnings (or remittances). It includes all receipts (cash and in kind) in exchange for employment, in return for capital investment, or transfer earnings e.g. inherited wealth, remittances, donations, etc. (Uganda Bureau of Statistics, 2007). The Uganda Bureau of Statistics applies a nominal value of income, implying that it is adjusted for inflation or decreasing purchasing power.

Remittances (domestic and international) are the monies or goods in kind that migrants send back home to their families or another individual, usually a relative who remains at home in their countries, cities or towns of origin. Transfer earnings capture both domestic and international transfers in the Uganda National Household Surveys data (UNHS, 2005/2006 and UNHS, 2009/2010), but excludes the international sale and transfer of goods, and the cross-border transfer of funds between businesses (Uganda Bureau of Statistics, 2007). In the analysis of relations, 
the cash value of remittances is applied because the majority of households receive remittances in this form. This also helps eliminate any possible chance that there may be undisclosed values of remittance in kind that are reported in the data. Migrant and non-migrant households in this study are disaggregated on the basis of those that receive remittances as a component of their household income.

Given this approach to the analysis, it becomes important to define a household, despite it not being an explanatory variable in itself. According to the Uganda Bureau of Statistics (UBoS), a household is a group of people who normally live and eat together, usually a family living in the same house or compound and eating together. In addition, the following also constitute a household: one person who lives and eats on his or her own; several persons who are not related to each other yet live together in the same house or compound and eat together; and a man with two or more wives who, together with their children, live and eat together. However, if the wives and their children live and eat separately, in such cases they form separate households. Moreover, if two or more groups of persons, each of which has its own separate eating and housekeeping arrangements, live in the same dwelling, they are also treated as separate households, i.e. cooking and eating together takes precedence over living together in the definition of the household. People who live together yet each of them buys food from a restaurant using their own money are also regarded as separate households (Uganda Bureau of Statistics, 2007).

The dependent variable in this thesis is housing. Adebayo (2010) observes that housing is theoretically viewed by many authors as a process and activity by which shelter is provided, and as part of the human settlement fabric that facilitates normal life and enduring wellbeing. From this perspective, housing is also a complex product that serves a varying number of purposes, including shelter, social relation and economic imperatives. Rapoport (2002) defines housing as a system of settings within which a certain system of activities takes place, and thus housing represents more than a dwelling, and includes the neighbourhood and its environmental quality. As a shelter, "housing is more than mere physical barrier against the natural elements or weather; it provides the economic, social, biological and physiological needs of man" (Mabogunje et al., 1978).

Housing in Uganda is defined as a separate and independent place of abode, intended for habitation by one household, or as one not intended for habitation yet occupied as a living quarters by a household (Uganda Bureau of Statistics, 2006). In this thesis, housing is a compound variable with three elements of quality, tenure status and market, defined as follows: 
(i) Housing tenure refers to the financial or other arrangements under which someone has the right to live in a house. According to UBoS (2006), there are three possible tenure categories of housing in Uganda that are applied to the data used in this thesis, namely:

(a) Renting: defined as all non-owner-occupied property rented from private owners or developers, local authorities and housing agents.

(b) Owner occupancy: owner-occupied dwellings (or private enterprise) i.e. financed and built by private developers for owner occupiers or private landlords, whether persons or companies). This includes accommodation that is owned outright or bought with a mortgage.

(c) Dwelling supplied free by an employer or relation: Includes all housing from private or public bodies occupied by virtue of employment. This includes property occupied rent-free by someone other than the owner.

(ii) Housing quality is measured in various ways. For instance, Fiadzo (2004) uses physical conditions, welfare and access to amenities in household data to measure housing quality in Ghana, including: physical status and condition of housing access to welfare amenities for households and access to quality of life amenities. According to Goodman (1977), there are infinite numbers of ways of combining any selected components (of housing situations) into a summary measure or index for differential assessment. The term of housing quality has two dimensions in this thesis:

(a) Physical condition attributes, which includes the type of building materials used in constructing the floor, walls and roof;

(b) Access to welfare amenities for households, which includes aspects related to access to energy sources (lighting and cooking), sanitation or toilet facilities and sources of drinking water.

This thesis does not intend to evaluate the suitability of housing, but rather the relationship between physical conditions and access to welfare amenities in relation to household income and remittances received at the household level. It is neither based on subjective nor the normative determination, but is constructed and interpreted on the basis of the situational status of household housing as captured in the Uganda National Household Survey data in 2005 and 2010.

(iii) The analysis of housing market has a particular focus on real estate services provided by agents, individuals or companies licensed to negotiate and arrange real estate sales (of either land or housing) as intermediaries of owners, or as owners of real estate property in providing for dwelling units. Real estate is a legal term encompassing land along with anything 
permanently affixed to it, such as buildings, but more specifically property that is fixed in location. It includes the services of construction, maintenance, operation, occupancy, use or appearance of dwelling units and the services of real estate agents licensed to negotiate and arrange sales (of either land or housing) as an intermediary for house owners or owners of real estate property. The explanatory variable is remittances received as payment for real estate services, and those used by migrant households (including members of their households).

\subsection{Research Questions and Hypothesis}

The overall research question is: Can remittances (as a share of household income) influence the tenure and quality of housing at the household level in Uganda? This overall research question is answered through three sub-questions:

Sub-Question One: What is the relationship between remittances and housing tenure at the household level in Uganda? The hypotheses tested are:

(i) The receipt of remittances improves the status of housing ownership for migrant households

(ii) The receipt of remittances improves the status of housing rental for migrant households

Sub-Question Two: What is the relationship between remittances and housing quality at the household level in Uganda? The hypotheses tested are:

(i) The receipt of remittances improves the physical conditions of housing for migrant households, specifically the material of the roof, external walls and floor

(ii) The receipt of remittances improves access to welfare amenities such as lighting, cooking fuel and technologies, toilet facilities and drinking water for migrant households

Korn and Graubard (2003) assert that the explanatory variables in regressions applied to survey data are almost always observed, given that they exist in the population rather than being randomly assigned, and thus the regression coefficients based on survey data simply reflect relationships that exist between the dependent variable and the explanatory variables in the population, and do not necessarily imply causation. The analysis aims at obtaining simple correctional relationships and patterns of relationships to show either positive/negative relations or higher/lower values using the household as the unit of analysis for one-tailed hypotheses. 
Sub-Question Three: Is the use of remittances evident in Kampala's (Uganda) housing market? The financing of housing is investigated through a summative narrative on the situation of the housing market and the variance likely to occur due to the inflow of remittances. This narrative contextualizes the subsequent conclusions and research sub-questions in the broader socio-economic context of Uganda's housing market. Three key studies form the base of the literature review, namely: Endo et al (2010) in their study of Uganda's Remittance Corridors from United Kingdom, United States, and South Africa addressing the challenges to linking Remittances to the use of formal Services; the second study is undertaken by Kalema and Kayiira (2008) on access to Housing Finance in Africa: Exploring the Issues, with a specific overview of the Housing Finance Sector in Uganda and lastly, Giddings' (2009) research on the Land Market in Kampala, Uganda and its effect on settlement patterns.

The literature review was complemented by extracts from semi-structured qualitative interviews questionnaires administered through face-to-face interviews with 37 real estate firms in Kampala, who were tasked with considering the inflow of remittances into their operations over the last 2 years. Results from the interviews were transcribed, manually coded and assembled in a descriptive naming scheme, and subsequently constructed into "quasi-statistics" in which the trends or patterns are coded based upon counts or the number of times a particular response was mentioned in interviews as an estimate of frequency. In this respect, the codes served both as heuristic tools - primarily flags or signposts that point to things in the data - and as objective codes - transparent representation of facts as captured in the interview process - described in the data (Seidel and Kelle, 1995).

\subsection{Data Description}

The Uganda Bureau of Statistics (UBOS) has conducted an integrated household survey, popularly known as the Uganda National Household Survey (UNHS), every other year since the late 1980s. Through the UNHS, Uganda has very rich household time series data covering over 13 years. The UNHS IV (2009/10) round of household surveys is the latest in a series conducted by UBOS, while the previous household survey, namely the UNHS III (2005/06), was undertaken from May 2005 to April 2006 and covered around 7,400 households randomly selected countrywide. The UNHS IV (2009/10) was undertaken from May 2009 to April 2010 and covered around 6,800 households randomly selected countrywide. These two surveys are the major datasets used for analysis in this thesis, and contain sample survey data for monitoring poverty levels, trends and related welfare issues. 
According to the Uganda Bureau of Statistics (2010), a two-stage stratified sampling design was used in both the UNHS III (2005/2006) and UNHS IV (2009/10). In the first stage, Enumeration Areas (EAs) were grouped by districts and rural-urban location, and subsequently drawn using Probability Proportional to Size (PPS). In the second stage, households, which are the Ultimate Sampling Units, were drawn using Simple Random Sampling (SRS). Consequently, a total of 712 Enumeration Areas representing the general household population were selected using the Uganda Population and Housing Census Frame for 2002 for UNHS IV (2009/2010), while this figure was 783 for the UNHS III (2005/06). When determining the required sample size, the degree of precision (reliability) desired for the survey estimates, the cost and operational limitations, and the efficiency of the design were taken into consideration. A qualitative study was conducted alongside the UNHS IV (2009/10) quantitative survey to complement the findings, as was the case in the UNHS III (2005/06). The main objective of the qualitative module was to provide an in-depth understanding of the issues investigated in the quantitative module.

This thesis makes use of the quantitative socio-economic module from both surveys, which gathers information concerning all aspects of living conditions in Uganda through face-to-face interviews. In both surveys, the module questionnaire collected information on household characteristics including education and literacy, overall health status, the health-seeking behaviour of household members, malaria, fever and disability, activity status of household members, wage employment, enterprise activities, transfers and household incomes, housing conditions, assets, loans, household expenditure, welfare indicators and household shocks.

The Uganda Bureau of Statistics (2010), draws the attention of any researcher utilising the Uganda National Household Survey of 2005/06 (UNHS III) and the Uganda National Household Survey of 2009/10 (UNHS IV) to a number of similarities and differences between the two survey data sets. The first difference pointed out concerns the sampling frames, based on the Population and Housing Census of 2002 of Uganda which differ in terms of stratification. The difference is "UNHS III used a region as stratum divided into rural and urban whereas UNHS IV divided the four traditional regions (of north, south east and central) into subregions as strata". Another difference is that "the UNHS IV visited the sampled Enumeration Areas (EAs) once, whereas UNHS III visited EAs twice over a 12 months period". The Uganda Bureau of Statistics (2010) also calls the attention of the data sets user, to the fact that there are similarities between the two data sets and states that, "both survey data sets were conducting during the same months of the year". An additional similarity that eases the analysis in this thesis is the fact that both surveys administered "similar household consumption sections, with the same list of item codes and identical recall periods", which allows for favourable comparison across the five period which is under analysis in this thesis. 


\subsection{Reliability of Data Reported on Income / Expenditure}

The Uganda National Household Survey of 2005/06 (UNHS III) and the Uganda National Household Survey of 2009/10 (UNHS IV) were derived from a randomly selected sample. The UNHS IV had a sample survey of 6,775 households compared to 7,426 households covered in the UNHS III. It has to be pointed out that "both surveys were nationally representative, despite differences in the number of sampled households". Sampling Errors (SE) and Coefficients of Variations (CVs) of some of the variables are provided to any data user by the Uganda Bureau of Statistics in order to show the precision levels.

According to the Uganda Bureau of Statistics (2010), "different recall periods were used to capture information on the different sub-components of household expenditures". The bureaus further points out that, "a 7-day recall period was used for expenditure on food, beverages and tobacco, a 30-day recall period was used in the case of household consumption expenditure on non-durable goods and frequently purchased services, whereas a 365-day recall period was used for semidurable and durable goods and services, and non-consumption expenditures". Uganda Bureau of Statistics (2010), also "valued and recorded all purchases by household members and items received as free gifts as per the current prices. The items consumed out of home produce including food consumed from ownproduction, purchases and free collection/gifts were valued at the current farmgate/producer prices, while for owner-occupied houses; rent was imputed at current market prices".

In its computation of expenditure data, the Uganda Bureau of Statistics (2010), "collected data on an item-by-item basis, with expenditure subsequently aggregated according to the recall period used and by broader sub-components of expenditure to the household level". The Uganda Bureau of Statistics (2010) further points out "that different recall periods used during the collection of data on household expenditures" however "some conversion factors were applied to change and standardise the data to a 30 day (monthly) basis, after which all the different subcomponents of the expenditures were aggregated to derive the total expenditures at household level". An additional aspect of the data sets that aids the analysis in this this is that the Uganda Bureau of Statistics (2010), also makes "a distinction between consumption expenditure and total expenditures" by pointing the fact that the "former refers to expenditure excluding non-consumption expenditure, the latter includes the non-consumption expenditure sub-component". 
Uganda is selected because remittances, when compared to Uganda's budget for the fiscal year 2008/2009, are is equivalent to around 23 percent of the budget. Put differently, it is bigger than the largest allocation to any one sector in the country (New Vision, 2010). Housing is one of the major beneficiary sectors, absorbing approximately $25 \%$ of the said remittances. This thesis aims to establish correlations between households that received remittances and the extent to which this accounts for changes in their housing tenure or quality, based on household survey data drawn from two points in time Uganda National Household Survey of 2005/06 (UNHS III) and the Uganda National Household Survey of 2009/10 (UNHS IV). In this analysis, household changes are captured over a five year period, to make comparisons concerning aggregate changes in households' statuses on housing tenure and quality. In the analysis, household changes over a five year period are investigated, which allows for a pooled cross-section using the year 2005 as the base year, to make comparisons based on aggregate changes in households by 2010, which thus represents the apex year.

Both the UNHS IV and UNHS III represent sample survey data. It would be difficult to construct correlations and tests of group differences without applying binary variables, with two such levels constructed accordingly. At the first level, households are segregated into "migrant" and "non-migrant" households, on the basis of those receiving remittances as a share of their household income and those that do not receive remittances. Receipt of remittances was dealt with on a binary scale coded into 1 if a household received remittances and 0 for households that didn't receive remittances. The advantage lies in having household income as a gross aggregate of: income from agricultural activities, income from non-agricultural activities, income from wage and salaries and income from transfer earnings (or remittances) in the UNHS IV and UNHS III, which partially addresses the challenge of how to distinguish "the dollar of remittance" from other incomes, and thus the disaggregating of migrant and non-migrant households.

At the secondary level, households are distinguished on the basis of explanatory variables and binary characterization is introduced. Several dependent variables were transformed into binary responses and coded as shown below:

\section{Housing Quality:}

(i) Major construction materials of floor: 0 for households with floors made of earth, earth \& cow dung and other materials (rudimentary) and 1 for households that had floors made of cement, mosaic or tiles, bricks or stones (advanced). 
(ii) Major construction materials of roof: 0 for households with floors made of thatch, straw, mud, wood planks, tin and others (primitive sources) and 1 for households that had iron sheets, asbestos, tiles and cement (advanced sources).

(iii) Major construction materials of external wall: 0 for households with materials of the external wall including; thatch, straw, mud, poles, timber un-burnt bricks, burnt bricks with mud and others (primitive sources) and 1 for households that had burnt bricks with cement, cement blocks and stone (advanced sources).

(iv) Main source of house lighting: 0 for households with sources of light such as paraffin, kerosene or gas lantern, tadooba - a locally manufactured lantern, firewood and others (primitive sources) and 1 for households that had electricity, solar and bio gas (advanced sources).

(v) Type of fuel used for cooking: 0 for households with sources of cooking fuel such as firewood, charcoal, paraffin/kerosene, saw dust and others (primitive sources) and 1 for households that had electricity, gas, solar and bio gas (advanced sources).

(vi) Type of toilet used: 0 for households that used uncovered pit latrines, bushes and other facilities (primitive facilities) and 1 for those that had covered pit latrines, VIP latrines and flush toilets (advanced facilities).

(vii) Main sources of drinking water: 0 for households that used unprotected wells/springs, rivers, streams, lakes, ponds, rain water and other sources (unprotected sources) and 1 for those that had pipelines, public taps, boreholes, protected wells/springs, vendor/tanker trucks, gravity flow schemes (protected sources).

\section{Housing Tenure:}

(i) Rent status: 0 for households that were not renting, 1 for those that were renting.

(ii) Household ownership: 0 for households that did not own houses, 1 for those that owned houses.

Having constructed the binary (two-level) categorical variables, these are analysed in three different ways in this thesis. First is the basic description of trends on variables of interest within the households in both data sets - 2005/2006 and 2009/2010. This is followed by cross tabulations to determine the existence of relationships between the variables under study. To test linear relationships, the Pearson's chi-square test was performed to test the null hypothesis of no association between remittances and the attributed variables of housing quality and housing tenure. This test measures the goodness of fit and finds if an observed frequency distribution differs from a theoretical distribution and secondly to determine 
whether paired observations on two variables are independent of or not related with each other, since the data depicts true values.

I also applied the Spearman's correlation matrices because my data was converted into ordinal categorical scales. I computed both coefficients (Pearson's and Spearman's) to compare the differences. In many cases, they will be exactly the same, when they are different then the assumptions of Pearson's (constant variance and linearity) have not been met, therefore I take the Spearman's prediction as my conclusion to the analysis. The third level of analysis was the logistic regressions to measure the association and find the odds of one outcome relative to another. The odds ratios are therefore equivalent to the structure of association between remittances and housing tenure or housing quality.

The logistic regression approach is chosen for this analysis because it is the most appropriate when dealing with categorical responses. In this case all my response/dependent variables were transformed into binary form. Logistic regressions were carried out for each of the dependent variables against the independent variable (receipt of remittances) which had been hypothesized to be of influence on each of these variables. They are then compared to discern which ones are migrants and which ones are non-migrant over the five year period. It was hypothesized that receipt of remittances (the independent /explanatory variable) had an effect on the dependent variables. The common approach is to regress the outcome of interest on a remittance variable and a set of control variables, that is:

Outcome $=\alpha+\beta^{*}$ remittance $+\gamma^{*} X+\varepsilon$

This assumes that some households just happen to receive remittances thus ignoring endogeneity, so the coefficient $\beta$ is (most likely) biased. Measures are taken to correct for bias in this coefficient and are discussed in the next sections on endogeneity due to omitted variables, selection bias and unobserved effect, as well as on measures to correct for fungibility of remittance income. In this analysis, control variables include household expenditure, distribution of income, rate of household formation (as a function of population growth) and household size, household priorities, nature of employment, age, and occupation.

It is important to point out here, that the resulting observations are not the probability, but the actual status of the variables as captured in the two data sets (UNHS III and UNHS IV) under investigation; therefore the results do not reflect the probability. Korn and Graubard (2003) assert that it is usually impossible to assign "cause" to any observed relationships between a dependent and explanatory variable, except in the case of well-designed controlled and randomised experiments. As opposed to controlled experiments that employ randomisation and 
control of auxiliary variables, household survey data is usually observational, with little or no control over other factors that might influence the relationships among variables. At best, this thesis offers an exploratory data analysis that can lead to useful insights about the data and relationship among observed variables, although the statistical significance of findings from such "unplanned" analysis should remain a topic for future confirmation or validation through another study of survey data.

\subsection{Endogeneity in Analysis}

The limitations arising owing to endogeneity often invoked in non-experimental research include - yet are not limited to - those in which "the relation between $\mathrm{x}$ and y might be due to y causing x (i.e., reverse causality)," or "common-method variance may explain the strong relationship," or "the relationship is an association given the non-experimental data" (Antonakis et al, 2010). If $x$ is endogenous, the coefficient of $x$ simply has no meaning. The true coefficients could be higher, lower or even of a different sign (Antonakis et al, 2010). Endogeneity could be a possible result of omitted variables, omitted selection, simultaneity, common-method variance and measurement errors. As indicated by Antonakis et al (2010), "the effect of x on y cannot be interpreted, because endogeneity renders estimates causally uninterpretable". In this thesis, if the relation between remittances and housing tenure or quality is partly due to other reasons, then remittances are endogenous, and the coefficient of regressing remittances on housing quality or tenure cannot be interpreted, even as a simple correlation. To ensure that the correlations of this thesis are not the result of estimation biases, I address or correct for the joint endogeneity of the explanatory variables, which would lead to inconsistent coefficients that would render an over or underestimation of the effects of remittances on housing quality and tenure, depending on the sign of the reverse causality.

The application of single difference comparisons, which can be either reflexive (before and after) comparisons that track gains solely, or with and without comparisons that take single differences in mean outcomes between migrant and non-migrant households using cross-sectional data is used to correct for joint endogeneity. The datasets in this analysis are only derived from nationally representative surveys, and thus do not suffer from biases stemming from estimates based on subsets of the Ugandan population. The reflexive comparison is unable to separate the remittance influence from the general economic and other changes that would have occurred without the remittance. The "with and without" comparison can only identify the remittances if one can deal with the selection bias. Furthermore, primary income and expenditure data is based on the comprehensive coverage of different sources of income and types of expenditure, and thus do not contain biases 
derived from the exclusion of non-monetary income, given that they are part of what the database covers.

However, this thesis does not aim to determine or analyse causality. Accordingly, the analysis is limited to two aspects; first, determining the existence of relations, namely whether they exist between the variables and their measures; while the second involves ascertaining the nature and extent of relations, based on the status of households. However, it is important to note that if certain essential design and methodological conditions are not present, the coefficient cannot be interpreted, not even in terms of an association or relation - even in the correlational sense. In this respect, the coefficient may have an allure of authenticity, yet it is specious. In terms of this thesis, it would be ideal to demonstrate that 'correlation can mean causation in non-experimental settings if some essentials design conditions are present and the appropriate statistical methods are used' (Antonakis et al, 2010). However, owing to limitations associated with the dataset (is not from a randomised experiment), the following steps were taken to deal with endogeneity.

Identification of the counterfactual is the organising principle based on the necessity to: (a) clearly define control groups; and (b) identify all variables that impact outcomes, with the estimation of a proxy variable to capture these effects. In this analysis, I used counterfactuals as one means of dealing with endogeneity. With the counterfactual, one asks the following questions: (a) if the households that received the remittances had not received them, what would be observed in their housing quality or housing tenure? Alternatively, (b) if the households who did not receive the remittances had in fact received them, what would have been observed in terms of their housing tenure or quality? Therefore, the counterfactual for those receiving the housing are those who did not receive remittances (and vice-versa), and the "treatment effect" or the "remittance effect" is simply the difference in housing quality and tenure for those that received remittances and those that did not.

Antonakis et al (2010) assert that when the two groups of households are not the same in terms of observable (or unobservable) characteristics and one has received remittances, the counterfactuals cannot be observed. However, they also concede that when analysis is based exclusively on quantitative data, as is the case with the UNHS data used in this thesis, where the households are approximately the same, this allows for solid conclusions and counterfactuals, whether correlational or testing for group differences. Therefore, if the samples of the UNHS data used in this analysis are representative and random, which is the case, it is also possible to observe counterfactuals correctly. Regression methods can sometimes remove the effects of these uncontrolled confounding variables, in order to obtain less biased estimates of the true relationship. Both the unobserved effects and selection terms are removed by taking the difference between any two periods in which the 
selection index is the same (or, in practice, "similar"), in this case, the UNHS III in 2005/2006 and UNHS IV in 2009/2010.

In addition, I adopt McKenzie and Mistiaen's (2007) tactic, supporting the innovative use of household survey data in pooled cross-section to control for time-invariant unobservable characteristics and the use of cross tabulations of remittances versus outcomes to overcome endogeneity. Cross-tabulations of migration or remittances versus outcomes (e.g. poverty or education) can be informative in providing a description of the situation. In tabulating remittances by income deciles, it makes sense first to deduct remittances from the total income, prior to constructing poor/rich rankings. Naturally, this approach treats remittances as exogenous; however, by displaying averages only, these tabulation methods do not identify causal relations and provide rather weak grounds for policy recommendations.

\subsection{Fungibility of Income}

De Haas (2010) while theorizing on perspectives of international migration, observes that empirical work and studies are clearly contradictory, which cannot simply pertain to differences in paradigmatic orientation - leading to different interpretations of similar empirical data - political ideology or methodology, yet also relates to real, existing differences. Accordingly, two main theoretical problems may have caused such inconsistent results: 1) the fungibility of money; and 2) the separation of investment strategies. Two main approaches have been employed in the literature, the most basic descriptive of which asks households to identify what remittances are spent on or for what purpose they are intended. Ozden and Schiff (2006), observe that, "resources are fungible, and even if the remittance itself is used for one purpose, it may free up other sources of income that may be used for other means". They therefore advise, that the next best approach is to "examine an outcome of interest, such as poverty, education, business ownership, housing tenure or housing quality, by comparing households that receive remittances with those that do not".

Ozden and Schiff (2006) highlight LaLonde and Topel (1997) observation that, remittance receiving household and non-remittance receiving household are inherently similar, because "all systematic differences between remittance-receiving and non-remittance receiving households can be explained by a set of observable characteristics of the migrant and non-migrant households, and subsequently estimates the impact of remittances on an outcome of interest through regression analysis". Nevertheless this is not satisfactory, "because if the two groups of households (remittance receivers and non-receivers) are truly the same after controlling for observable differences, they should have the same migration and remittance behaviour". Ozden and Schiff (2006) further argue that, "whether a 
household receives remittances or not may be correlated with unobserved variables. However, if migration has other impacts on the outcome of interest in addition to its effect through remittances, the other effects of migration are excluded (omitted variables), yet may be correlated with remittances and the outcome variable. Consequently, estimates of the effect of remittances will suffer from omitted variables bias owing to these other impacts of migration". Given the data sets I am using in the analysis in this thesis, such a scenario is plausible.

There are two main concerns according to Ozden and Schiff (2006), "unobserved shocks and unobserved attributes of the household". As an example of the first concern, consider the impact of a sudden improvement in income from a household's cash crop causing a positive shock in income, and is likely to free further remittance resources for additional housing improvement activities. As an analyst, I am unlikely to precisely observe all such shocks, and thus may understate the effect of remittances. Ozden and Schiff (2006) further point out, that is possible for households to receive remittances for different purposes depending on the intent of the sender and the concern they have for housing tenure or quality. For example, a poor household that particularly values housing quality may decide to send a migrant to earn remittances to pay for housing improvements, and also undertakes a number of other actions to improve the environmental qualities of their housing. In such a case, regression of the variables will overstate the impact of remittances on housing quality and tenure, given that most of the variables that help predict whether a household improves housing quality or tenure or receives remittances are likely to have an impact on the outcomes of interest.

In this analysis, the explanatory variables used are restricted to those available within the UNHS III and IV survey data, and consequently the variables selected to explain the variation in a dependent variable may only be strong correlates of the actual causative factor. There may be competing correlates of the causative factor, none of which logically seem to be related to the dependent variable. Accordingly, this is a limitation in both UNHS III and UNHS IV datasets used in this thesis. The concept of control implies that, in exploring causality in relation to two variables (factors), you set up your study in a way that minimizes the effects of other factors affecting the relationship. In this case, remittances affect total income and the effect can be best understood through studying the entire household investment portfolio rather than separate investment options. However, the key argument rests beyond merely establishing the relationships stated; rather, it involves aggregating the significance of these relations to examine whether they are overstated in terms of the total effect at the household for housing. 


\subsection{Conclusion}

In this chapter, I have introduced the research questions, the variables and their measures including the hypotheses to be tested. I described the data sets used based on national sample survey, showing how the data is reliable. In the data analysis methods, I have concentrated on how endogeneity is dealt with either as a result of omitted variables, omitted selection, simultaneity, common-method variance and measurement errors. The fact that qualitative data sets are used in the analysis are from a random and representative sample of an entire population significantly reduces the challenge of endogeneity in the analysis with the application of single difference comparisons and counterfactuals methods. The fungibility of income arising from observed and unobserved shocks on household income is reduced with consideration of the full household income and expenditure portfolio together with disclosure of incomes in data collection. With all these measures taken, the overall outcome of this thesis is a reflection of the actual status of housing for migrant and non-migrant households and not the probability of housing tenure or quality arising out of receipt of remittances. 


\section{Chapter 5:}

\section{Remittances and Housing Tenure in Uganda}

\subsection{Introduction}

The essential consideration for housing tenure in this analysis relates to whether remittances, as a share of household income, exhibit influencing tendencies on ownership and the rental status of housing for migrant and non-migrant households. Housing economists contend that household income (remittances) is a major explanatory variable accounting for tenure changes and disparities between migrant and non-migrant households with regard to housing. Of specific interest are the odds that a household will advance its ownership or rental of housing upon receipt of remittances. My analysis is at three levels: the descriptive data, followed by cross-tabulations showing the status of relationships between variables; the Pearson's chi-square and Spearman's correlation matrices to prove the independence of variables; and subsequently logistic regression to ascertain the structure of relations established.

I base my analysis on a convergence of models in the discipline of housing economics, particularly Henderson and Ioannide's (1986, 1989) hypothesis that "increase in household income increases the probability of housing (home) ownership", and migration theory, to demonstrate how remittances may be critical in attaining home-ownership or meeting rental costs, in addition to serving the purposes of investment or consumption use, often-cited in migration literature. Secondly, I argue that remittances serve more than simply bridging wage differentials between locations, as articulated by the neo-classical economists, but rather are a source of additional household income that can aid migrant households to attain secure housing tenure (ownership and rental), as articulated by the new economics of labour migration and transnational theorists. Furthermore, I draw conclusions in the context of what is posited by theory, remarking upon any affirmations or departures from existing studies.

\subsection{Theory and Evidence from Other Studies}

In the review of literature on migration and remittances which is relevant to analysis in this chapter, the new economics of labour migration theory analyses migration as a household decision rather than an individual decision, whose benefits are enjoyed by the family or household as a whole. Taylor (1999) offers the view that the positivity of remittances should be nurtured through economic policies, despite its impacts varying across locations, and is influenced by migrants' remittance 
behaviour. Taylor (1999) further acknowledges that research on migration has tended to study migrants themselves, or their contribution to the economy, despite Stark and Lucas's (1988) suggestions that migrants play the role of financial intermediaries, enabling rural households to overcome credit and risk constraints. Therefore, remittances represent additional incomes, not to individuals within households but as beneficial accruals to households as units arising out of a migration decision.

Mazzucato's (2008) application of the trans-nationalism theory to migrant investments in urban housing in Accra, Ghana, offers an excellent entry point for this thesis to anchor its findings. Their keenness on actors (notably trusted non-kin actors) and the institutional embedding as influencing factors in the choice of housing construction as investment, offer this analysis the opportunity to situate at the household level, arguing that the opportunities for housing ownership and rental improve with the receipt of remittance. Nonetheless, I am well aware of the fact that "findings cannot be considered in isolation from the context in which they are embedded", as cautioned by Taylor (1999).

However, literature on housing tenure shows that, researchers engage existing theories from other disciplines that bear on housing phenomena, owing to the absence of compound theories within the discipline. In the words of King (2009), "different disciplines have come to bear on housing", with two prominent approaches to tenure choice amongst these are; one based on economics, while the other is presented by demographers, geographers and sociologists. Clark et al (1996) observe that these two approaches do not cross-reference each other, despite their models, concepts, variables and even ideas often being extremely similar.

The economics perspective assumes that households are economically rational and choose a certain type of housing tenure (either ownership, rental or freely supplied) to maximise utilities within a given budget constraint (Arnott, 1987). Within this approach, home-ownership is not simply a consumption decision by households, but also an investment decision in competitive housing markets. Henderson and Ioannides $(1985,1987$, and 1989) confirm that as wealth increases the probability of home ownership increases, thus home ownership increases with household income. From the perspective of Clark et al (1992), housing economists are almost entirely focused on the elasticity of housing prices, providing an understanding of the role that income plays in tenure change and specifically in house purchase, concluding that the demand for housing is quite wealth inelastic for both renters and owners.

Haurin and Gill (1987) consider the certainty of income, and specifically whether additional incomes from uncertain sources to spouses of military personnel improve the opportunity for home-ownership, with their findings confirming the value of 
additional incomes to housing consumption. Haurin (1991) explicitly measures income uncertainty as the coefficient of variation of income across time, finding a negative relationship between income risk and the likelihood of home ownership, yet does not find a significant relationship between risk and housing demand.

Plaut (1987) provides additional insights by focusing on the timing of tenure changes, concluding that the timing of changes reflects both consumption and financial (investment) considerations. Dynarski and Sheffrin (1985) divide income into permanent and transitory components. Positive transitory shocks (increases in transitory income over time) increase the likelihood of home purchases, with no significant relationship between negative transitory shocks and home purchases. These results suggest that the variance in transitory income may have a positive effect on housing purchases.

By contrast, demographers, geographers and sociologists argue that housing tenure choice is not a simple investment or consumption decision, but rather a complicated event that is inextricably linked with characteristics of households and changes in the housing market (Clark et al, 1996). Indeed, "it is directly linked to positions and change in the family life-cycle, and the place of the household in the ageing--having children continuum" (Clark et al, 1996). Morrow-Jones (1988) emphasises the strong effects of the life-cycle to the extent of arguing that housing affordability may not be so critical. Indeed, she reports that the desire to own is not diminished by the high cost of housing, reiterating an often-cited finding that housing has both shelter and investment roles in society.

Kendig (1990) used the notion of housing careers as an organising principle to examine the intersection of housing choices and family composition, suggesting a link between the housing tenure decision and the family life-cycle. From his perspective, households pass through a series of dwellings that increasingly meet their long-term housing aspirations, and consequently housing careers reflect the means for linking mobility and the life-cycle. The demographic view suggested by Myers (1985) provides specific evidence that first-time house or home buyers increasingly delay child-bearing and continue full-time employment to enter the ownership market. However, on the other hand, Rudel (1987) highlights links between income, inflation and rising interest rates and home ownership, thus concluding that wealthy young couples without children are more likely to own than less wealthy couples with children.

A number of studies and theories in the discipline of housing are generally concerned with the event of transfer from rent to ownership of housing, and thus do not examine the time-sequence of the event or the larger context of economic changes in society as a whole. Even if buying a house for the first time is primarily 
driven by consumption considerations and does not involve a conscious investment in the housing market, it is nonetheless a major financial action that ties up a large share of a household's assets and requires a substantial proportion of current income to be diverted to housing (Clark et al., 1984).

From the above review, studies in housing provide us with evidence that households are economically rational and choose a certain type of housing tenure (either ownership, rental or freely supplied) to maximise utilities within a given budget constraint. This view augurs well with the new economics of labour migration theory which also views migration as a household decision, whose benefits are enjoyed by the family or household as a whole. Housing studies also show that increases in household incomes improve the probability of home (housing) ownership; migration theory affirms that remittances are additional incomes within households with beneficial accruals to households as units with a trans-national context. This congruence of income and household abilities informs the findings of this chapter and anchors the conclusions in a firm theoretical grounding offered by both migration theory and housing scholars.

\subsection{Household Size}

Household size refers to the number of usual members in a household, defined as those who have lived in the household for at least 6 months during the past 12 months. However, it does include persons who may have spent less than 6 months during the last 12 months in the household yet joined the household with the intention of living permanently or for an extended period of time (Uganda Bureau of Statistics, 2010). As family size increases, so do the requirements for non-housing expenditures, and this could reduce resources available for housing tenure. Greater space requirements are often met by reductions in other dimensions of housing, such as neighbourhood quality. In 2005/2006, the UNHS III estimated the population of Uganda to be 27.2 million, which included slightly more females than males. Furthermore, the population below 15 years accounted for 51 per cent of the total population, while the average household size was estimated at 5.2, and was larger in rural than urban areas. 
Figure 5.1: Distribution of households by household size

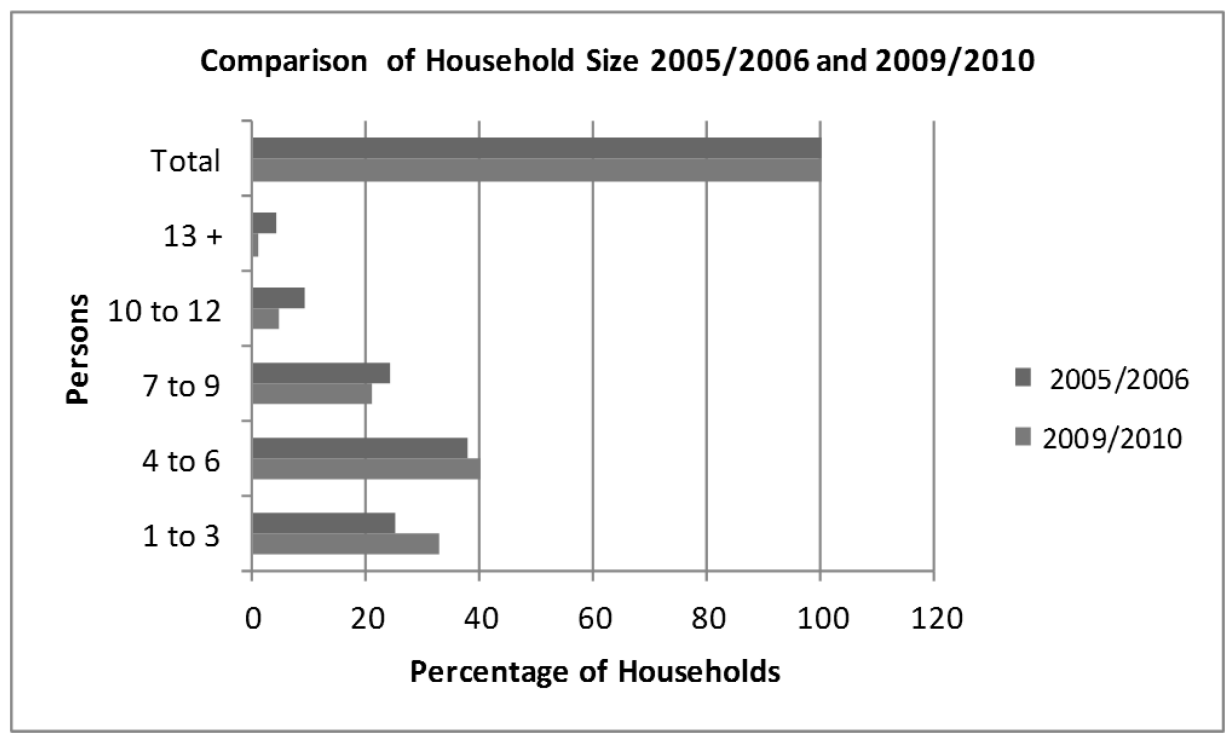

In 2009/2010, the UNHS IV estimated the population of Uganda to have increased to 30.7 million, with 49 per cent of the population male and 51 per cent female. The average household size was estimated at 5.0, which has remained more-or-less the same when compared with the UNHS III in 2005/2006. However, the average household size remains larger in rural than urban areas. Figure 5.1 shows a comparison of household size in 2005/2006 and 2009/10. Households of 4 to 6 members represent the majority in both surveys, with 38\% in 2005/2006 and 40\% for 2009/2010, implying that there have been no significant changes in household size across the two time periods.

\subsection{Household Distribution}

Considering the spatial distribution of the population, Uganda's population is predominantly rural (85\%) this has not significantly changed since $2005 / 06$. The number of households increased from 5.2 million in 2005/2006 to 6.2 million in 2009/2010, with the average household size estimated at 5 persons per household. Eighty two per cent of the household population constituted the nuclear family members in 2009/2010. Figure 5.2 compares the two time periods under analysis and shows a slight increase in the percentage of households residing in urban areas from 17 per cent in 2005/06 to 19 per cent in 2009/10. The trend shows an increasing percentage of households resident in urban areas over time. There is also a decrease in rural households from 83 per cent in 2005/2006 to 81 per cent in 2009/2010. 
Figure 5.2: Household Distribution in Rural and Urban Areas - 2005 to 2010

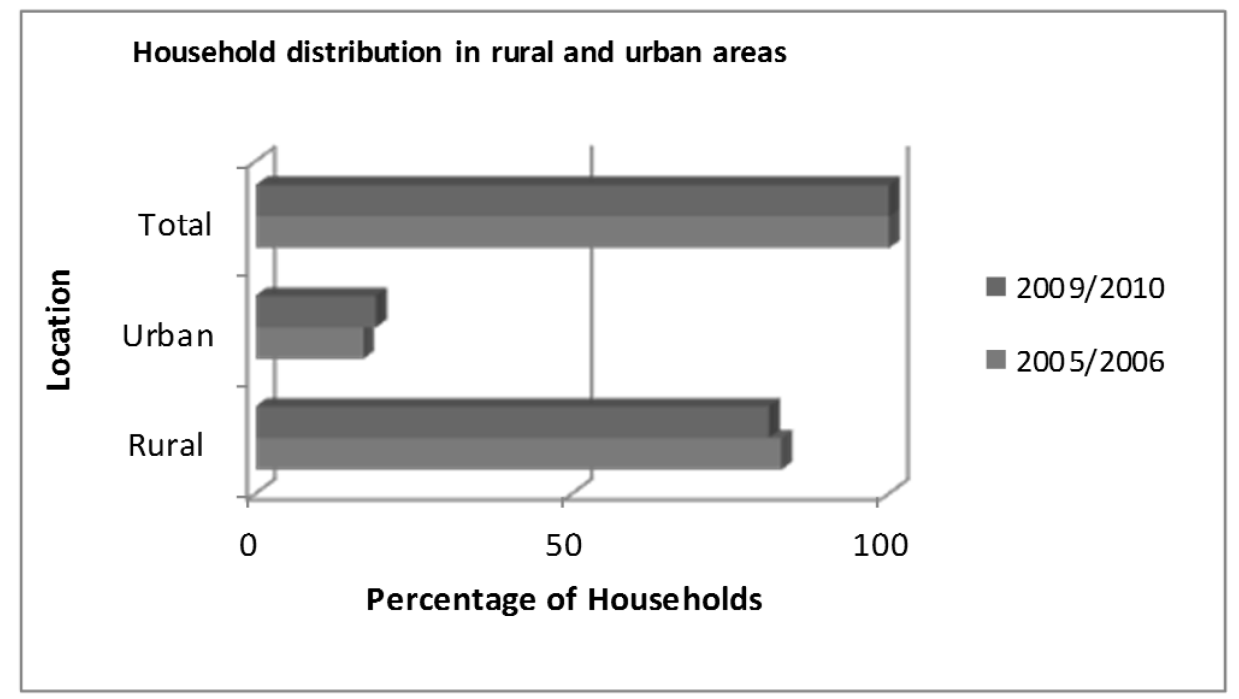

Figure 5.3: Distribution of households by remittances and Location in 2005/2006

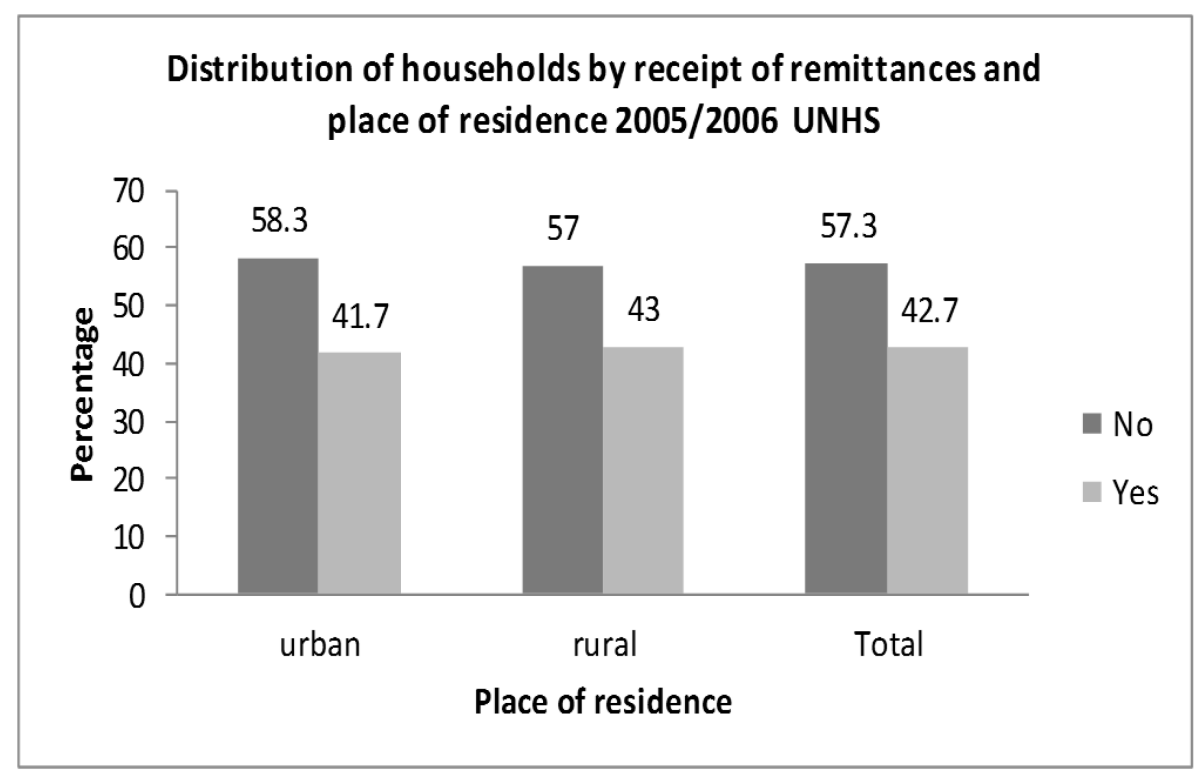


Figure 5.4: Distribution of households by remittances and location in 2009/2010

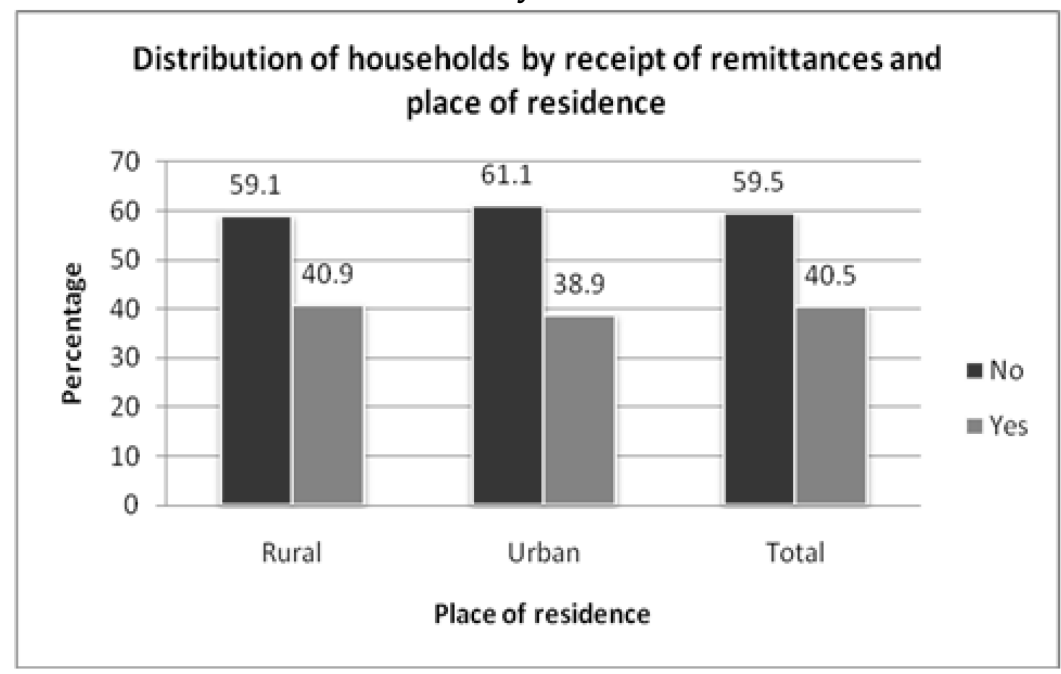

\section{$\underline{\text { Household Distribution and Remittances }}$}

Figures 5.3 and 5.4 show a larger percentage of the households did not receive remittances, regardless of their location whether in rural or urban areas. Overall, 42.7 per cent of the households received remittances, while 57.3 per cent did not receive any remittances. Therefore, the location factor seems to have no significant impact on the analysis of remittance data from the 2005/06 household survey. In the 2009/2010 survey, a similar finding obtains that a larger percentage of the households enumerated did not receive remittances, regardless of the place of residence. Furthermore, the percentages of respondents receiving remittances was more-or-less the same in rural (40.9\%) and urban (38.9\%) households. Overall, 40.5 per cent of the households received remittances, while 59.5 per cent did not receive any remittances. Therefore, the location factor seems to have no significant impact on the analysis of remittance data from the 2009/10 household survey. Moreover, as previously illustrated in figure 4.2, 82 per cent of the household respondents were rural. Therefore, this variable is not considered in the subsequent logistic regression analysis in terms of establishing correlations with remittances.

\subsection{Relations: Remittances and Housing Tenure}

\section{a) Remittances}

Household income is taken as a gross aggregate of the following income sources: agricultural activities; non-agricultural activities; wage and salaries and transfer earnings (or remittances). It includes all receipts (cash and in kind) in exchange for employment, in return for capital investment, or transfer earnings (Uganda Bureau 
of Statistics, 2007). 57.3 per cent of households in the 2005/2006 survey do not receive any remittances, compared to 42.3 per cent that received remittances in either cash or kind, expressed in cash values in the survey data for the period 2005/2006. There was a larger percentage (37.75) of households receiving remittances whose cash value is less than 500,000 shillings (US\$ 294.12) ${ }^{1}$ followed by 2.49 per cent of the households that received remittances of a cash value ranging between 500,000 shillings to 1 million shillings (between US\$ 294.12 and US\$ 588.24), while only 2.14 per cent of the households received remittances with a cash value ranging between 1 million and 5 million shillings (between US\$ 588.24 and US\$ 2,941.18). Finally, households that received remittances with a cash value of 10 million Uganda shillings (US\$ 5,882.35) or more are only represented by 0.1 per cent.

\section{Table 5.5: Value of Total Remittances at Household Level in 2005/2006}

\begin{tabular}{|c|c|c|c|c|c|c|}
\hline \multirow[b]{2}{*}{ Value in UGX } & \multicolumn{2}{|c|}{ Total $($ Cash + Kind $)$} & \multicolumn{2}{|c|}{ Total (Cash) } & \multicolumn{2}{|c|}{ Total (Kind) } \\
\hline & Freq. & Per cent & Freq. & Per cent & Freq. & Per cent \\
\hline 0 & 4,249 & 57.30 & - & - & - & - \\
\hline Less or equal to 500,000 & 2,799 & 37.75 & 3,226 & 88.82 & 3,225 & 97.88 \\
\hline 500,000 to $1,000,000$ & 185 & 2.49 & 172 & 4.74 & 50 & 1.52 \\
\hline $1,000,000$ to $5,000,000$ & 159 & 2.14 & 202 & 5.56 & 14 & 0.42 \\
\hline $5,000,000$ to $10,000,000$ & 15 & 0.20 & 23 & 0.63 & 2 & 0.06 \\
\hline Greater than $10,000,000$ & 8 & 0.11 & 9 & 0.25 & 4 & 0.12 \\
\hline Total & 7,415 & 100.00 & 3,632 & 100.00 & 3,295 & 100.00 \\
\hline
\end{tabular}

Table: 5.6: Value of Total Remittances at Household Level in 2009/2010

\begin{tabular}{|c|c|c|c|c|c|c|}
\hline \multirow[b]{2}{*}{ Value in UGX } & \multicolumn{2}{|c|}{ Total (Cash +Kind) } & \multicolumn{2}{|c|}{ Total (Cash) } & \multicolumn{2}{|c|}{ Total (Kind) } \\
\hline & Freq. & Per cent & Freq. & Per cent & Freq. & Per cent \\
\hline 0 & 4,029 & 59.5 & 4,954 & 73.12 & 4,752 & 71.00 \\
\hline Less or equal to 500,000 & 2,265 & 33.4 & 1,488 & 21.96 & 1,705 & 25.47 \\
\hline 500,000 to $1,000,000$ & 261 & 3.9 & 176 & 2.60 & 100 & 1.49 \\
\hline $1,000,000$ to $5,000,000$ & 188 & 2.8 & 133 & 1.96 & 131 & 1.96 \\
\hline $5,000,000$ to $10,000,000$ & 19 & 0.3 & 14 & 0.21 & 3 & 0.04 \\
\hline Greater than $10,000,000$ & 13 & 0.2 & 10 & 0.15 & 2 & 0.03 \\
\hline Total & 6,775 & 100.00 & 6,775 & 100.00 & 6,693 & 100.00 \\
\hline
\end{tabular}

In the 2009/2010 survey, 59.5 per cent of households do not receive any remittances, compared to 40.6 per cent that received remittances in either cash or kind, expressed in cash values in the survey data for the period 2009/2010. There was a lower percentage (33.4) of households that received remittances with a cash value less than

\footnotetext{
${ }^{1}$ In 2005/2006, the average exchange rate was approximately Uganda Shillings 1,700 to US\$ 1
} 
$500,000$ shillings (US $\$ 294.12)^{2}$ compared to the $2005 / 2006$ period, followed by 3.9 per cent of the households receiving remittances of a cash value ranging between 500,000 shillings to 1 million shillings (between US\$ 294.12 and US\$ 588.24). Furthermore, only 2.8 per cent of the households received remittances with a cash value ranging between 1 million and 5 million shillings (between US\$ 588.24 and US\$2,941.18), while those with larger values of remittances are a notch higher in this time period compared to the 2005/2006 time period, with households receiving remittances whose cash value is 10 million Uganda shillings (over US\$ 5,882.35) or more representing 0.2 per cent.

\section{b) Cash Remittances}

The majority of the households in Uganda received remittances in the form of cash, both in the 2005/2006 and 2009/2010 survey. In 2005/2006, 88.8 per cent of households received remittances in the form of cash that did not exceed 500,000 Uganda Shillings (US\$ 294.12), while only 202 households (5.6 per cent) received cash remittances ranging between one million to five million Uganda shillings (between US\$ 588.24 and US\$2,941.18), and a small percentage ( 0.25 per cent) received cash remittances greater than ten million Uganda shillings (over US\$ 5,882.35). In 2009/2010, 59.5 per cent of the households did not receive remittances, followed by 33.4 per cent receiving remittances in cash of less than 500,000 Uganda Shillings (US\$247.893), 3.9 per cent receiving remittances ranging between 500,000 Uganda Shillings (US\$ 247.89) to 1,000,000 Uganda shillings (US\$ 495.78), and 2.8 per cent ranging between one million to five million Uganda shillings (US\$2,478.89), while a small percentage of households $(0.2 \%)$ received remittances greater than ten million Uganda shillings (over US\$4,957.85).

\begin{tabular}{lrrrr}
\hline \multicolumn{2}{l}{ Table 5.7: Cash Value of Remittances Received } & & & \\
\hline & & $2005 / 2006$ & 2009/2010 \\
\cline { 2 - 5 } Cash value of remittances & No. & Col \% & No. & Col \% \\
\hline 0 & 4,249 & 57.3 & 4,029 & 59.5 \\
$<500,000$ Shs & 2,799 & 37.8 & 2,265 & 33.4 \\
500,000 to 1,000,000 Shs & 185 & 2.5 & 261 & 3.9 \\
$1,000,000$ to 5,000,000 Shs & 159 & 2.1 & 188 & 2.8 \\
$5,000,000$ to $10,000,000$ Shs & 15 & 0.2 & 19 & 0.3 \\
Greater than 10,000,000 Shs & 8 & 0.1 & 13 & 0.2 \\
\hline Total & $\mathbf{7 , 4 1 5}$ & $\mathbf{1 0 0}$ & $\mathbf{6 , 7 7 5}$ & $\mathbf{1 0 0}$ \\
\hline
\end{tabular}

\footnotetext{
${ }^{2}$ In 2005/2006, the average exchange rate was approximately Uganda Shillings 1,700 to US\$ 1

${ }^{3}$ In 2009/2010, the average exchange rate was approximately Uganda Shillings 2,017 to US\$ 1
} 
The majority of cash remittances were valued at 500,000 Uganda Shillings or less in both 2005/2006 and 2009/2010. Given that the majority lies within this receiving bracket, this marks where to focus in terms of trends and changes. This finding is close to that of Endo et al (2010) finding in their analysis of Uganda's Remittance Corridors from United Kingdom, United States and South Africa among documented Ugandan migrants, placing the most frequent amounts of remittances per transaction in range between US\$ 401 to US\$ 600, followed by between US\$ 201 to US\$ 400. While there is a 4 per cent decline in the amount of remittances below 500,000 Uganda Shillings (US\$ 247.89) during the period 2006-2010, this could possibly correspond with the recession periods in the remitting countries at this time.

\section{c) Housing Tenure}

Housing tenure refers to arrangements under which a household resides in a dwelling or housing unit, which may entail the payment of rent, owner-occupancy or free occupancy that is relative-supplied or employer-provided (Uganda Bureau of Statistics, 2007). In this section, I use cross tabulations in this household survey data to obtain a description of the situation by treating remittances as exogenous. Over the 5 year period investigated by the UNHS III (2005/2006) and UNHS IV (2009/2010), 59.16 per cent of households surveyed in 2005/2006 had independent houses, this percentage dropped to 55.10 per cent in 2009/2010 to as shown by table 5.8. The second most common form of housing is huts, which sheltered 1,684 households (22.68\%) in 2005/2006, compared to 1,798 (26.6\%) in 2009/2010, which reflects an increase of approximately 4 per cent, corresponding with the rate of formation of new households. As a form of dwelling, huts are common in rural areas, while the most common form of dwelling units in urban areas is tenements, accounting for 1,137 households (15.3\%) in 2005/2006, this rises slightly by approximately 1 per cent to 1,097 households (16.2\%) in 2009/2010. This rise corresponds with the observed growth in households in urban areas, increasing from 17 per cent to 19 per cent between 2005 and 2010. 


\begin{tabular}{|c|c|c|c|c|}
\hline \multirow[t]{2}{*}{ Structure of House } & \multicolumn{2}{|c|}{$2005 / 2006$} & \multicolumn{2}{|c|}{$2009 / 2010$} \\
\hline & Frequency & Per cent & Frequency & Per cent \\
\hline Independent House & 4,393 & 59.16 & 3731 & 55.1 \\
\hline Tenement / Muzigo (Single Room) & 1,137 & 15.31 & 1,097 & 16.2 \\
\hline Independent Flat/Apartment & 37 & 0.50 & 21 & 0.3 \\
\hline Sharing house/Flat/Apartment & 136 & 1.83 & 79 & 1.2 \\
\hline Boys Quarters & 18 & 0.24 & 22 & 0.3 \\
\hline Garage & 2 & 0.03 & 2 & 0.1 \\
\hline Hut & 1,684 & 22.68 & 1,798 & 26.6 \\
\hline Uni-Port & 2 & 0.03 & 10 & 0.1 \\
\hline Other & 16 & 0.22 & 10 & 0.1 \\
\hline Total & 7,425 & 100.00 & 6,770 & 100.00 \\
\hline
\end{tabular}

Figure 5.9: Status of Tenure in 2005/2006

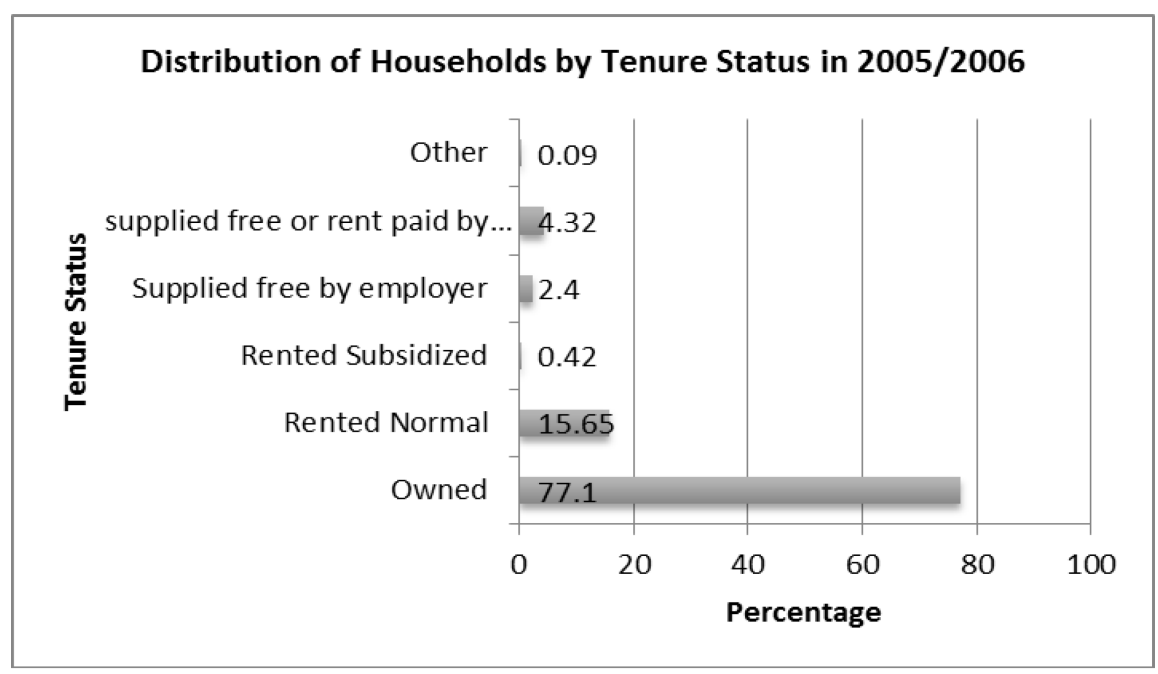


Figure 5.10: Status of Tenure in 2009/2010

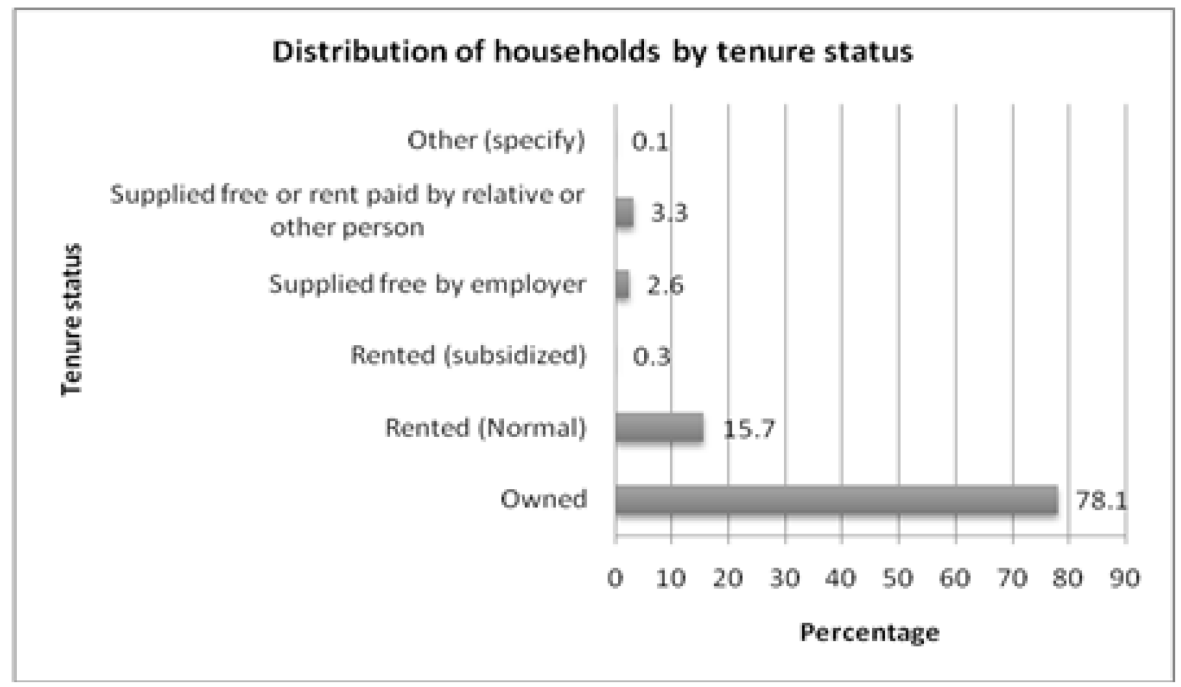

Findings in the UNHS IV in 2009/2010 indicate a small change of approximately 1 per cent in the status of households that owned their housing, from 77.11 per cent in 2005/2006 to 78.1 per cent of households, as shown in Figure 5.9 and Figure 5.10. However, this implies that the majority of housing in Uganda is owner-occupied. In terms of renting, there is a small change of approximately 1 per cent in the status of rent, which stands at 15.7 per cent in 2009/2010 compared to 15.6 per cent in $2005 / 2006$. Housing that is either supplied free or with rent paid by relatives other persons declined to 6.3 per cent in 2009/2010 from 7.23 per cent in 2005/2006. From the survey data, it is not possible to deduce why this drop happened.

\section{d) Remittances and Tenure:}

Housing tenure is investigated using three attributes in this analysis; ownership, tenure and supplied free. In addition to cross tabulations determining the existence of relationships between the variables, I apply the Pearson's Chi-square test to ascertain whether an observed frequency distribution differs from a theoretical distribution, testing the independence of two variables, namely renting and owning housing. In this data, renting connotes all non-owner-occupied property rented from private owners or developers, local authorities and housing agents. While ownership refers to owner-occupied including housing owned outright or bought with a mortgage, and supplied free by an employer or relation includes property occupied rent-free by someone other than the owner. The correlation between remittance and housing tenure was determined through cross-tabulation with the 
housing tenure sub variables of rent, ownership and freely supplied housing captured in the UNHS III and UNHS IV.

In graph 5.11 and table 5.12, it is observed for the period 2005/2006 that a greater number of households $(3,220)$ do not receive remittances yet own their houses, compared to 2,945 households receiving remittances. Amongst the households that rent housing, a greater number 775 do not receive remittances, compared to 417 receiving remittances. However, there are more households living in houses supplied free among those who received remittances, as opposed to those who did not receive remittances. The p-value (0.000) from the Pearson's chi square test of significance implies a significant influence of remittances on the housing tenure for all the three options of rent, ownership and freely supplied amongst households.

Figure 5.11: Remittances and status of housing tenure in 2005/2006

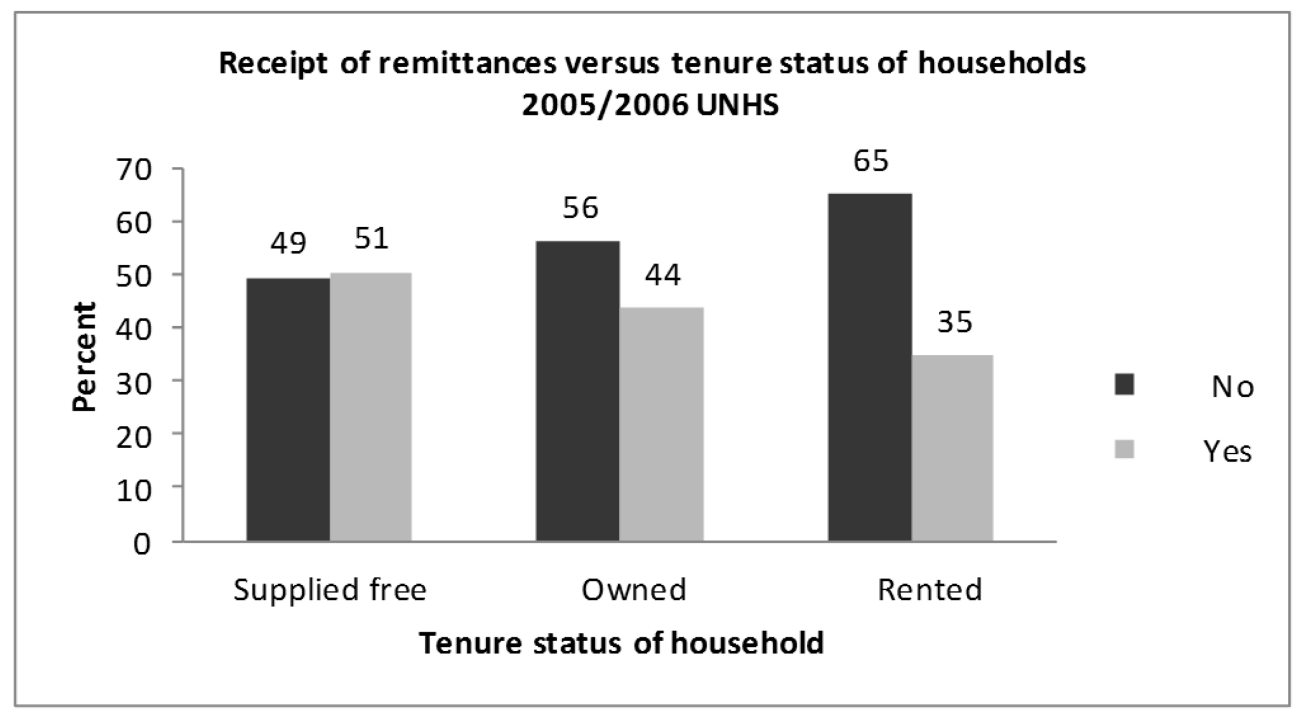


Table 5.12: Remittances and status of Housing Tenure in 2005/2006

\begin{tabular}{lcccr}
\hline & \multicolumn{3}{c}{ Tenure Status } & Total \\
\cline { 2 - 4 } Remittances & Supplied Free & Owned & Rented & 4,241 \\
No & 246 & 3,220 & 775 & 3,163 \\
Yes & 251 & 2,495 & 417 & $\mathbf{7 , 4 0 4}$ \\
Total & $\mathbf{4 9 7}$ & $\mathbf{5 , 7 1 5}$ & $\mathbf{1 , 1 9 2}$ & \\
\hline \multicolumn{4}{c}{} \\
\hline
\end{tabular}

In graph 5.13 and table 5.14, its observed for the period 2009/2010 that a greater number of households $(3,074)$ do not receive remittances yet own their houses, compared to 2,215 households receiving remittances. Amongst households that rent housing, a greater number (723) do not receive remittances, compared to 356 that received remittances. However, there are more households living in houses supplied free among those who received remittances, as opposed to those who did not receive remittances. The p-value $(0.000)$ from the chi square test of significance implies a significant influence of the receipt of remittances on the tenure status of households for all the three options of rent, ownership and freely supplied amongst households. From the tables and graphs for both 2005/2006 and 2009/2010, it is evident that a large number of households owned their dwellings regardless of whether they received remittances. The p-value of $(0.000)$ from the Pearson's chi square test of significance for both periods confirms a significant relationship between remittances and the tenure status of households for all the three options of rent, ownership and freely supplied amongst households.

Figure 5.13: Remittances and status of housing tenure in 2009/2010

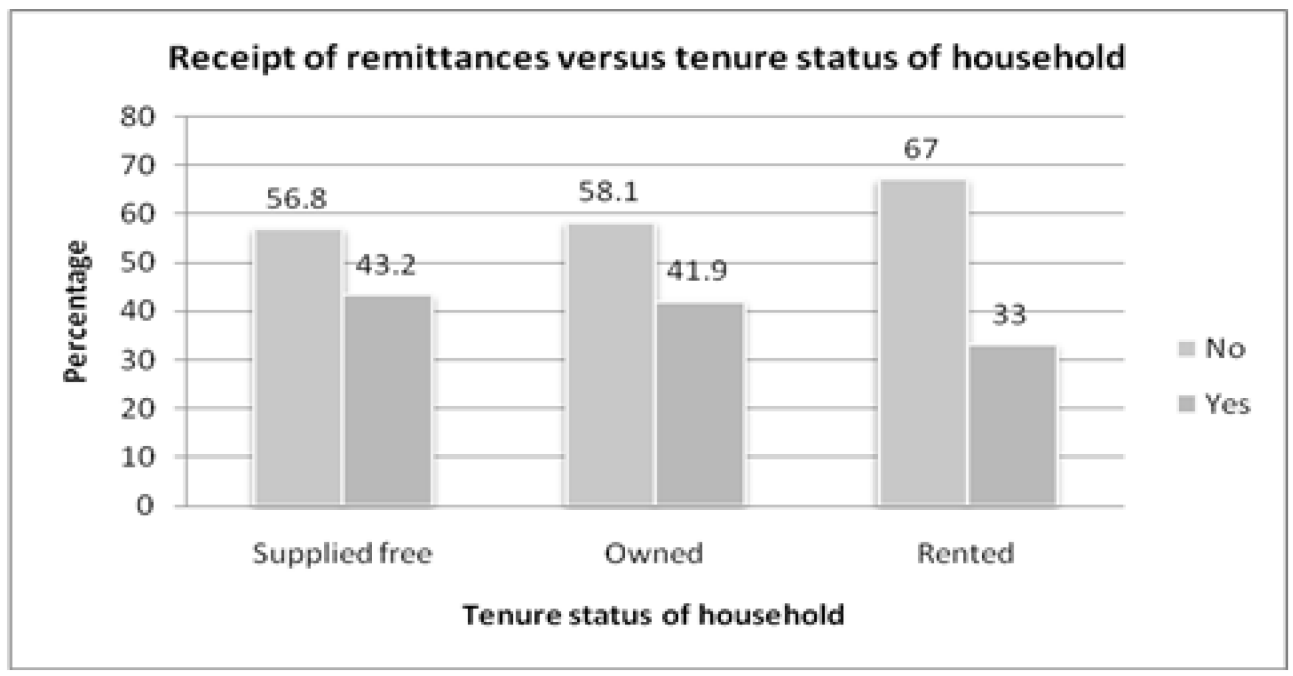




\begin{tabular}{lrrrr}
\hline \multicolumn{4}{l}{ Table 5.14: Remittances } & \multicolumn{3}{c}{ and status of Housing Tenure in $\mathbf{2 0 0 9 / 2 0 1 0}$} \\
\cline { 2 - 4 } Remittances & \multicolumn{3}{c}{ Tenure status } & Total \\
\hline No & Supplied free & Owned & Rented & 4026 \\
Yes & 229 & 3,074 & 723 & 2745 \\
Total & 174 & 2,215 & 356 & $\mathbf{6 7 7 1}$ \\
\hline \multicolumn{4}{c}{} \\
\hline
\end{tabular}

In table 5.15, the Spearman's Correlation Matrix shows that neither of the variables household rent status or ownership status was highly correlated with receipt of remittances for the period 2005/2006. The highest correlation was found between household rent status and ownership status at 80.6 per cent in the opposite direction, implying that the chances of someone renting a house whilst owning one are very low.

Table 5.15: Correlation matrix for receipt of remittances and status of housing tenure

\begin{tabular}{lccc|cccc}
\hline 2005/2006 & recvrem & hhrent & hhown & $\mathbf{2 0 0 9 / 2 0 1 0}$ & recvrem & hhrent & hhown \\
\hline recorem & 1.000 & -0.069 & 0.035 & recvrem & 1.000 & -0.067 & 0.052 \\
hhrent & -0.069 & 1.000 & -0.806 & hhrent & -0.067 & 1.000 & -0.823 \\
hhown & 0.035 & -0.806 & 1.000 & hhown & 0.052 & -0.823 & 1.000 \\
\hline
\end{tabular}

A similar observation is evident in the 2009/10 data, where neither the variables household rent status nor ownership status are highly correlated with the receipt of remittances. The highest correlation was found between household rent status and ownership status at 82.3 per cent in the opposite direction, which is sensible given that the chances of someone renting a house whilst owing one are very low.

\subsection{Logistic Regressions for Hypothesis Testing}

In this analysis, having established the relationship between remittances and housing tenure through the cross tabulation and the correlation tests of the Pearson Chi Square and Spearman's matrix as positive and significant, I now proceed to hypothesis testing to confirm the structure of the relationship. Results from the regression show that when a household receives remittances, its odds for owning housing improve compared to those not receiving remittances. Housing ownership is likely to be higher for households receiving remittances compared to those that do not receive remittance. Indeed, the odds due to remittances are 1.184 times higher, and this difference was statistically significant at a level of 5 per cent with a p-value of 0.003 in 2005/2006. Furthermore, the odds of housing ownership increase to 1.294 
in 2009/2010, at a level of 5 per cent and with a p-value of 0.000 for households receiving remittances than those that do not receive remittances. The results of this hypothesis testing are presented in tables 5.16 and 5.17 below:

\begin{tabular}{lccc}
\hline \multicolumn{4}{l}{ Table 5.16: Regression of Remittances with Housing Tenure in 2005/2006 } \\
\hline Response variable & Odds ratio & [95\% Confidence Interval] & P-value \\
\cline { 2 - 4 } Rent status & 0.679 & $0.597-0.773$ & 0.000 \\
Household ownership & 1.184 & $1.060-1.323$ & 0.003 \\
\hline
\end{tabular}

Table 5.17: Regression of Remittances with Housing Tenure in 2009/2010

\begin{tabular}{lccc} 
Response variable - & Odds ratio & [95\% Confidence Interval] & P-value \\
\cline { 2 - 4 } Rent status & 0.681 & $0.593-0.781$ & 0.000 \\
Household ownership & 1.294 & $1.149-1.458$ & 0.000 \\
\hline
\end{tabular}

Additionally, the receipt of remittances also improves the odds of a household renting housing, albeit at a consistent level in both time periods under analysis. The odds of for households receiving remittances are 0.679 times higher in 2005/2006 at a level of 5 per cent and with a p-value of 0.000 and 0.681 times higher in 2009/2010 at a level of 5 per cent and with a p-value of 0.000. 0.679

\begin{tabular}{lcccc}
\hline Table 5.18: Overall & Influence of Remittances on Housing Tenure & \\
\hline Housing Tenure & Relationship & Significant & Odds in & Odds in \\
& & & $2005 / 2006$ & $2009 / 2010$ \\
\cline { 2 - 5 } Ownership & Positive & Yes & 1.184 & 1.294 \\
Renting & Positive & Yes & 0.679 & 0.679 \\
Freely Supplied & Positive & Yes & - & - \\
\hline
\end{tabular}

In summary, as shown by table 5.18, logistic regressions prove that the receipt of remittances by a migrant household improves its odds of owning housing in both periods of analysis by at least 1.2, with a positive relationship between the ownership of housing and remittances. Similarly, a positive relationship exists between remittances and the rental status of migrant household by at least 0.6 in both time periods under analysis.

\subsection{Summary of Findings}

This analysis aimed at obtaining simple correlations and patterns of relationships to show either positive or negative relations, or higher or lower values. Besides the descriptive analysis, three additional levels of analysis were applied. First, crosstabulation was used to determine whether remittances, as a share of household income, influence ownership and rental status of housing for migrant and nonmigrant households. Second, the Pearson's Chi- Square tests and the Spearman's 
correlation matrices were applied to determine the independence of variables, confirming remittances as an explanatory variable. Third, logistic regressions tested hypothesis and determined the odds (chances) in a normal data distribution (for categorical variables) determine the structure of relations between remittances and housing tenure.

Uganda is a country with a fast growing population, estimated at 30.7 million in 2010 by the UNHS IV, while the average household size was estimated at 5.2, varying slightly from 5.6 in the East Africa/North Africa regions to 4.8 in Latin America (Bongaarts, 2001). The majority of households have 4 to 6 members, with sizes larger in rural than urban areas. The spatial location of a household either in rural or urban areas does not affect its receipt of remittances, and consequently the distinction of this effect on housing tenure or quality in rural or urban areas could not be determined through this analysis. In 2005, 42.69 per cent of the households in the UNHS III reported the receipt of remittances, either international or locally, compared to 40.6 per cent of households during the UNHS IV survey in 2010. Moreover, the most common form of remittances was cash in both time periods, with the majority of cash remittances of the value of 500,000 Uganda Shillings in both 2005/2006 (US\$ 294.12) and 2009/2010 (US\$ 247.89). It is noted that remittances in the bracket of less than or equal to 500,000 Uganda shillings declined by 4 per cent in 2010 compared to 2005, corresponding with the decline of markets, depression and unemployment in Europe, Australia and USA, which, according to Endo et al (2010) host the majority of international migrants from Uganda who remit back home regularly.

Overall, 55.1 per cent and 16.2 per cent of households resided in independent housing or tenements (mostly in urban areas), respectively, in 2009/2010, compared with 59.16 per cent and 15.31 per cent in 2005/2006. Furthermore, 26.6 per cent of households used huts as their dwelling units (mostly in rural areas) in 2009/2010, compared to 22.68 per cent of households in 2005/2006. A small change of approximately 1 per cent is observed in 2009/2010, with 78.1 per cent of households owning their housing, compared to 77.11 per cent in 2005/2006. In terms of renting, a similar change of approximately 1 per cent is noted between the two time periods. This increase can be attributed to a natural increase in households, given that the number of new households (household formation) is higher in 2009/2010 (33\%) than $2005 / 2009$ (25\%). This interpretation is supported by the fact that a greater number of households do not receive remittances yet own their houses, compared to households receiving remittances in both periods. Therefore, apart from remittances, the rate of formation of new households could reflect an influencing factor on housing tenure. 
However, the results of the Pearson's chi-square test confirm the independence of variables, implying a significant relationship between both owning or renting housing and a household's receipt of remittances, thus confirming that remittances are an explanatory variable for housing tenure. In this case, I was able to determine that the categorical outcome variable $(Y=$ housing tenure $)$ is related or associated with the categorical predictor variable ( $\mathrm{X}=$ household's receipt of remittances). Given that the Pearson's chi-square does not show the strength of the relationship, I subsequently applied the Spearman's correlation matrix to measure the strength of relatedness of two variables (housing tenure and remittance).

Accordingly, the result of this measure shows that the receipt of remittance was not highly co-related, therefore remittances are independent and an explanatory variable for changes in both rental and ownership status of housing. Therefore, the conclusion is that whether a household receives remittances does not affect their choice of either owning or renting, because the backward transition from ownership to rental is very limited, whereas the forward transition from rental to ownership is common. It is only logical that if a household owns its housing, it cannot opt for rental, regardless of whether it receives remittances, therefore housing rental and housing ownership are related variables.

Logistic regression results determined the structure of relationship between remittance and housing tenure, and the odds of a household advancing its ownership or rental of housing upon receipt of remittances. The findings show a positive relationship between receiving remittances and the opportunity for ownership in both periods under analysis, to the extent of 1.184 in 2005/2006, increasing to 1.294 in 2009/2010. This implies that a household that has remittance as a second line of income has a better chance of advancing its ownership of housing than one that does not receive remittances. Similarly, a household receiving remittance has higher odds of meeting its rental obligations of at least 1.2, rather than one that does not receive remittances. In both instances, the structure of the relationship is positive and significant a level of 5 per cent with the p-values of 0.000 and 0.003 in 2009/2010 and 2005/2006, respectively.

\subsection{Discussion and Conclusions}

In the introductory chapter of this thesis, remittances are stressed as a significant source of financing at the household level and in the economies of countries in subSaharan Africa. The findings of this analysis do not necessarily dispute this fact, but rather advance the viewpoint that remittance flows to Uganda's housing sector are still very low in volumes and limited in value, to have a significant influence on a household probability to own or rent housing. However, there is a possibility that remittances will gain significant influence on housing, if the majority of the 
households receiving remittance, were to receive a cash value of more than the current threshold of 500,000 Uganda Shillings (US\$ 247.89 in 2010) per year. The current values received are too low to support outright purchase of houses or to support continuous rental of either tenements or independent houses, which are the most common forms of housing structures in Uganda. This is not to set aside the fact that remittance flows to Uganda and indeed the whole of sub-Sahara have continued to steadily grow in the last decade. What seems to be missing is a facilitated channelling of these resources to housing acquisition or construction through deliberate policy incentives that encourage, migrants sending funds and the recipients at home to prioritize or earmark such resources for ownership or purchase of housing.

In the meantime, remittances are private funds. In order for remittance to focus on housing, migrant households and their remitters would have to be supported by networks which avail information. The housing market in Uganda needs to make a deliberate move, to organise itself to respond to the "diaspora market", by availing housing options that meet their expectations and progressive financing arrangements that fit the volume and value of remittance received by migrant households. The specific actions required on part of policy could primarily include: (a) designated contact offices or department in the government of Uganda for diaspora housing transactions; (b) schemes specifically designed to enhance diaspora ownership of housing, potentially run by the National Housing Corporation, Housing Finance Company and Development Finance Cooperation of Uganda. The role of these housing companies in the provision of housing in Uganda is detailed in chapter 3 of this thesis. From literature, efforts of this nature have been limited and policy details associated with such innovations are still elusive, however pilots based on small networks of migrant households could provide opportunity for experimenting with such proposals, so that the unknowns can be answered for both rural and urban locations in Uganda.

It is my anticipation, that remittances will become a source of financing for housing in Uganda, given their exponential growth, even though the analysis of UNHS III and UNHS IV in this thesis shows a number of households own housing even without receiving remittances. In such situations, it plausible to conjecture remittances as additional income within the household, that allows the household latitude to diversify or bridge the financing of other household needs. It has to be recognised that housing is a basic need, which carries with other utilities in the social and cultural life of the migrant sending the remittances and the household receiving remittances. At the very minimum, this analysis raises the issues that need to be considered by policy makers, and verifies the key relations that need to be addressed in policy formulation. 
Even with the possibility that the analysis may have failed to adequately control for endogeneity, it is still plausible to conclude on the nature of relationships obtaining between housing tenure and remittances. For instance, the analysis demonstrates that the receipt of remittances by a household significantly progresses its chances of owning housing and meeting rental obligations by at least 0.6 chances. At the moment, remittances cannot be placed beyond their current role, but with a potential to increase, a prudent policy maker in the housing sector should begin to take first steps in understanding how remittances aid households to improve their housing tenure. Consequently, thinking creatively on how to encourage their flow into housing, while removing offsetting other limitations for example costs of transfers, to levels that are encouraging is a necessity that cannot be understated and will be supported by further research on how this can be carried forward.

Lastly, given the correlation between remittances and housing, and the fact that value and volume of remittances is still low, it is conceivable that remittances could be a gradual enabler, offering little in the immediate and short run for a household to secure housing tenure, but serving an aiding role in the longer term, to the extent of incremental building of sections or parts of housing and other shelter. This is because of the consistency or regularity of flow of remittances, which allows a household to plan and strategize on how to improve housing tenure or ownership. In this way remittances can support a household to incrementally move closer to the kind of housing they desire and thus draw utility from placing their remittances in housing. In any case remittances contribute to the welfare of a household and housing is one of the indicators of decent welfare. 


\section{Chapter 6: \\ Remittance and Housing Quality in Uganda}

\subsection{Introduction}

In this chapter, I determine whether households that receive remittances have a better prospect of improved physical conditions and access to welfare amenities than those that do not. I used a comparative approach and considered differentials in housing quality for migrant and non-migrant households using selected attributes of the physical condition of housing and access to welfare amenities to confirm such differences. My assumption is that households that receive remittances have a second line of income that enables them to make improvements in their housing situation. By aggregating the various attributes of housing quality into a compound measure, I construct a housing quality index to compare the status of housing quality at two different points in time (2005/2006 and 2009/2010), for households receiving remittances and those not receiving.

Several studies have justified the usefulness of a housing quality index as a basis for comparing progress in housing of specific groups over time. Empirically, I use a housing quality index to prove that households receiving remittances have a better status of housing quality, both in terms of access to amenities and the physical condition of housing. Beginning with a general description of trends to map changes in the sub-variables over a 5 year period between 2005 and 2010, the analysis subsequently moves to determining co-relations between the variable attributes and the receipt of remittances by constructing cross-tabulations, Pearson Chi square test and Spearman correlation matrices.

Finally, the hypotheses constructed are tested for each variable attribute and aggregated into a conclusion. I draw conclusions to affirm or dispute the applicability of findings in the context of Uganda and what is posited by theory. Furthermore, I argue that the receipt of remittances influences improvement in housing condition, and thus serves more than simply bridging differentials between locations, as articulated by the neo-classical economists, but rather reflects a source of additional household income that can aid migrant households in improving the quality of their dwelling units, as advanced by the transnational theorists. 


\subsection{Theory and Evidence from other Studies}

Faidzo (2004) acknowledges that despite a history of economists' attempts to measure housing quality, disagreements still exist regarding housing quality measures. Buckenberger (2010) emphasizes that the notion of housing quality has received modest attention in the housing literature, despite several researchers having attempted to conceptualize housing quality in different contexts. However, Lawrence (1995) admits that housing quality "is a complex concept that is neither absolute nor static" while Goodman (1977) contends that measuring housing quality is complex, given that it is an unobservable variable. Indeed, he asserts that it is far easier to enumerate dwelling units than evaluate them and their suitability for occupants based on quality.

Magbogunje et al (1978) contend that housing quality is a highly controversial concept that transcends the boundary of economic and technological empowerment yet extends to the entails cultural and racial differences. More often, geographical and ethnographic peculiarities define the type of quality and standard that prevail within a particular socio-cultural setting (Rapoport 2002). It is also apparent that previous attempts to determine notions of housing quality are predominantly of a quantitative nature, aimed at compiling housing quality indices (Meng \& Hall, 2006; Daniere, 1994).

It has been widely acknowledged within housing literature that homes and dwellings represent more qualities than the physical structure (Lutz-Strulik \& Vale 2002; Sommerville and Chan 2001; King 1996). Accordingly, housing quality has three components, namely neighbourhood, location and structural quality. Neighbourhood quality refers to the quality conferred on a residence by virtue of the surrounding environment in which it is located, reflecting extrinsic values of the neighbourhood (Rapoport, 2002). Furthermore, locational quality refers to the spatial positioning of a dwelling relative to the Central Business District or the centrality of location, which reflects the positional attributes (Adebayo, 2010), while structural quality refers to the attributes of houses in external and internal designs, which reflect the intrinsic values of housing (Cirman, 2006).

Goodman (1977) perceives housing quality (or its inverse, namely housing deprivation) as an abstract theoretical entity with no straightforward operational definition. Fiadzo (2004) suggests a focus on a building elements approach, with materials and amenities constructed into an index (wall material, floor material, roof material, and availability of electricity, type of sewerage and water facilities), arguing that these items recommended by the United Nations; "tend to be present in most housing censuses; tend to be highly related to each other; and tend to have a similar valuation, thus making them excellent measures of housing quality". 
Moreover, as a concept, housing quality also varies between countries, between specific groups of people in each country at one point in time, as well as over long time periods.

Goodman (1997) succeeded in classifying housing quality according to housing types in the UK, which subsequently led to a categorization of quality criteria that distinguishes between the house as a system and as a home. He builds on Lynch's (1971) and Rapoport's (1977) classifications of housing quality in a broader sense, relating to access, control, space and time, along with meaning and communication. Lin, Mai and Wang (2004) establish an endogenous growth model in which housing quality is measured using housing capital regarded as an intermediate input to enhance household production and quality-augmented leisure time.

Buckenberger (2010) argues that international housing literature has predominantly framed the concept of housing quality around the provision and availability of housing. Here, the dwelling represents a physical entity only constituted through building codes, regulations and standards. According to King (1996), in this context housing is seen as an object and commodity by key housing players, such as architects, developers and policy makers. However, this view offers limited value as to how housing quality can be determined. Buckenberger (2010) shows that housing quality extends beyond the physical structure of buildings, and that perceived qualities for particular age groups can become meaningful, as it is implicit that physical housing qualities seem to be central for families.

Besides contradictions in definition and measures, there are infinite ways of combining any selected set of components into a summary measure of housing quality (Goodman, 1977). The various measures carrying its meaning have been relatively agreed upon as including the subjective judgment of structure defects (Morris et al, 1972), market value, which is community and neighbourhood specific (Morris and Winter, 1997), and a focus on service amenities (Harris, 1976) and housing materials (Morris et al 1994). Haines (2010) measures housing quality by making a distinction between, among others, property qualities, on the one hand based on the recognition by Porell (1985), and identifying property characteristics based on recognition by Sternlieb (1966), on the other. However, researchers (Fiadzo 2004; Goodman 1977; Lawrence 1995) agree that whatever is chosen to constitute the housing quality index, it should reflect the quality of the dwelling unit alone and not the characteristics of the residents or dwellers, given that the dwelling exists irrespective of occupiers. 


\subsection{Status of Housing Quality}

Housing quality is measured in this thesis through an aggregate of seven variable attributes concerning the access to welfare amenities and physical condition of housing, defined at the start of each sub-section.

\subsubsection{Access to Welfare Amenities by Households}

Four sub-variables of welfare amenities of housing are considered in this analysis, in relation to the remittances amongst the 7,425 households covered by the 2005/2006 UNHS III survey and 6,775 households covered by the 2009/2010 UNHS IV survey. These include the household's access to drinking water, the type of toilet facility used by household, the household's source of lighting, and the type of cooking fuel used by a household.

\section{a) Source of Drinking Water}

In 2005/2006, 30.36 per cent of households $(2,254)$ in the survey accessed drinking water from boreholes, 20.6 per cent $(1,528)$ accessed protected wells /springs as their main source of drinking water, while 18.7 per cent $(1,387)$ accessed unprotected wells as their main source. Moreover, only 4 per cent of households had a private connection to piped water in 2005/2006, as shown in figures 6.1 and 6.2 below. Private connections to piped water represent an advanced form of access to drinking water. Households' housing advances to this form of access as incomes increase, whilst the opposite is also true.

Figure 6.1: Status of access to drinking Water in 2005/2006

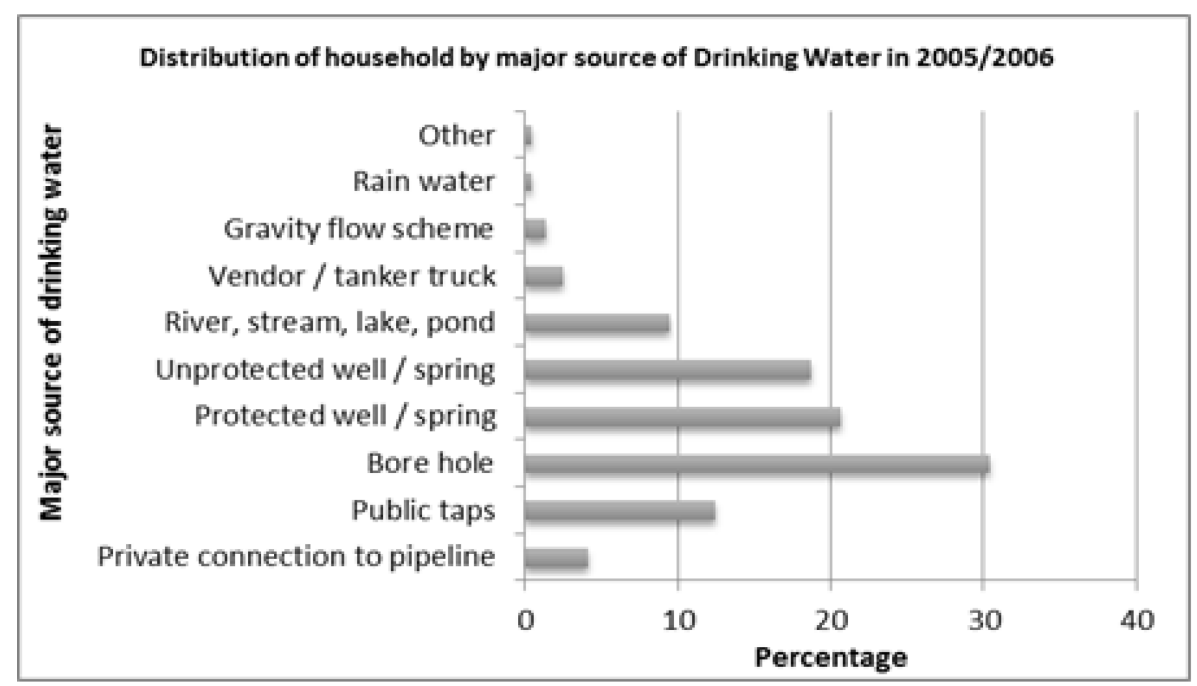


Figure 6.2: Status of access to drinking water in 2009/2010

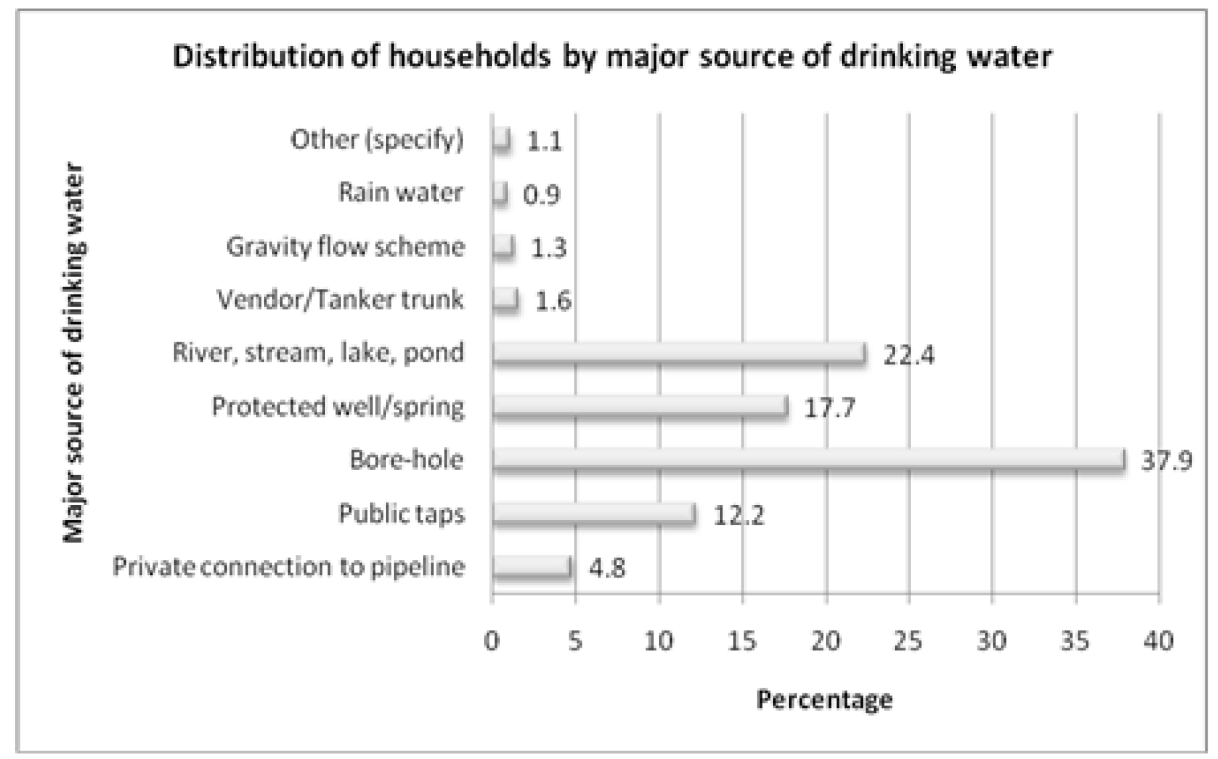

Figure 6.2 shows a higher percentage of the households using boreholes to access drinking water in 2009/2010 (37.9\%), which is approximately 10 per cent higher than in 2005/2006. Similarly, the number of households accessing drinking water from rivers, streams, lakes or ponds almost doubled to 22.4 per cent in 2009/2010. While the changes in these two sub-variables indicate an overall improvement in households' access to drinking water sources, there is a 2 per cent decline in the number of households accessing drinking water from protected well-springs, with 17.7 per cent of households using this source. Households that access water from public taps remain nearly constant in 2009/2010 when compared with 2005/2006, at 12.2 per cent, while only 4.8 per cent of the households had private connections to pipelines in 2009/2010, reflecting a small increment of 0.8 per cent. All increments in access to water sources are an indication in improvement of welfare of households in both periods of the surveys.

\section{b) Type of Toilet Used}

Considering the type of toilet used by households, the findings indicate that the top three ranks are taken by rudimentary forms of toilets, namely covered pit latrines, uncovered pit latrines, and the bush. The majority of the households (39.16 per cent in 2005/2006 and 35.2 per cent in 2009/2010) use private covered pit latrines, with a reduction of 3.96 per cent in the number of households using this type of toilet facility across the two periods compared as shown in table 6.3. Furthermore, 33.28 per cent of the households used shared covered pit latrines in 2005/2006, which fell 
to 31.5 per cent in 2009/2010, marking a decline of 1.78 per cent as shown in table 6.3. Uncovered pit latrines were used by 12.32 per cent of households in 2005/2006, rising by 2.78 per cent to 15 per cent in 2009/2009. The use of bush as a toilet type implies that a household has no access to any form of constructed toilet facilities, and in 2005/2006, 10.44 per cent of households had no such access to toilets, which increased to 12.5 per cent in 2009/2010. This increment is an indicator in decline of welfare of households.

\begin{tabular}{lrrrr}
\hline \multicolumn{2}{c}{ Table 6.3: Type of Toilet used by Households } \\
\multicolumn{1}{c}{ Variable Attributes } & $\mathbf{2 0 0 5 / 2 0 0 6}$ & \multicolumn{2}{c}{$\mathbf{2 0 0 9 / 2 0 1 0}$} \\
& Frequency & Per cent & Frequency & Per cent \\
\hline Covered pit latrine private & 2,906 & 39.16 & 2387 & 35.2 \\
Covered pit latrine shared & 2,470 & 33.28 & 2135 & 31.5 \\
VIP latrine private & 70 & 0.94 & 74 & 1.1 \\
VIP latrine shared & 118 & 1.59 & 146 & 2.2 \\
Uncovered pit latrine & 914 & 12.32 & 1018 & 15 \\
Flush toilet private & 61 & 0.82 & 116 & 1.7 \\
Flush toilet shared & 48 & 0.65 & 23 & 0.3 \\
Bush & 775 & 10.44 & 845 & 12.5 \\
Other (Specify) & 59 & 0.80 & 28 & 0.4 \\
\multicolumn{1}{c}{ Total } & $\mathbf{7 , 4 2 1}$ & $\mathbf{1 0 0 . 0 0}$ & $\mathbf{6 7 7 2}$ & $\mathbf{1 0 0}$ \\
\hline
\end{tabular}

All these findings indicate a general decline in the quality of toilets used by households, given that the most common forms are rudimentary. This is one of those findings that may point to other reasons for decline, which may include a general decline in standards of living, the formation of new households or a failure in data capture. According to our hypothesis however, we would expect that as remittances come in over the 5 year interval improvements in access to better toilets facilities and their quality would improve, rather than an overall decline, at least for those households receiving remittances.

\section{c) Source of Lighting}

The most commonly used source of lighting in both periods of comparison is a traditional lamp, locally known as tadooba, which is graded as the most primitive source of lighting. 70 per cent of households used this as their main source of lighting in 2006, which fell by $6.55 \%$ to 63.5 per cent in $2009 / 2010$. This is not a significant decline, which can be related to a change in household income, whereby households advance their lighting sources, but it could alternatively relate to the rate of new household formation. Similarly, there is a decline in the number of households using paraffin or kerosene and gas lanterns, from 14.96 per cent in 2005/2006 to 12.5 per cent in 2009/2010, as shown in table 6.4. 
Firewood is one of the most primitive forms of lightning and is mostly used in rural areas, in form of log fires for visibility and firewood for cooking energy. In 2005/2006, 2.87 per cent of households were using this form of energy for lighting, in 2009/2010, the number of households using this form of energy almost tripled to 8 per cent, which is a very significant increment. In view of receipt of remittances, this is one of the forms of energy whose use ought to be declining as household incomes improve their energy sources to more modern means with the inflow of remittances. A number of possible reasons could account for this increment, such as the increase in the cost of fuels such as paraffin and the rising costs of electricity country wide that have taken place over the five year period.

\section{Table 6.4: Status of Household's Access to Lighting Source}

\begin{tabular}{lrrrr}
\hline \multirow{2}{*}{ Variable Attributes } & \multicolumn{2}{c}{$\mathbf{2 0 0 5 / 2 0 0 6}$} & \multicolumn{2}{c}{$\mathbf{2 0 0 9 / 2 0 1 0}$} \\
\cline { 2 - 5 } & Frequency & Per cent & Frequency & Per cent \\
\hline Electricity - grid or generator & 753 & 10.14 & 724 & 10.7 \\
Paraffin kerosene or gas lantern & 1,111 & 14.96 & 845 & 12.5 \\
Tadooba- local lantern & 5,201 & 70.05 & 4,301 & 63.5 \\
Firewood & 213 & 2.87 & 543 & 8 \\
Solar & 15 & 0.20 & 41 & 0.6 \\
Other (Specify) & 132 & 1.77 & 314 & 4.6 \\
\multicolumn{1}{c}{$\quad$ Total } & $\mathbf{7 , 4 2 5}$ & $\mathbf{1 0 0 . 0 0}$ & $\mathbf{6 , 7 6 8}$ & $\mathbf{1 0 0 . 0 0}$ \\
\hline
\end{tabular}

However, it is surprising that there is almost no change in the number of households using electricity from the national grid or generators as their source of lighting over the 5 year period, which is considered a more advanced form of lighting; this could due to the rising costs of access and fuel associated with this form of energy. In 2005/2006, only 10.14 per cent of households' accessed electricity from the grid or generator, compared to 10.7 per cent of households in 2009/2010. If incomes of households increased due to changes in income or remittances, there would be an improvement in this indicator or variable, which is important to observe.

\section{d) Cooking Fuel}

The status of households' access to cooking fuel shows that a large percentage of the households used firewood in the traditional open fire cooking methods in both periods under comparison. Indeed, this is reported by 76.46 per cent of households in $2005 / 2006$, compared to 76 per cent in 2009/2010, similarly there is a small decline the number of households using charcoal from 19.78 per cent to 18.9 per cent. These declines are small and could be indicative of an indicative of an overall improvement in household income because firewood and charcoal are considered rudimentary. This change may be explained by more households moving to more 
advanced forms of cooking fuel. These include the electricity, gas and solar energy. Table 6.5 summarizes the status of access to cooking fuel.

\begin{tabular}{|c|c|c|c|c|}
\hline \multicolumn{5}{|c|}{ Table 6.5: Status of Households' access to Cooking Fuel } \\
\hline \multirow[t]{2}{*}{ Variable Attributes } & \multicolumn{2}{|c|}{$2005 / 2006$} & \multicolumn{2}{|c|}{$2009 / 2010$} \\
\hline & Frequency & Per cent & Frequency & Per cent \\
\hline Firewood & 5,647 & 76.46 & 5,133 & 76 \\
\hline Charcoal & 1,461 & 19.78 & 1,274 & 18.9 \\
\hline Paraffin / kerosene & 83 & 1.12 & 147 & 2.2 \\
\hline Electricity & 16 & 0.22 & 39 & 0.61 \\
\hline Gas & 11 & 0.15 & 36 & 0.5 \\
\hline Solar & 2 & 0.03 & 4 & 0.1 \\
\hline Others (Specify) & 166 & 2.25 & 123 & 1.81 \\
\hline Total & 7,386 & 100.00 & 6,757 & 100.00 \\
\hline
\end{tabular}

Charcoal is predominantly used in urban areas or middle-income households, often together with kerosene/paraffin as cooking fuel. The use of kerosene is almost consistent over the 5 year period, with a change of less than 1 per cent. Electricity and gas, considered the most advanced forms of cooking fuel, were used by less than one per cent of households in 2005/2006, increasing slightly over one per cent in 2009/2010. However, this change is small but still indicates an improvement in household incomes that allows households to advance to more modern forms of cooking energy.

\subsubsection{Physical Conditions of Housing}

Three variable attributes of physical condition of housing are considered in this analysis, within the 7,425 households covered by the 2005/2006 UNHS III survey and 6,775 households covered in the 2009/2010 UNHS IV survey, namely; the roofing, external wall and floor materials of houses.

\section{a) Roofing Material}

Iron sheets were the most used form of construction materials for roofing houses in both survey periods as shown in table 6.6. In 2005/2006, 59.8 per cent of households used iron sheet roofs compared to 56.4 per cent of households in 2009/10, representing a reduction of 3.4 per cent, which could imply an advancement of roofing materials by households. Indeed this is plausible because tiles, which are the next level of advancement, also show an increment of approximately 0.24 per cent, from 0.36 per cent in 2005/2006 compared to 0.6 per cent in 2009/2010. In both instances households are advancing the roofing materials of their housing, which is a positive move. 


\begin{tabular}{|c|c|c|c|c|c|}
\hline \multicolumn{6}{|c|}{ Table 6.6: Construction Materials of Roof of Houses } \\
\hline \multirow[b]{2}{*}{ Variable Attributes } & & \multicolumn{2}{|c|}{$2005 / 2006$} & \multicolumn{2}{|c|}{$2009 / 2010$} \\
\hline & & Frequency & Percent & Frequency & Percent \\
\hline Thatch, straw & & 2,874 & 38.71 & 2,849 & 42.1 \\
\hline Iron sheets & & 4,442 & 59.82 & 3,819 & 56.4 \\
\hline Tiles & & 27 & 0.36 & 39 & 0.6 \\
\hline Others (Specify) & & 82 & 1.1 & 59 & 0.9 \\
\hline & Total & 7,425 & 100.00 & 6,766 & 100 \\
\hline
\end{tabular}

In addition, there is an increase of 3.39 per cent in the number of households with straw or thatch, a lower grade of roofing materials, from 38.71 per cent in 2005/2006 to 42.1 per cent in 2009/2010. This is one of the most rudimentary forms of roofing materials that is most common in newly formed households. It is possible that such changes may be accounted for by the difference in rate of household formation between the two time periods, since according to the Uganda Bureau of Statistics, the total number of households in Uganda has increased from 5.2 million in 2005/06 to 6.2 million in 2009/10.

\section{b) Material of External Walls}

For both survey periods under comparison, mud and poles represent the most common material for the external walls of houses, as shown in table 6.7. In 2005/2006, 40.94 per cent of households in the survey reported using mud and pole, compared with 40.9 per cent in 2009/2010. Evidently, there is no change between the two time periods in terms of the percentage of households with this form of external wall materials. While mud and poles are the most rudimentary forms of external wall, it is also the most common among low-income households. Un-burnt bricks are the third most common form of external wall materials used by households, reported by 19.73 per cent of households in 2005/2006, and 18.7 per cent in 2009/2010, which represents a small reduction of approximately 1 per cent. Since unburnt bricks are second to mud and pole as rudimentary materials, it is possible that this reduction could be accounted for by an increase in household income, or the receipt of remittances. 


\begin{tabular}{|c|c|c|c|c|}
\hline \multirow[b]{2}{*}{ Variable Attributes } & \multicolumn{2}{|c|}{$2005 / 2006$} & \multicolumn{2}{|c|}{$2009 / 2010$} \\
\hline & Frequency & Per cent & Frequency & Per cent \\
\hline Mud and poles & 3,040 & 40.94 & 2,771 & 40.9 \\
\hline Burnt bricks with cement & 1,889 & 25.44 & 1,917 & 28.3 \\
\hline Un burnt bricks & 1,465 & 19.73 & 1,269 & 18.7 \\
\hline Burnt bricks with mud & 677 & 9.12 & 559 & 8.3 \\
\hline Cement blocks & 68 & 0.92 & 75 & 1.1 \\
\hline Thatch, straw & 79 & 1.06 & 51 & 0.8 \\
\hline Timber & 31 & 0.42 & 35 & 0.5 \\
\hline Stone & 2 & 0.03 & 7 & 0.1 \\
\hline Other (Specify) & 174 & 2.34 & 88 & 1.3 \\
\hline Total & 7,425 & 100.00 & 6,772 & 100 \\
\hline
\end{tabular}

Burnt bricks and cement represent the second most advanced and common form of external wall material used by households, with 25.44 per cent of households in 2005/2006 and 28.3 per cent of households in 2009/2010 using such forms, as shown in table 6.7. This reflects an increase of 2.86 per cent of households using this form of material for external walls, which can be related to changes in household income or remittances, given that it is considered an advanced form of wall material. Moreover, there is a reduction in the number of households whose external wall material of housing is burnt bricks with mud, with 9.12 per cent households in 2005/2006 compared to 8.3 per cent of households in 2009/2010. Burnt bricks with mud are also considered advanced materials of external wall, but are most common in rural areas.

\section{c) Floor Materials}

The two most common forms of floor materials for both periods of comparison are rudimentary i.e. earth, earth and cow dung. Earth, which reflects the most rudimentary of floor materials, is reported by 42.18 per cent of households in $2005 / 2006$, compared to 47 per cent or houses in 2009/2010, while earth and cow dung is reported by 30.53 per cent of households in 2005/2006 and 26.7 per cent of households in 2009/2010, as shown in table 6.8. The fact that two of the most rudimentary forms of floor materials are reported by 72.71 per cent of households in 2005/2006 and 73.7 per cent in 2009/2010 implies that very few households experienced positive changes or increase in household income, so as to undertake improvements of floor materials of housing. Furthermore, it may also point to the possibility of the cost of floor improvements being beyond the incomes of most households, even those with the receipt of remittances. Cement, which is an advanced form of floor material, is reported by 26.32 per cent of households in 2005/2006, compared to 24.9 per cent of households in 2009/2010. Moreover, mosaic 
or tiles, which are the most advanced of all forms of floor materials, were reported by less than one per cent of all households in both time periods under comparison in this analysis.

\begin{tabular}{|c|c|c|c|c|}
\hline \multirow[b]{2}{*}{ Variable Attributes } & \multicolumn{2}{|c|}{$2005 / 2006$} & \multicolumn{2}{|c|}{$2009 / 2010$} \\
\hline & Frequency & Percent & Frequency & Per cent \\
\hline Earth & 3,132 & 42.18 & 3,185 & 47 \\
\hline Earth and cow dung & 2,267 & 30.53 & 1,809 & 26.7 \\
\hline Cement & 1,954 & 26.32 & 1,683 & 24.9 \\
\hline Mosaic or tiles & 15 & 0.20 & 62 & 0.9 \\
\hline Others (Specify) & 57 & 0.77 & 33 & 0.5 \\
\hline Total & 7,425 & 100.00 & 6772 & 100 \\
\hline
\end{tabular}

\subsection{Relations: Remittances and Housing Quality}

In this section, I analyse the relationship between remittance and the four variable attributes of access to housing amenities; and the three variable attributes of the physical condition of housing using cross-tabulations, the Pearson's Chi square tests and Spearman's correlation matrices.

\subsubsection{Remittances and Household Welfare Amenities}

\section{a) Source of Lighting}

Households with sources of light such as paraffin lanterns, tadooba- locally made lantern, firewood and others were classified as primitive sources, while those with electricity and solar as the main sources of lighting were classified as having advanced sources. As shown in table 6.9, the majority of the households that received no remittances $(3,807)$ in the period 2005/2006 had primitive sources of lighting. A large number of the households that received remittances of cash value less than 500,000 shillings $(2,594)$ had primitive sources of lighting. As the cash value of remittances increased, there was a gradual increase in number of households with advanced sources of lighting. The p-value (0.001) from the chi square test implies a significant influence of the amount received in cash from remittances on the source of house lighting accessed by a household. 


\begin{tabular}{|c|c|c|c|c|}
\hline \multicolumn{5}{|c|}{ Table 6.9: Cash value of Remittances and source of Lighting in 2005/2006 } \\
\hline Lighting & & Primitive & Advanced & Total \\
\hline 0 & & 3,807 & 435 & 4,242 \\
\hline Equal to or Less than 500,000 & & 2,594 & 203 & 2,797 \\
\hline 500,000 to $1,000,000$ & & 146 & 39 & 185 \\
\hline $1,000,000$ to $5,000,000$ & & 86 & 72 & 158 \\
\hline $5,000,000$ to $10,000,000$ & & 3 & 12 & 15 \\
\hline Equal to or more than $10,000,000$ & & 2 & 6 & 8 \\
\hline & Total & 6,638 & 767 & 7,405 \\
\hline
\end{tabular}

\begin{tabular}{|c|c|c|c|c|}
\hline \multicolumn{5}{|c|}{ Table 6.10: Cash value of remittances and source of lighting in 2009/2010 } \\
\hline Lighting & & Primitive & Advanced & Total \\
\hline 0 & & 3531 & 494 & 4025 \\
\hline Equal to or less that 500,000 & & 2126 & 136 & 2262 \\
\hline 500,000 to $1,000,000$ & & 210 & 51 & 261 \\
\hline $1,000,000$ to $5,000,000$ & & 126 & 62 & 188 \\
\hline $5,000,000$ to $10,000,000$ & & 9 & 10 & 19 \\
\hline \multirow[t]{2}{*}{ Equal to or more than $10,000,000$} & & 1 & 12 & 13 \\
\hline & Total & 6003 & 765 & 6768 \\
\hline \multicolumn{5}{|c|}{ Pearson $\operatorname{chi}^{2}(5)=290.1570 \quad \operatorname{Pr}=0.000$} \\
\hline
\end{tabular}

From table 6.10, majority of the households that did not receive remittances $(3,531)$ during the period 2009/2010 had primitive sources of lighting. In addition, a large number of the households that received remittances of cash value less than 500,000 shillings $(2,126)$ had primitive sources of lighting. As the cash value of remittances increased, there was a slight increase in number of households with advanced sources of lighting. The p-value (0.000) from the chi square test of significance implies a significant influence of the cash value of remittances on the main source of house lighting.

Trends for both periods under comparison show four main observations. First, households that do not receive remittances have primitive sources of lighting. Second, households that receive remittances of a cash value that is less than Uganda Shillings 500,000 also have primitive sources of lighting. Third, advancement in the source of lighting from primitive to advanced lightning sources only became evident when the cash value of remittance increased to Uganda Shillings 500,000 and beyond; therefore, as the value of remittances increases the chances of a household advancing, its source of lighting also improves. Finally, given that the p-values from Pearson Chi Square test are very close to 0.000 for both periods, the significance of remittances as an explanatory variable for improvements in households' access to improved sources of lighting is confirmed. 


\section{b) Source of Cooking Fuel}

Households with types of cooking fuel such as firewood, charcoal, paraffin/kerosene and others were classified as primitive types, while those with electricity, gas and solar as the main types of cooking fuel were classified as having advanced types. In the 2005/2006 period shown in table 6.11, the majority of households that did not receive remittances $(4,197)$ had primitive sources of cooking fuel. It is evident that a large number of the households that received remittances of cash value of less than Uganda shillings 500,000 $(2,783)$ had primitive sources of lighting. Moreover, only 29 households used advanced sources of cooking fuel. The p-value (0.000) from the chi square test of significance implies a significant influence of receipt of remittances on the main type of fuel used for cooking.

\begin{tabular}{|c|c|c|c|}
\hline \multicolumn{4}{|c|}{ Table 6.11: Cash value of Remittances and cooking fuel in 2005/2006 } \\
\hline Cooking Fuel & Primitive & Advanced & Total \\
\hline 0 & 4,197 & 19 & 4,216 \\
\hline Equal to or Less than 500,000 & 2,783 & 6 & 2,789 \\
\hline 500,000 to $1,000,000$ & 180 & 1 & 181 \\
\hline $1,000,000$ to $5,000,000$ & 158 & 0 & 158 \\
\hline $5,000,000$ to $10,000,000$ & 12 & 3 & 15 \\
\hline Equal to or more than $10,000,000$ & 7 & 0 & 7 \\
\hline Total & 7,337 & 29 & 7,366 \\
\hline \multicolumn{4}{|c|}{ Pearson $\operatorname{chi}^{2}(5)=150.4232 \operatorname{Pr}=0.000$} \\
\hline
\end{tabular}

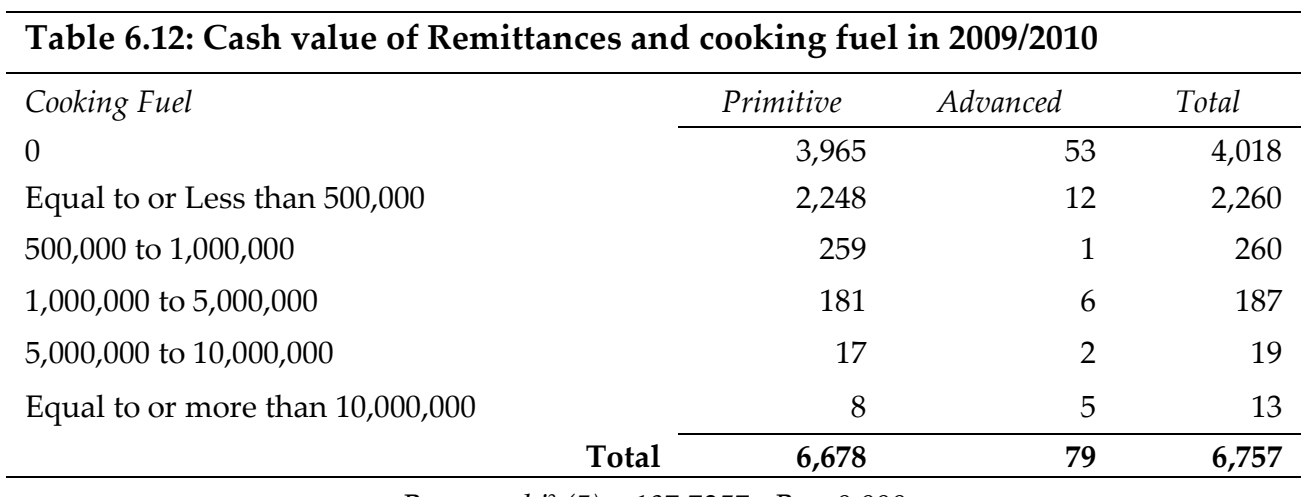

Pearson chi $^{2}(5)=187.7257 \quad \operatorname{Pr}=0.000$

From table 6.12, the majority of the households that did not receive remittances $(3,965)$ had primitive types of cooking fuel during the period 2009/10. In addition, a large number of the households that received remittances of a cash value less than Uganda shillings 500,000 $(2,248)$ had primitive types of cooking fuel. However, a 
large number of households still used primitive types of cooking fuel, regardless the cash value of remittances. Moreover, only 79 households used advanced sources of cooking fuel during this period. The p-value (0.000) from the chi square test of significance implies a significant influence of the cash value of remittances on the main type of fuel used for cooking.

The tendencies for both periods under comparison show four main observations. First, households that do not receive remittance overall have primitive sources of cooking fuel. Second, households that receive remittances of cash value less than Uganda Shillings 500,000 also have primitive sources of cooking fuel. Third, advancement in the cooking fuel from primitive to advanced sources only became evident when the cash value of remittances increased to Uganda Shillings 500,000 and beyond; therefore, as the cash value of remittances increases, the chances of a household advancing its source of cooking fuels also improves. Finally, given that the p-values from Pearson Chi Square test is 0.000 for both periods, implies that the significance of remittances as an explanatory variable for improvements in households' access to improved sources of cooking fuel is confirmed.

\section{c) Type of Toilet Used}

Households that used uncovered pit latrines, bushes and other facilities were classified as primitive facilities, while those with covered pit latrines, VIP latrines and flush toilets were classified as having advanced toilet facilities. As illustrated in table 6.13 and graph 6.13 , the majority of the households $(5,656)$ had advanced toilet facilities during the period 2005/2006. Similarly, the number of households with good toilet facilities increased as the cash value of remittances increased. The pvalue (0.000) from the chi square test of significance confirmed the significance of remittances as an explanatory variable for the type of toilet used by households.

\begin{tabular}{|c|c|c|c|c|}
\hline \multicolumn{5}{|c|}{ Table 6.13: Cash value of Remittances and type of toilet used in 2005/2006 } \\
\hline Type of Toilet Used & & Primitive & Advanced & Total \\
\hline 0 & & 1,009 & 3,231 & 4,240 \\
\hline Equal to or Less than 500,000 & & 699 & 2,097 & 2,796 \\
\hline 500,000 to $1,000,000$ & & 27 & 158 & 185 \\
\hline $1,000,000$ to $5,000,000$ & & 10 & 147 & 157 \\
\hline $5,000,000$ to $10,000,000$ & & 0 & 15 & 15 \\
\hline \multirow[t]{2}{*}{ Equal to or more than $10,000,000$} & & 0 & 8 & 8 \\
\hline & Total & 1,745 & 5,656 & 7,401 \\
\hline
\end{tabular}

Pearson $\operatorname{chi}^{2}(5)=44.4352 \quad P r=0.000$ 


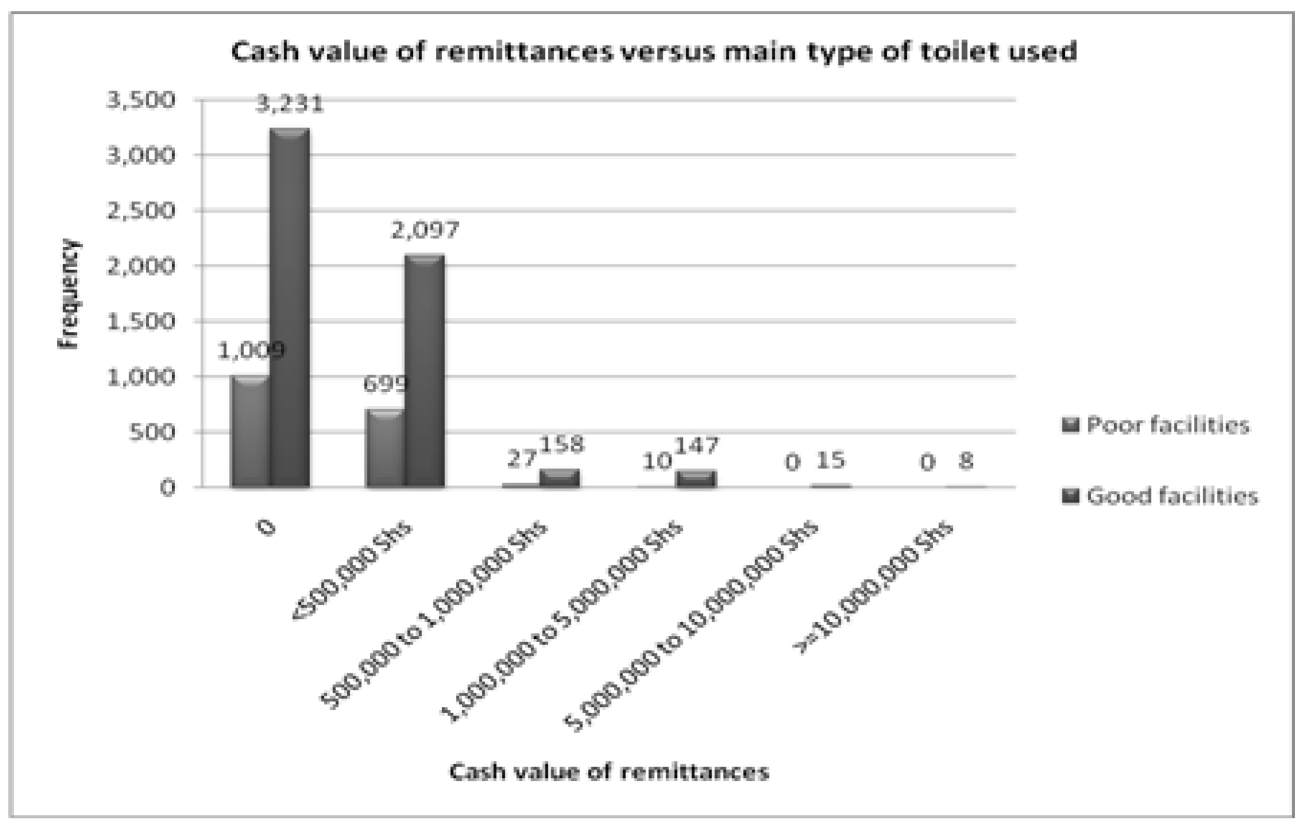

\section{Table 6.14: Cash value of Remittances and type of toilet used in 2009/2010}

Type of Toilet Used

0

Equal to or Less than 500,000

500,000 to $1,000,000$

$1,000,000$ to $5,000,000$

$5,000,000$ to $10,000,000$

Equal to or more than $10,000,000$

\begin{tabular}{rrr} 
Primitive & Advanced & Total \\
\hline 1,033 & 2,994 & 4,027 \\
793 & 1,471 & 2,264 \\
42 & 219 & 261 \\
22 & 166 & 188 \\
0 & 19 & 19 \\
1 & 12 & 13 \\
\hline $\mathbf{1 8 9 1}$ & $\mathbf{4 8 8 1}$ & $\mathbf{6 7 7 2}$ \\
\hline
\end{tabular}

Pearson chi $^{2}(5)=119.8159 \quad \operatorname{Pr}=0.000$ 


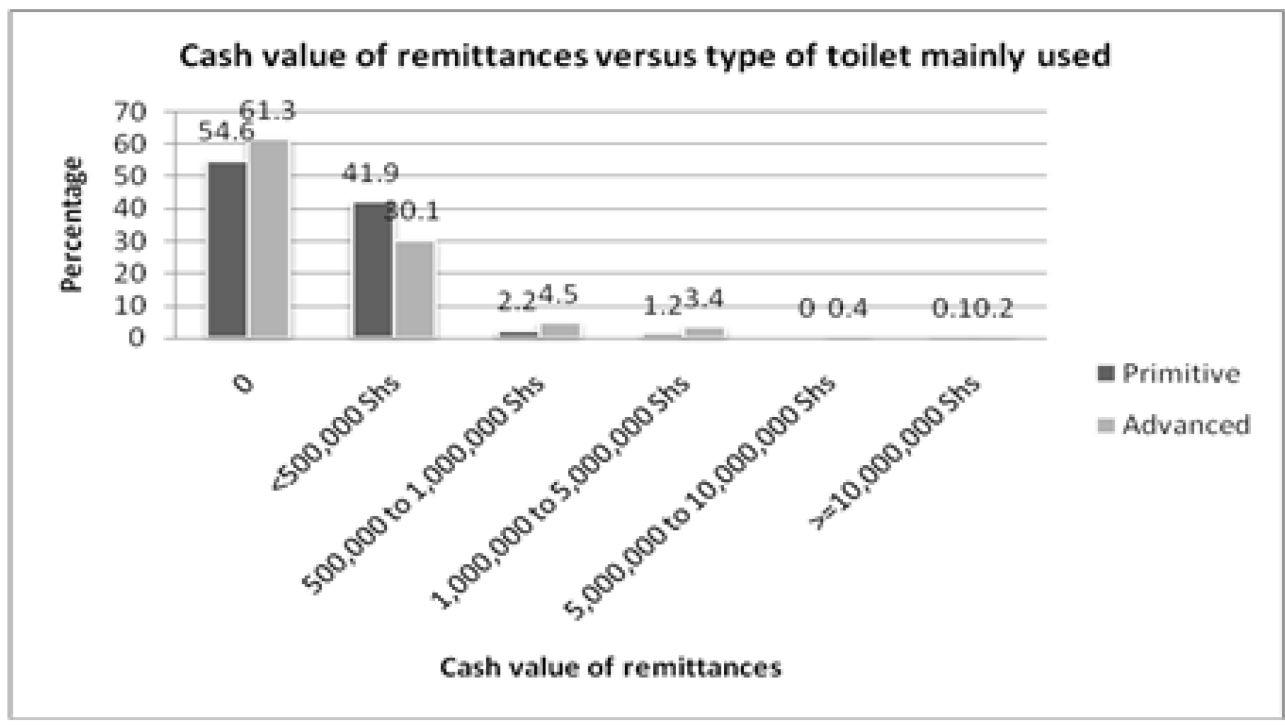

From table 6.14 and graph 6.14 , the majority of the households $(4,881)$ had advanced toilet facilities during the period 2009/10. Furthermore, it is evident that the number of households with good toilet facilities increased in accordance with the cash value of remittances. The p-value (0.000) from the chi square test of significance implies a significant influence of the cash value of remittances on the type of toilet mainly used.

Trends for both periods confirm four main observations. First, households that receive remittance have use advanced types of toilets. Second, households that receive remittances of cash value higher than Uganda Shillings 500,000 use advanced types of toilets. Third, as the cash value of remittances increases, households are able to advance their types of toilets used. Finally, the p-values from Pearson Chi Square test is 0.000 for both periods, implying the significance of remittances as an explanatory variable for improvements in households' use of advanced types of toilet facilities.

\section{d) Source of Drinking Water}

Households that used rivers, streams, lakes, ponds, rain water and other sources were classified as having unprotected sources of drinking water, while those with pipelines, public taps, boreholes, protected wells/springs, vendor/tanker trucks and gravity flow schemes were classified as having protected sources. 


\begin{tabular}{|c|c|c|c|}
\hline \multicolumn{4}{|c|}{ Table 6.15: Remittances and Source of drinking water in 2005/2006 } \\
\hline Source of Drinking Water & Unprotected & Protected & Total \\
\hline 0 & 1,328 & 2,913 & 4,241 \\
\hline Equal to or Less than 500,000 & 762 & 2,035 & 2,797 \\
\hline 500,000 to $1,000,000$ & 33 & 152 & 185 \\
\hline $1,000,000$ to $5,000,000$ & 13 & 145 & 158 \\
\hline $5,000,000$ to $10,000,000$ & 1 & 14 & 15 \\
\hline \multirow[t]{2}{*}{ Equal to or more than $10,000,000$} & 0 & 8 & 8 \\
\hline & 2,137 & 5,267 & 7,404 \\
\hline Pearson $\operatorname{chi}^{2}(5)=66$ & $7 \quad \operatorname{Pr}=0.000$ & & \\
\hline
\end{tabular}

Table 6.16: Remittances and Source of drinking water in 2009/2010

\begin{tabular}{|c|c|c|c|c|}
\hline Source of Drinking Water & & Unprotected & Protected & Total \\
\hline 0 & & 1,078 & 2,946 & 4,024 \\
\hline Equal to or Less than 500,000 & & 495 & 1,769 & 2,264 \\
\hline 500,000 to $1,000,000$ & & 55 & 205 & 260 \\
\hline $1,000,000$ to $5,000,000$ & & 22 & 166 & 188 \\
\hline $5,000,000$ to $10,000,000$ & & 1 & 18 & 19 \\
\hline Equal to or more than $10,000,000$ & & 2 & 11 & 13 \\
\hline & Total & 1,653 & 5115 & 6,768 \\
\hline
\end{tabular}

Pearson $\operatorname{chi}^{2}(5)=42.5793 \quad \operatorname{Pr}=0.000$

As shown in table 6.15, a larger number of households had protected sources of water for drinking during the period 2005/2006, as compared to those with unprotected sources, even without receiving remittances. It is evident that the proportion of households with protected sources increased as the cash value of remittances increased. The p-value $(0.000)$ from the chi square test of significance implies a significant influence of the amount received in cash from remittances on the main source of water for drinking for households. From table 6.16, a larger proportion of households had protected sources of water for drinking during the period 2009/10, as compared to those with unprotected sources, even without receiving remittances. Furthermore, it is also evident that the proportion of households with protected sources increased as the cash value of remittances increased. The p-value (0.000) from the chi square test of significance implies a significant influence of the cash value of remittances on the main source of water for drinking.

Data for both periods under comparison prompt two main observations. First, even without receiving remittances, households have better access to protected sources of drinking water, which implies that remittances may not be the only explanatory variable for changes in households' access to water in this analysis. However, the proportion of households with access to protected water sources increases as the cash value of remittances increases; therefore, the cash value of remittances increases 
the chances of a household advancing its access to protected sources of drinking water. Finally, given that the p-values from Pearson Chi Square test are 0.000 for both periods, it implies that the significance of remittances as an explanatory variable for improved access to protected sources of drinking is confirmed.

\subsubsection{Remittances and Physical Conditions of Housing}

\section{a) Roof Material}

Households whose major roof construction materials included thatch, straw and others were classified as having rudimentary materials, while households that had iron sheets or tiles as the main roof materials were classified as having advanced materials. As shown in the table 6.17, the majority of the households that did not receive remittances $(2,635)$ during the time period 2005/2006 had advanced roof materials. Furthermore, it is also evident that a large proportion of the households that received remittances of cash value less than 500,000 shillings $(1,555)$ had advanced roof materials. The p-value (0.000) from the chi square test of significance implies a significant influence of receipt of remittances on the major construction material of the roof.

Table 6.18 shows roof materials for the period 2009/2010, the majority of the households that did not receive remittances $(2,318)$ had advanced roof materials. It is also evident that a large proportion of the households that received remittances of cash value less than 500,000 shillings $(1,160)$ had advanced roof materials. It is therefore apparent that no matter the cash value of remittances, a larger number of households had advanced roof materials. It is thus plausible that there are other explanatory variables for advanced roof materials, apart from changes in income or remittances. However, the p-value (0.000) from the chi square test of significance implies that there is a significant influence of cash value of remittances on the major construction material of the roof. 


\section{Table 6.17: Remittances and Roof Materials in 2005/2005}

\begin{tabular}{|c|c|c|c|}
\hline Roof Materials & Rudimentary & Advanced & Total \\
\hline 0 & 1,607 & 2,635 & 4,242 \\
\hline Equal to or Less than 500,000 & 1,242 & 1,555 & 2,797 \\
\hline 500,000 to $1,000,000$ & 42 & 143 & 185 \\
\hline $1,000,000$ to $5,000,000$ & 22 & 136 & 158 \\
\hline $5,000,000$ to $10,000,000$ & 0 & 15 & 15 \\
\hline Equal to or more than $10,000,000$ & 0 & 8 & 8 \\
\hline Total & 2,913 & 4,492 & 7,405 \\
\hline
\end{tabular}

Pearson $\operatorname{chi}^{2}(5)=112.9845 \operatorname{Pr}=0.000$

Table 6.18: Remittances and Roof Materials in 2009/2010

\begin{tabular}{lrrr}
\hline \multicolumn{1}{c}{ Roof Materials } & Rudimentary & Advanced & Total \\
\cline { 2 - 4 } 0 & 1,706 & 2,318 & 4,024 \\
Equal to or Less than 500,000 & 1,102 & 1,160 & 2,262 \\
500,000 to 1,000,000 & 61 & 199 & 260 \\
$1,000,000$ to 5,000,000 & 38 & 150 & 188 \\
$5,000,000$ to 10,000,000 & 0 & 19 & 19 \\
Equal to or more than 10,000,000 & Total & 1 & 13 \\
\cline { 3 - 5 } & Pearson chi $^{2}(5)=132.0579$ & Pr $=0.000$ & $\mathbf{3 , 8 5 8}$ \\
\hline \multicolumn{4}{c}{}
\end{tabular}

Trends for both periods under comparison prompt one main observation, namely that despite the results from the p-value (0.000) from the chi square test of significance confirming remittances as an explanatory variable for changes in the material of the roof, the possibility of other explanatory factors cannot be ruled out. This is due to a large proportion of households - over 50 per cent - in both time periods having advanced roof materials with or without receiving remittances.

\section{b) External Wall}

Households with major construction materials of the external wall including thatch, straw, mud, poles, timber, un-burnt bricks, burnt bricks with mud and others were classified as primitive materials, while those with burnt bricks with cement, cement blocks and stone as the main construction materials were classified as having advanced materials. As shown in table 6.19 and graph 6.19, the majority of the households that did not receive remittances $(3,105)$ during the period 2005/2006 had primitive external wall materials. Furthermore, it is also evident that a large number of the households that received remittances of a cash value less than Uganda 
Shillings 500,000 $(2,205)$ had primitive materials of the external wall. The p-value (0.000) from the chi square test of significance implies a significant influence of receipt of remittances on the major construction material of the external wall.

\begin{tabular}{|c|c|c|c|}
\hline \multicolumn{4}{|c|}{ Table 6.19: Remittances and Material of External Wall in $2005 / 2006$} \\
\hline Material of External Wall & Rudimentary & Advanced & Total \\
\hline 0 & 3,105 & 1,137 & 4,242 \\
\hline Equal to or Less than 500,000 & 2,205 & 592 & 2,797 \\
\hline 500,000 to $1,000,000$ & 94 & 91 & 185 \\
\hline $1,000,000$ to $5,000,000$ & 52 & 106 & 158 \\
\hline $5,000,000$ to $10,000,000$ & 2 & 13 & 15 \\
\hline Equal to or more than $10,000,000$ & 2 & 6 & 8 \\
\hline 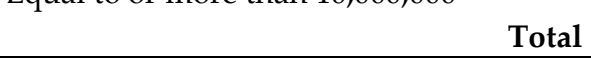 & 5,460 & 1,945 & 7,405 \\
\hline
\end{tabular}

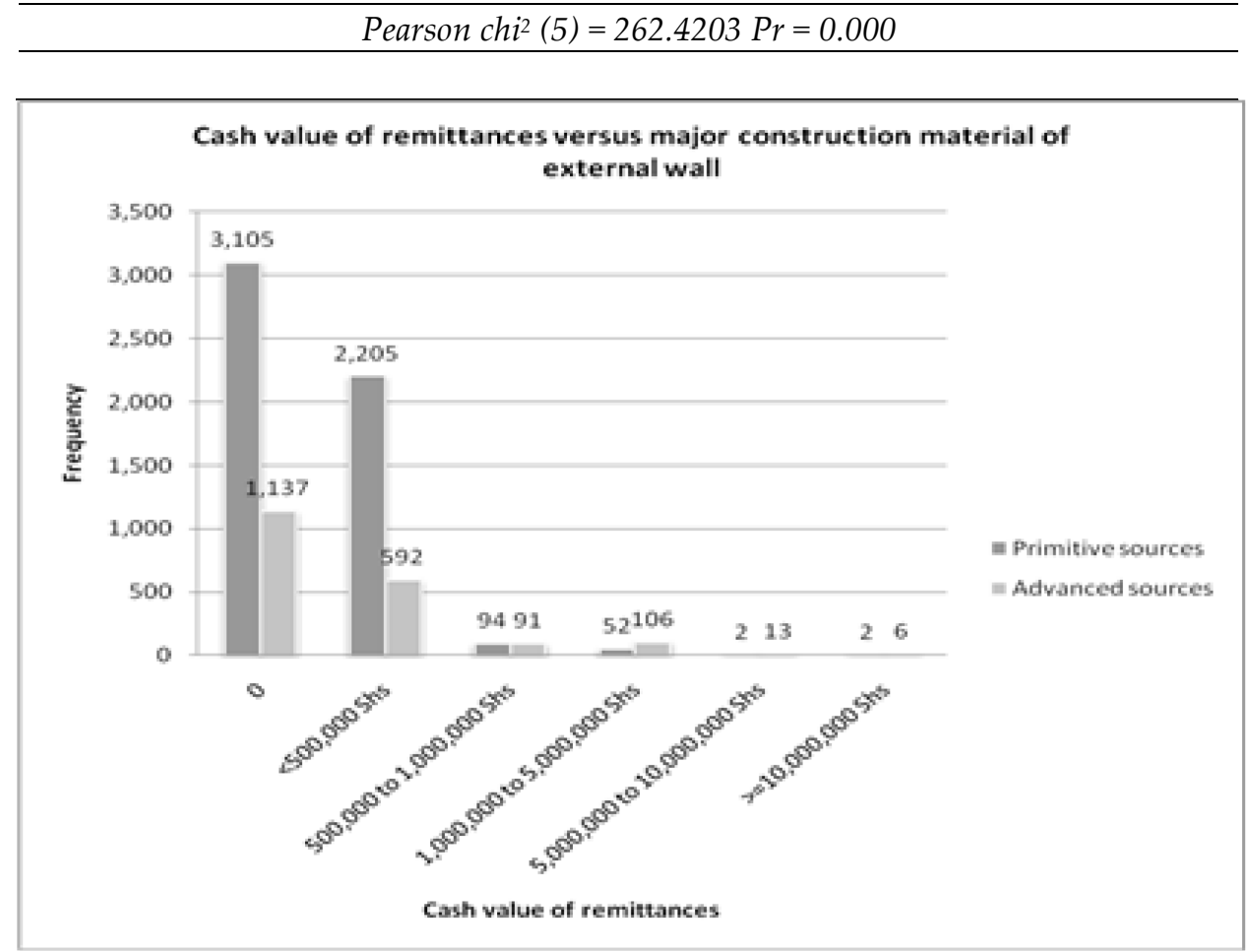

Table 6.20 and graph 6.20 show that the majority of the households that did not receive remittances $(2,793)$ during the period $2009 / 10$ had primitive materials of the external wall. Furthermore, it is also evident that a large proportion of households that received remittances of cash value less than Uganda Shillings 500,000 $(1,778)$ had primitive materials of the external wall. The p-value $(0.000)$ from the chi square test of significance confirms that remittances significantly influence the construction material of the external wall. 


\begin{tabular}{|c|c|c|c|}
\hline \multicolumn{4}{|c|}{ Table 6.20: Remittances and Material of External Wall in 2009/2010 } \\
\hline Material of External Wall & Rudimentary & Advanced & Total \\
\hline 0 & 2,793 & 1,234 & 4,027 \\
\hline Equal to or Less than 500,000 & 1,778 & 486 & 2,264 \\
\hline 500,000 to $1,000,000$ & 133 & 128 & 261 \\
\hline $1,000,000$ to $5,000,000$ & 65 & 123 & 188 \\
\hline $5,000,000$ to $10,000,000$ & 2 & 17 & 19 \\
\hline Equal to or more than $10,000,000$ & 2 & 11 & 13 \\
\hline Total & 4,773 & 1,999 & 6,772 \\
\hline
\end{tabular}

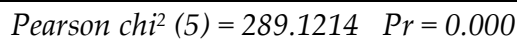

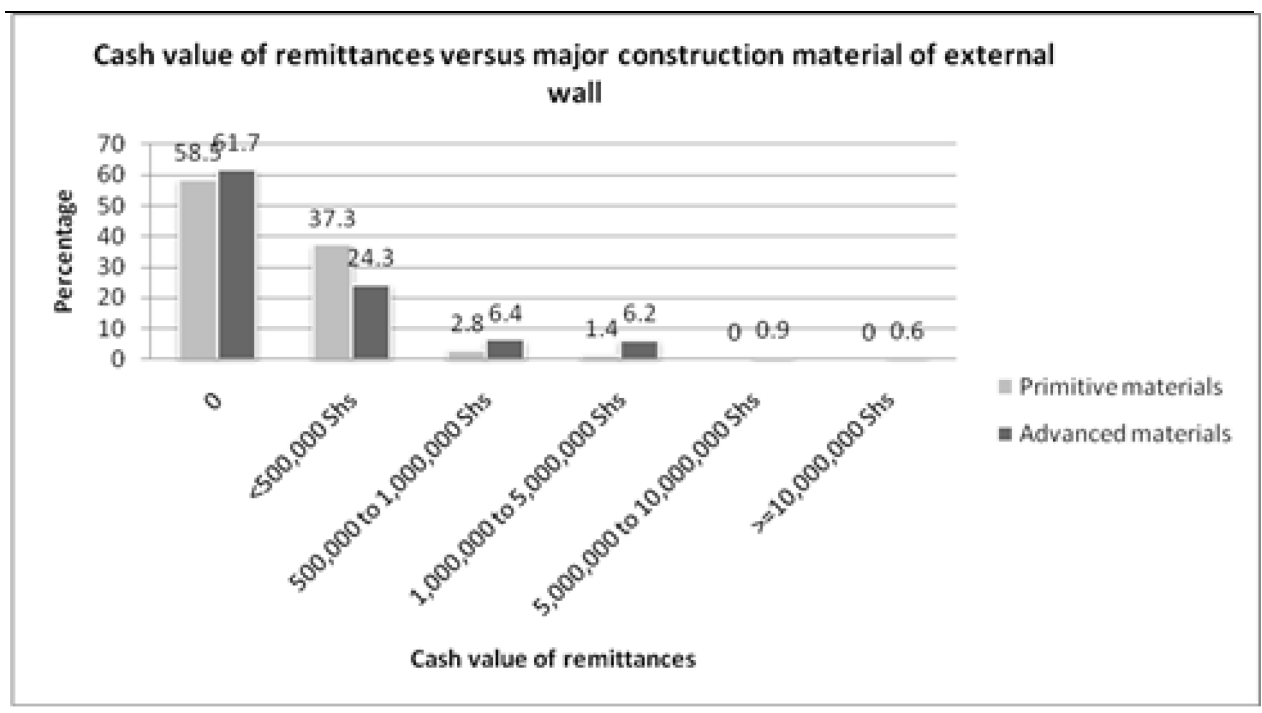

Trends for both periods under comparison show three main observations, First, households that do not receive remittance overall have primitive external wall materials. Second, households that receive remittances of a cash value less than Uganda Shillings 500,000 also have primitive external wall materials. Finally, given that the p- values from Pearson Chi Square test are 0.000 for both periods, confirms the significance of remittances as an explanatory variable for advanced external wall materials for households.

\section{c) Floor Material}

Households with floors made of earth, earth and cow dung, and other materials were classified as rudimentary floor types, while those with floors made of cement, mosaic or tiles were classified as having advanced floor types. As shown in table 6.21 and graph 6.21, the majority of households that did not receive remittances $(3,073)$ during the time period 2005/2006 had rudimentary floor types, while those 
that received remittances of a cash value less than 500,000 shillings $(2,199)$ also had rudimentary floor types. As the cash value of remittances increased, there is a gradual increase in number of households with advanced floor types. The p-value (0.000) from the chi square test of significance implies a significant influence of the amount received in cash from remittances on state of the floor within households that receive remittances.

\begin{tabular}{|c|c|c|c|}
\hline \multicolumn{4}{|c|}{ Table 6.21: Remittances and Floor Material in 2005/2005 } \\
\hline Floor Material & Rudimentary & Advanced & Total \\
\hline 0 & 3,073 & 1,169 & 4,242 \\
\hline Equal to or Less than 500,000 & 2,199 & 598 & 2,797 \\
\hline 500,000 to $1,000,000$ & 92 & 93 & 185 \\
\hline $1,000,000$ to $5,000,000$ & 41 & 117 & 158 \\
\hline $5,000,000$ to $10,000,000$ & 1 & 14 & 15 \\
\hline Equal to or more than $10,000,000$ & 0 & 8 & 8 \\
\hline Total & 5,406 & 1,999 & 7,405 \\
\hline
\end{tabular}

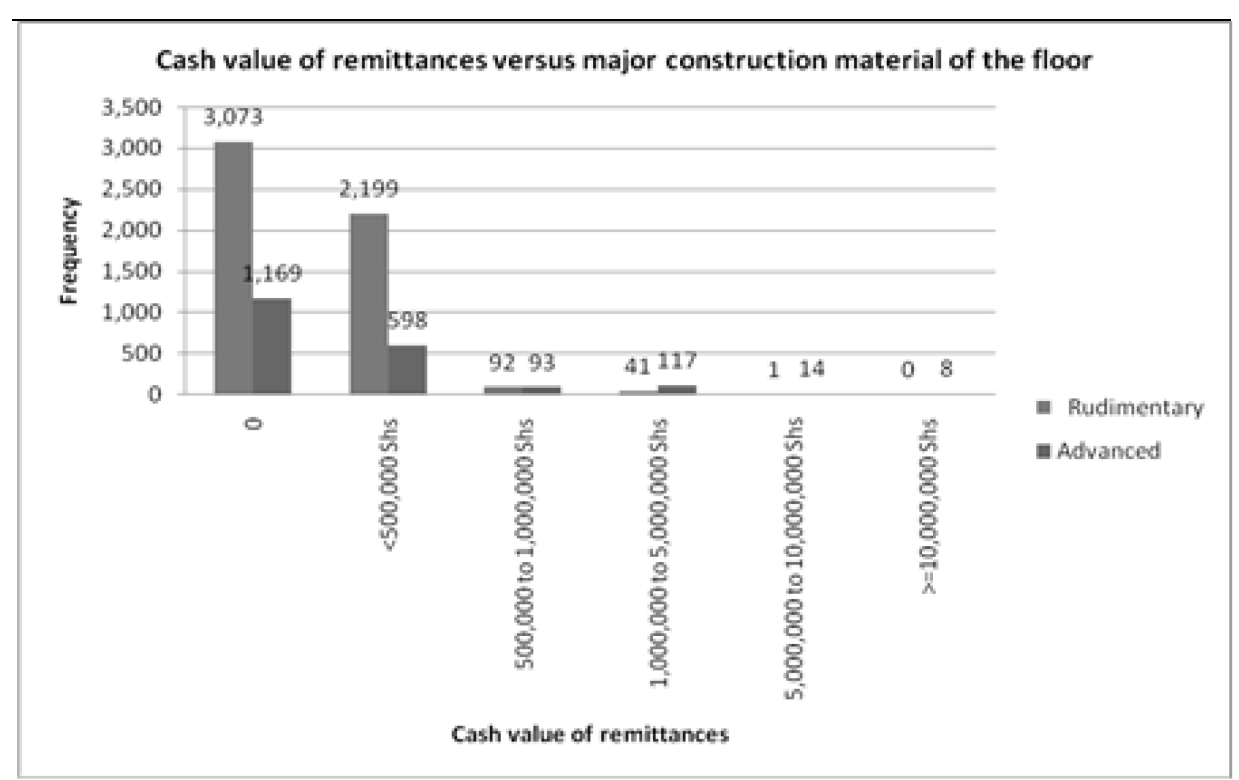




\begin{tabular}{|c|c|c|c|}
\hline \multicolumn{4}{|c|}{ Table 6.22: Remittances and Floor Material in 2009/2010 } \\
\hline Floor Material & Rudimentary & Advanced & Total \\
\hline 0 & 1,963 & 1,065 & 3,028 \\
\hline Equal to or Less than 500,000 & 1,096 & 414 & 1,510 \\
\hline 500,000 to $1,000,000$ & 103 & 122 & 225 \\
\hline $1,000,000$ to $5,000,000$ & 55 & 113 & 168 \\
\hline $5,000,000$ to $10,000,000$ & 0 & 19 & 19 \\
\hline Equal to or more than $10,000,000$ & 1 & 12 & 13 \\
\hline Total & 3,218 & 1065 & 4,963 \\
\hline
\end{tabular}

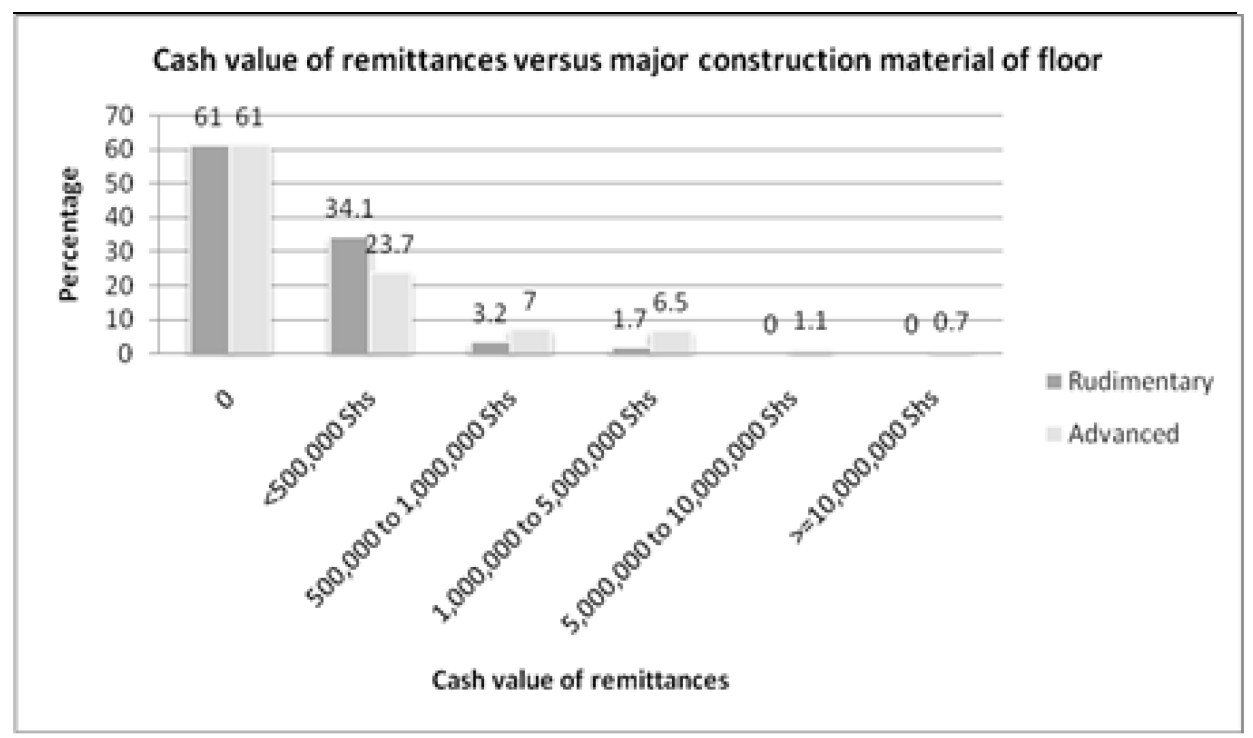

Similarly, graph 6.22 and table 6.22 , show that majority of the households that did not receive remittances $(1,963)$ during the time period $2009 / 10$ had rudimentary floor types. A large proportion of the households that received remittances of a cash value less than Uganda shillings 500,000 (1,096) also had rudimentary floor types. As the cash value of remittances increased, a gradual increase in number of households with advanced floor types was noted. The p-value (0.000) from the chi square test of significance implies a significant influence of the cash value of remittances on the major construction material of the floor.

Tendencies for both periods under comparison show four main observations. First, households that do not receive remittances overall have rudimentary floor types. Second, households that receive remittances of a cash value less than Uganda Shillings 500,000 also have rudimentary floor types. Third, advancement in floor types from rudimentary to advanced floor types only became evident when the cash value of remittances increased to Uganda Shillings 500,000 and beyond; therefore, as 
the cash value of remittances increases, the chances of a household advancing the type of floor materials improves. Finally, given that the p-values from Pearson Chi Square test are 0.000 for both periods, it implies that the significance of remittances as an explanatory variable for improvements in the type of floor materials used is confirmed.

\subsubsection{Correlation Matrix: Remittances and Housing Quality}

Table 6.23 shows that none of the variables floor type, roof type, major material of wall, major source of house lighting, main source of cooking fuel, main source of drinking water and type of toilet used was highly correlated with receipt of remittances for the period 2005/2006. The highest correlation was found between the material of wall and floor type at $66.4 \%$ followed by between the floor type and major source of house lighting at $51.2 \%$.

Table 6.23: Spearman's Correlation Matrix for 2005/2006

\begin{tabular}{lcccccccc}
\hline & recvrem & floor & roof & wall & light & $\begin{array}{c}\text { cookfue } \\
\text { 1 }\end{array}$ & drinkwater & toilet \\
\hline recvrem & 1.000 & -0.012 & -0.034 & -0.013 & 0.005 & -0.011 & 0.062 & 0.008 \\
floor & -0.012 & 1.000 & 0.437 & 0.664 & 0.512 & 0.079 & 0.209 & 0.289 \\
roof & -0.034 & 0.437 & 1.000 & 0.431 & 0.244 & 0.042 & 0.078 & 0.278 \\
wall & -0.013 & 0.664 & 0.431 & 1.000 & 0.437 & 0.076 & 0.193 & 0.239 \\
light & 0.005 & 0.512 & 0.244 & 0.437 & 1.000 & 0.150 & 0.176 & 0.176 \\
cookfuel & -0.011 & 0.079 & 0.042 & 0.076 & 0.150 & 1.000 & 0.035 & 0.030 \\
drinkwater & 0.062 & 0.209 & 0.078 & 0.193 & 0.176 & 0.035 & 1.000 & 0.112 \\
toilet & 0.008 & 0.289 & 0.278 & 0.239 & 0.176 & 0.030 & 0.112 & 1.000 \\
\hline
\end{tabular}

Table 6.24 shows the results of the Spearman's correlation matrix for receipt of remittances and all the variable attributes of status of physical condition of housing for the period 2009/2010, which includes floor type, roof type, major material of the wall and the variable attributes of access to amenities, including major source of household lighting, main source of cooking fuel, main source of drinking water and type of toilet mainly used. The findings show that none of the variables; floor type, roof type, major material of wall, major source of house lighting, main source of cooking fuel, main source of drinking water and type of toilet used was highly correlated with receipt of remittances. Indeed, the highest correlation was found between the material of wall and floor type at $68.1 \%$, followed by between the floor type and major source of house lighting at $53 \%$. 
Table 6.24: Spearman's Correlation Matrix for 2009/2010

\begin{tabular}{lcccccccc}
\hline & recvrem & floor & roof & wall & light & cookfuel & drinkwater & toilet \\
\hline recvrem & 1.000 & -0.002 & -0.016 & -0.012 & -0.032 & -0.017 & 0.074 & -0.038 \\
floor & -0.002 & 1.000 & 0.401 & 0.681 & 0.530 & 0.151 & 0.234 & 0.297 \\
roof & -0.016 & 0.401 & 1.000 & 0.458 & 0.241 & 0.069 & 0.070 & 0.224 \\
wall & -0.012 & 0.681 & 0.458 & 1.000 & 0.465 & 0.137 & 0.224 & 0.237 \\
light & -0.032 & 0.530 & 0.241 & 0.465 & 1.000 & 0.265 & 0.186 & 0.213 \\
cookfuel & -0.017 & 0.151 & 0.069 & 0.137 & 0.265 & 1.000 & 0.049 & 0.067 \\
drinkwater & 0.074 & 0.234 & 0.070 & 0.224 & 0.186 & 0.049 & 1.000 & 0.087 \\
& & & & & & & & \\
toilet & -0.038 & 0.297 & 0.224 & 0.237 & 0.213 & 0.067 & 0.087 & 1.000 \\
\hline
\end{tabular}

Therefore, it is evident from the correlation matrices of both periods under analysis that all the variable attributes of access to amenities and physical condition of housing are not co-related with remittances. A household's receipt of remittances affects the status of the variable attributes of physical condition of housing and access to amenities, and thus remittances represent an independent or explanatory variable. However, changes in the material of wall in housing are related to a change in floor type at $66.4 \%$, followed by the floor type and major source of house lighting at $51.2 \%$ during the period $2005 / 2006$. Similarly, changes in the material of wall and floor type are related at $68.1 \%$, followed by the floor type and major source of house lighting at 53\% during the period 2009/2010. This implies that when a household changes its wall materials it also likely to follow that with changes in its floor material as well.

\subsection{Logistic Regressions for Hypothesis Testing}

Logistic regressions were conducted for each of the selected dependent variables against the independent variable (receipt of remittances), which had been hypothesized as being of influence. Accordingly, the results of the regression analysis for the periods 2009/2010 and 2005/2006 are summarized in table 6.25.

In terms of the period 2009/2010, I observe that the odds of finding advanced construction materials of the floor at the $95 \%$ significance level were not significantly different for households that received remittances from those that did not receive remittances ( $p$-value $=0.983$ ). Similarly, the odds of finding advanced construction materials of roofs and advanced types of cooking fuel were also not significantly different for households that received remittances from those that did not receive remittances. However, the odds of finding advanced construction materials of walls, 
advanced sources of house lighting, advanced toilet facilities, protected sources of drinking water were significantly different for households that received remittances from those that didn't (p-values less than 0.05). Table 6.25 highlights that the odds of finding protected sources of drinking water were 1.38 times higher for households that received remittances than those that didn't in 2009/2010.

\begin{tabular}{lccc}
\hline \multicolumn{4}{l}{ Table 6.25: Regression of Remittances on Housing Quality Variables } \\
\hline & Odds ratio & $\begin{array}{c}\text { [95\% Confidence } \\
\text { Interval] }\end{array}$ & P-value \\
Response Variable in 2009/2010 & 0.999 & $0.886-1.125$ & 0.983 \\
Major construction materials of floor & 0.943 & $0.855-1.040$ & 0.240 \\
Major construction materials of roof & 0.874 & $0.786-0.973$ & 0.014 \\
Major construction materials of wall & 0.784 & $0.670-0.917$ & 0.002 \\
Main source of house lighting & 0.717 & $0.447-1.149$ & 0.167 \\
Type of fuel used for cooking & 0.759 & $0.682-0.845$ & 0.000 \\
Type of toilet used & 1.380 & $1.230-1.549$ & 0.000 \\
Main sources of drinking water & Odds ratio & {$[95 \%$ Confidence } & P-value \\
\hline & & Interval] & \\
\cline { 2 - 4 } Response Variable 2005/2006 & 0.935 & $0.843-1.038$ & 0.207 \\
Major construction materials of floor & 0.867 & $0.789-0.953$ & 0.003 \\
Major construction materials of roof & 0.937 & $0.844-1.041$ & 0.224 \\
Major construction materials of wall & 1.026 & $0.883-1.193$ & 0.736 \\
Main source of house lighting & 0.703 & $0.327-1.515$ & 0.369 \\
Type of fuel used for cooking & 1.029 & $0.923-1.147$ & 0.607 \\
Type of toilet used & 1.327 & $1.197-1.470$ & 0.000 \\
Main sources of drinking water & & & \\
\hline
\end{tabular}

In terms of the period 2005/2006, I observe that the odds of finding advanced construction materials of the floor at the $95 \%$ significance level were not significantly different for households that received remittances from those that didn't ( $\mathrm{p}$ value $=0.207$ ). Similarly, the odds of finding advanced construction materials of walls, advanced sources of house lighting, advanced types of cooking fuel and good toilet facilities were also not significantly different for households that received remittances from those that didn't. However, the odds of finding advanced roofing materials and protected sources of drinking water were significantly different for households that received remittances from those that didn't (p-values less than 0.05). Table 6.25 indicates that the odds of finding protected sources of drinking water were 1.327 times higher for households that received remittances than those that didn't in 2005/2006. 


\begin{tabular}{lcccc}
\hline \multicolumn{4}{c}{ Table 6.26: Overall Influence of Remittances on Housing Quality } \\
\hline \multicolumn{1}{c}{ Housing Quality } & Relationship & Significance & $\begin{array}{c}\text { Odds in } \\
\text { 2005/2006 }\end{array}$ & $\begin{array}{c}\text { Odds in } \\
\text { Physical Condition }\end{array}$ \\
\cline { 2 - 5 } Floor & & & \\
Roof & Positive & Yes & 0.935 & 0.999 \\
Walls & Positive & Yes & 0.867 & 0.943 \\
Access to Utilities & Positive & Yes & 0.937 & 0.874 \\
Source of Light & & & & \\
Source of Cooking Fuel & Positive & Yes & 1.026 & 0.784 \\
Toilet Facility & Positive & Yes & 0.703 & 0.717 \\
Water Source & Positive & Yes & 1.029 & 0.759 \\
\hline
\end{tabular}

Table 6.26 summarises the comparison of households that receive remittances and those that do not shows that remittances in both time periods, to show that remittances are independent of housing quality and are an explanatory variable for changes in housing quality and tenure. Whereas in the descriptive statistics, some variable measures such as type of toilet used, quality of floor materials decline or deteriorate, nevertheless the relationship with remittances is proven not by the changes in odds over time but by the relationship and significance are proven by statistical tests. Therefore;

a) Remittances are an explanatory variable for physical condition of housing, whereby households that receive remittances improve their odds for advanced floor type by 0.935 in 2005/2006 to 0.999 in 2009/2010, roof type by 0.867 in $2005 / 2006$ to 0.943 in 2009/2010, and major material of the external wall by 0.937 in $2005 / 2006$ declining to 0.874 in $2009 / 2010$. These changes show the incremental input of remittances on physical condition of housing.

b) Remittances are an explanatory variable for improved access to household utilities whereby households that receive remittance improve their odds for advanced for, main source of cooking fuel by 0.703 in 2005/2006 to 0.717 in 2010. They also improve their odds for access to protected source of drinking water by 1.327 in $2005 / 2006$ to 1.380 in 2009/2010. However, the source of house lighting which stands at 1.026 in 2005/2006 declines to 0.784 in 2009/2010 and their use of advanced type of toilet by 1.029 in 2005/2006 declines to 0.759 in 2009/2010. These changes are also gradual and incremental as well.

\subsection{Summary of Findings}

My analysis in this chapter begins with adopting Sinning's (2006) approach, examining homeownership disparities between native and immigrant households 
paying attention to housing quality disparities. From their approach, I establish that it is possible to determine the status of housing quality between the two sets of households using a housing quality index, which I constructed by first distinguishing households as either migrant or non-migrant. I then used a comparative approach and considered differentials in housing quality for migrant and non-migrant households based upon selected attributes of physical condition of housing and access to welfare amenities to confirm differences. I mapped changes in the sub-variables over a 5 year period between 2005 and 2010 to show the trends.

\section{(a) Access to Welfare Amenities}

Findings show that households improved their access to safe drinking water sources, between the two periods under consideration. The advancement is significant with 10 per cent of household accessing boreholes, approximately 18 per cent of households improved to protected well-springs and 50 per cent of households advanced to streams, lakes or ponds as their sources for safe drinking water. These trends however, show that even without receiving remittances households advanced their access to safe drinking water sources, which not only confirms the relationship with remittance at $\mathrm{p}$-value of 0.000 but also underscores the fact that remittances may not be the only explanatory factor for such advances.

With regards to the type of toilets in used by households as a sub-variable of access to amenities, the most common forms in use are rudimentary, and show mixed results within rudimentary types such as pit latrines declining in using over the two periods under comparison (by $2 \%$ ) and increase in users of bush as toilet (by $2.5 \%$ ). There is also a dismal increase in the number of households with advanced types of toilets such the flush and VIP latrines by approximately 1 per cent of households. Households that receive remittances have advanced toilet facilities but these are few in number, however with a p-value of 0.000 , the relation between remittances and the opportunities to have an advanced form of toilet type is affirmed and is evident after the 500,000 shillings $(\$ 2,594)$ threshold. There is a general decline in the quality of toilet used by households as most households fall under the rudimentary types of toilets during the time-period under consideration.

In respect of lighting, households with primitive sources of lighting remained dominant in both periods and in some cases there was a rise in the use of these sources by households these such as firewood, which goes up by approximately 5.4 per cent in the period under analysis. However, it is noted that households which do not receiving remittances have primitive sources of lighting, for those receiving remittances, advancing to modern lighting sources is only evident after the threshold of 500,000 shillings $(\$ 2,594)$, with the significance of relationship standing 
at a p-value of 0.001 . Therefore a household's chance of advancing its source of lighting energy improves as the value of remittances increases received increases.

Findings show that most households use rudimentary forms of cooking fuel, with little advancement to modern forms such as electricity, I see a dismal change of less than 1 per cent in the period under analysis. Households that do not receive remittances have rudimentary energy sources for cooking, with a significant relationship between cooking fuel and remittances is confirmed especially when the cash value is above 500,000 shillings $(\$ 2,594)$ at a p-value of 0.000 .

\section{(b) Physical Condition of Housing}

In the two periods under analysis, households experience an advance the state of their roof materials, with iron sheets showing a 3.4 per cent increase and tiles being taken on by only 0.24 per cent of households. More than $50 \%$ of households have advanced forms of roofing materials whether they receive remittances or not, despite confirming a significant relationship between roof materials and remittances with a $\mathrm{p}$ value of 0.000 . However, the fact that the materials are advanced without or without remittances implies the presence of other explanatory factors.

With regard to external wall materials, there is almost consistent use of materials without any significant changes in the period under comparison except for use of burnt brick materials that rises by approximately 3 per cent. Households not receiving remittances have primitive external walls, even those that receive remittances of less than 500,000 Uganda shilling $(\$ 2,594)$ threshold have primitive wall, despite a confirmed positive correlation between remittance and wall materials at $\mathrm{p}$-value of 0.000 .

Findings also confirm that the most common forms of floor materials for households are rudimentary, with earth floor increasing by 4.8 per cent in the period under comparison. There is a noted decline of cow dung as a floor material by approximately 3 per cent, even though there is no indication of positive changes in income to support advancement in the period. There is a drop in cement floor by approximately 2 per cent and tiles/mosaic at less than 1 per cent of households with this floor type. Households that do not receive remittance have rudimentary floor types, which confirms a relationship between remittances and floor materials with a p-value of 0.000 at threshold of 500,000 Uganda shilling $(\$ 2,594)$.

\section{(c) Overall Observations}

For both, access to amenities and physical condition of housing, the spearman's corelation matrix confirms receipt of remittances represents an independent or 
explanatory variable. The results confirm that none of the variable attributes floor type, roof type, major material of wall, major source of house lighting, main source of cooking fuel, main source of drinking water and type of toilet used were highly correlated with receipt of remittances. Therefore, remittances are independent of housing quality and represent an explanatory variable for changes in the quality of housing for households.

Logistic regressions on the other hand, show limited or low changes in odds for most sub-variables of both access to amenities or physical condition of housing, where by changes are likely to be slight or incremental in housing quality. The relationships tested are all significant for both housing conditions and access to utilities because the p-value is less than 00.05 , at $95 \%$ confidence level, perhaps the relationship between the remittances and housing quality variables and their attributes is not due to chance. There is also evidence of a gradual change in the quality of housing as evidenced by advancement in access to amenities and improvements in utilities as the amount of remittances received by households' increases to above Uganda Shillings 500,000. Therefore, it is logical that as the value of remittances increases, the chances of a household advancing in housing quality also improve.

\subsection{Discussion and Conclusions}

At the overall level, households which receive remittances, have a more advanced status of access to amenities and exhibit more advanced forms of physical condition of their housing which are measures for housing quality in this analysis. In this regard, therefore the aspect of receiving remittances on its own is a plus for most households, whether they are considering improvement in their quality of housing or not. This is not to dismiss the plausible contribution of remittances in this, which this analysis is unable to confirm, but to affirm that the relationship of influence are acknowledged by the findings of this analysis. The fact that there are positive correlations of significance between the sub variables of physical condition and access to amenities validates the hypotheses that a household in receipt of remittances has a higher chance at improving its housing quality for both physical conditions and access to amenities because of the extra household incomes, that becomes available with remittance flows.

However, the size or volume and frequency of the remittance received have implications on whether a household can advance its quality of housing. In all instances, findings show that once the household drives its receipts beyond the 500,000 Uganda shillings (US\$ 247.89 in 2010) threshold, then changes in wall materials (for physical conditions) and lighting, cooking energy and drinking water (access to amenities) begin to take place. This implies that, it is not sufficient to 
receive remittances, but they must be of a value or volume that can support the household to take on and sustain changes in the physical condition of housing and access to amenities. This analysis shows that households that received small amounts of remittances had no difference with those that did not receive remittances in terms of their access to amenities or the physical condition of their housing (housing quality). Therefore for one to assert that remittances influence the quality of housing, households must be receiving them with regularity, in addition to sums or volumes that are above the threshold of 500,000 Uganda shillings (US\$ 247.89 in 2010).

A critical review of the results of this analysis shows that, remittances as a share of household income are not the only determinants of housing quality. One could argue that the analyst failed to adequately control for endogeneity, which is a possibility, given the quality of data-sets used. However, the confirmation that remittances influence housing quality but are not the only factor to consider is evident when the analysis on access to amenities does not show all results to be going in a similar direction. For instance, regressions show that access to water sources does not change for both migrant and non-migrant households, whether remittances are present or not, significant changes are observed in toilet facilities used especially an increase in rudimentary ones, yet they ought to be been declining when households receives remittances.

In Uganda, cultural practices (which could not be applied as the data set did not have such variables) or geographical location (which was discounted on account of not having significant impact on receipt of remittances) are known to influence toilet habits of different populations. In this instance, it important to conclude that even though, the analysis demonstrates the influence of remittances on housing quality through significantly correlations obtained from regressions for both physical condition of housing and access to amenities, it is not the only factor, there other determinants, which are beyond the analysis undertaken in this thesis. Therefore, it is conceivable to conclude that remittances are part of but not the only financiers of improvements in housing quality.

Finally, the hypothesis constructed are tested for each variable attribute and aggregated into a conclusion. Indeed, regressions affirm that the odds of finding advanced construction materials of the floor and roof were not significantly different for households that received remittances from those that did not in both timeperiods. However, the odds of finding advanced construction materials of walls, advanced sources of house lighting, advanced toilet facilities, protected sources of drinking water were significantly different for households that received remittances from those that did not in both time-periods. It is my considered view that remittances improve incomes that enable households to build more permanent 
structures especially with burnt bricks for external wall and durable houses thus improve their housing quality. 


\section{Chapter 7: Thesis Conclusions}

\subsection{Introduction}

In this chapter, I bring together all emerging findings from the empirical analysis and contextualize them within the broader context of housing in Uganda. I offer my views and opinions by drawing conclusions and highlight areas of further research emerging from gaps in this thesis. The conclusions are offered in a topical format, with the overall aggregated conclusion at the beginning of the chapter and their limitations presented as the last section.

\subsection{Overall Conclusion}

It is the overall conclusion of this thesis, that remittances are an independent and explanatory variable for changes in tenure and quality of housing. The logistic regression results place the odds higher for households receiving remittances to advance their housing tenure and finance improvements in housing quality for both access to amenities and physical condition of housing than those households that do not receive remittances. Since remittances are analysed as a share of household income, the finding confirms assertions from housing economists that household income (remittances) is a major explanatory variable accounting for housing tenure changes and disparities between migrant and non-migrant households.

The findings also endorse the suggestion that trans-nationalism theory offers the most beneficial theoretical grounding for this thesis. Migrants are thus designated as "trans-migrants" when they develop and maintain multiple relations - social, economic, political, organizational and religious - that span borders. It is also concluded that it is possible for a state to create incentives for a targeted use of remittances in a particular sector of an economy, given the significant positive correlations between the attributes of housing tenure (ownership and rental) and housing quality (access to utilities and physical condition of housing) and remittances confirmed in this thesis.

Housing is a basic need, which carries with other utilities in the social and cultural life of migrants sending the remittances and the household receiving the remittances. At the very minimum, this thesis raises the issues that need to be considered by policy makers, and verifies the key relations that need to be addressed in policy formulation. At the moment, the role of remittances in improving housing tenure and quality cannot be over played, but with a potential to increase in volume and frequency, a prudent policy maker in the housing sector should begin to take first steps to creatively tap into these resources. Consequently, thinking creatively on 
how to encourage their flow into housing, while removing limitations to levels that are encouraging is a necessity that cannot be understated. This is one of the areas where further research needs to focus and move into the essential details and substance of how such programmes could potentially function, what form they should take and which institutions are best placed to manage such processes. This would obviously be in addition to specifying the policies needed to support such programs.

\subsection{Theoretical Base}

Theorists have bestowed upon us a variety of frameworks, bringing together housing and remittances. Whereas economists are the dominant thinkers in this area, they build on foundations laid by the neo-classical theorists, progressing from individual independence to mutual interdependence in the new economics of labour migration. In this theoretical frame, the household is the centre piece of action in an imperfect credit (capital) and risk (insurance) markets that prevail in most developing countries. An additional emerging trend that is very relevant to examining housing and remittances is the increased possibilities for migrants and their families to live trans-nationally and adopt transnational identities, and thus needing to maintain multiple relations - social, economic, political, organizational and religious - that span borders. Transnationalism underscores the importance of housing purchase or building, not only as an act of economic trans-nationalism, but also a transfer of equity, social influences across borders and societies. Remittances constitute one such explanatory factor for maintaining attachment to the home country as demonstrated by trans-nationalism theorists.

Although transnationalism theory is the most useful framework in understanding remittances, on its own, it is insufficient for examining housing and remittances. Therefore, income models in the discipline of housing economics become important in this exploration. Of particular importance is the perspective that improved incomes advance household tenure and support the financing of improvements in housing quality. Throughout this thesis, I have argued that remittances reflect a second line of income that ultimately increases the total resources at a household's disposal, which enables it to make decisions that require significant amounts of resources to undertake or require a regular and consistent inflow of funds. Such decisions include the purchase of housing for the first time that is primarily driven by consumption needs. Housing tenure and improvements in housing quality are conscious investments that require a substantial proportion of current income to be diverted to housing or its progressive building. In equal measure, I have also argued that improvements in the quality of housing and housing ownership increase with increases in household income. 


\subsection{Household Incomes and Remittances}

Remittances flows to Africa have increased exponentially over the last decade. Faced with this growth, some governments in developing countries have attempted to regulate the use of such inflows through policy, albeit without success. It is possible for a country to create incentives for a targeted use of remittances in particular sectors of an economy. The findings of this thesis show that one such key beneficiary sector can be housing, due to significant positive correlations between the attributes of housing tenure (own and rent) and housing quality (access to utilities and physical condition of housing) and remittances. Polices and models for channelling of these resources to housing acquisition or construction through deliberate incentives that encourage migrants sending funds and the recipients at home to prioritize or earmark such resources for ownership or purchase of housing are also missing.

Housing as a product in Uganda's economy is highly demanded with limited options of supply. The limitation in supply from the literatures arises due to narrow sources of financing for both construction and improvement of the existing housing stock. Aggregate household incomes for most Ugandans are low and wages/salaries for individuals are low. Yet, the unit cost of housing is way beyond the aggregate income of most households. Low income effectively locks out individuals and households from accessing mortgages to finance housing purchase or construction and indeed any improvements in quality of pre-existing housing stock. This situation is the basis on which, this thesis recommends remittances to become a visible part of the housing acquisition or improvement equation, especially for low income households.

\subsection{Remittances and Housing Tenure}

A comparison of households receiving remittances with those that do not receive remittances demonstrates the independence of the variable of housing tenure and confirms that remittances are an explanatory variable for changes in both rental and ownership status of housing. Remittances are a significant source of financing at the household level, however, remittance flows to Uganda's housing sector are still very low in volumes and limited in value, to have a significant influence on household chances to own or rent housing. It is conceivable that remittances will gain significant influence on housing, if the majority of the households receiving remittance, were to receive a cash value of more than the current threshold of 500,000 Uganda Shillings (US\$ 247.89 in 2010) per year. Ultimately, what makes the difference in my opinion is the extra marginal propensity or additional purchasing power that a migrant household attains as a result of receiving remittances. 
The current values received are too low to support outright purchase of houses or to support continuous rental of either tenements or independent houses, which are the most common forms of housing structures in Uganda. Therefore, I conclude that the size or cash value of remittances received on a regular basis is also a determinant of improvements or purchase of housing, and thus influences the tenure or quality of housing. Nevertheless, the analysis in this thesis is unable to further explore this matter owing to limitations in the datasets, this is therefore one of those areas that will require further research to support emerging policy agendas that attempt to utilize remittances for investment in housing quality or tenure.

Remittances are now an acknowledged source of additional income for households, given that they are private funds whose use does not only rely on one user but rather two users: the households and migrants themselves, with no intermediary or in service provision or standards maintained other than those set by the migrant and recipient. According to this description, remittances provide access to levels of capital that are prohibitively expensive for migrant households prior to the migration. Furthermore remittances do not require an intermediary to apportion out, nor do they require special knowledge to understand how the funds are accessed, nor do they have conditions for their use need imposed by an entity outside of the family except for the migrant and their household.

\subsection{Remittances and Housing Quality}

A comparison of household receiving remittances with those that do not receive remittances demonstrates that remittances are independent of housing quality and are an explanatory variable. Analysis in this thesis confirms that households which receive remittances, have a more advanced status of access to amenities and exhibit more advanced forms of physical condition of their housing which are measures for housing quality. In this regard, therefore the aspect of receiving remittances on its own is a plus for most households, whether they are considering improvement in their quality of housing or not. The fact that there are positive correlations of significance between the sub variables of physical condition and access to amenities validates the hypotheses that a household in receipt of remittances has a higher chance at improving its housing quality for both physical conditions and access to amenities because of the extra household incomes, that becomes available with remittance flows. This implies that, it is not sufficient to receive remittances, but they must be of a value or volume that can support the household to take on and sustain changes in the physical condition of housing and access to amenities.

Nonetheless, the analysis also demonstrates that remittances are not the only determinants for advanced physical condition of housing and access to amenities for migrant households despite the significant correlations obtained from regressions. 
There are other factors which are beyond the analysis undertaken in this thesis. Therefore, it is conceivable to conclude that remittances are part of but not the only financiers of improvements in housing quality. This outcome could also be explained by a possibility of failing to adequately control for endogeneity, which is plausible, given the quality of data-sets used in the analysis that do not allow further testing for causality since the data is not from experiments of two identical populations.

\subsection{Remittances and Gradual Improvements in Housing}

Given the correlation between remittances and housing, and the fact that value and volume of remittances is still low, it is conceivable that remittances could be a gradual enabler, offering little in the immediate and short run for a household to secure housing tenure, but serving an aiding role in the longer term, to the extent of incremental building of sections or parts of housing and other shelter. This is because of the consistency or regularity of flow of remittances, which allows a household to plan and strategize on how to improve housing tenure or ownership. In this way remittances can support a household to incrementally move closer to the kind of housing they desire and thus draw utility from placing their remittances in housing. In any case remittances contribute to the welfare of a household and housing is one of the indicators of decent welfare.

\subsection{Financing Housing Tenure and Quality}

Housing is an extremely durable (slowly depreciating) and composite commodity yielding a flow of 'housing services' or a set of individual characteristics. Housing is the largest asset owned by most households, and must generally be financed over time because of its high cost. Housing in Uganda is provided by the private sector (including individual households), and thus shifting remittance use to investment and wealth creation may require banks to recognize remittances as a stable source of income, innovatively developing remittance-related products as instruments to finance housing purchase, construction and maintenance.

The housing market in Uganda needs to make a deliberate move, to organise itself to respond to the "diaspora market", by availing housing options that meet their expectations and progressive financing arrangements that fit the volume and value of remittance received by migrant households. The housing and real estate sector is not adequately organized to managed or tap into the potential that remittances represent. There are no tailored products for migrants yet nor are there financing choices that use remittances as investment capital. The banking sector that is supposed to lead the way in developing such innovative financing mechanisms, is yet to respond to remittances in the manner necessary to plough them into the 
housing finance market. However, it is still a challenge for financial institutions to recognize remittances as a stable source of income to finance improvements in housing quality or purchase. Therefore, households are faced with limited choice in financing housing quality or tenure improvements, and thus find remittances an appealing and acceptable alternative.

\subsection{Remittances in the Real Estate Market}

There is evidence that the few organized real estate developers and a number of individuals who play a relatively substantial role in the supply of housing, yet whose activities cannot be easily quantified have begun to focus on self-regulation in the industry. Real Estate Developers under their professional association (AREA) are just beginning to re-align their services to required professional standards and enforce/adhere to ethical conduct. Housing products in the market have tended to be of low quality because they are built for a market that receives low incomes, yet migrants may want to focus on high-end quality products of housing.

However, the government might find it useful to consider increasing its role in regulation so as to encourage agents to professionalize and improve the services they can offer as this might place real estate developers in a position to respond to growing demand for diversified housing options by migrant households. The place of remittances in such a situation would ideally be to provide extra resources that raise the volume and rate of construction of new units or better quality. In this equation, remittances have no visibility as yet, calling for research into how remittance expenditures on housing may support local businesses and fuel the growth of local construction enterprises and employment, which could serve as a motivator to focus on the use of remittances in local real estate markets.

\subsection{Limitations}

Although the conclusions of this thesis are statistically significant, care must be taken in the way they are understood and applied. The thesis does offer an exploratory data analysis that can lead to useful insights concerning the relationship between remittances and housing quality. While it presents arguments on the basis of observed status of variables, the statistical significance of findings from such an "unplanned" analysis should remain a topic for future confirmation or validation through planned studies. It is important to emphasize here that the resulting observations do not reflect the probability, but rather the actual status of the variables under investigation. This analysis is context specific, and thus all conclusions are only meaningful or relate to situations similar to the context in Uganda. 


\section{References}

Adams, Richard H. Jr. 1991. "The Economic Uses and Impact of International Remittances in Rural Egypt." Economic Development and Cultural Change 39: 695722.

Adams, Richard H. Jr. 1998. "Remittances, Investment, and Rural Asset Accumulation in Pakistan." Economic Development and Cultural Change 47: 155-73.

Adams, Richard H. Jr. 2003. "International Migration, Remittances and the Brain Drain: A Study of 24 Labor-Exporting Countries." World Bank Policy Research Paper 3069.

Adams R. Jr. and Page John, 2003. International Migration, Remittances, and Poverty in Developing Countries, World Bank Policy working Paper, ISSN: 1813-9450

Adams R Jr. and Page John, 2005. Do International Migration and Remittances Reduce Poverty in Developing Countries? World Development 33(10):1645-1669

Adams, Richard H., Jr., Cuecuecha, Alfredo and Page, John, 2008. Paper provided by the World Bank in its series Policy Research Working Paper Series with number 4515, http://www-wds.worldbank.org/servlet/ WDS Content Server /WDSP/IB/2008/02/12 /000158349_20080212092546/Rendered/PDF/wps4515.pdf

ADB (Asian Development Bank) 2006, Workers Remittance Flows to South East Asia. Manila

Adebayo I.R. Aliu, 2010. Evaluating the Influence of Housing Quality on Urban Residents' Wellbeing: The Case of Lagos Nigeria, International Journal Of Academic Research Vol. 2. No. 6, November, 2010, Part II

Ahlburg, D., 1991. Remittances and their impact, a study of Tonga and western Samoa. Pacific Policy Paper 7, the Australian National University, Canberra. http://www.worldcat.org/isbn/0731509595

Altonji, Joseph G., Hayashi, Fumio, and Kotlikoff, Laurence J. 1992. "Is the Extended Family Altruistically Linked? Direct Tests Using Micro Data." The American Economic Review 82: 1177-1198.

Altonji, Joseph G., Hayashi, Fumio, and Kotlikoff, Laurence J. 1997. "Parental Altruism and Inter Vivos Transfers: Theory and Evidence." The Journal of Political Economy 105: 1121-1166.

Amuedo-Dorantes Catalina and Pozo Susan, 2008. Remittance Income Volatility and Labor Supply in Mexico, World Bank Policy Working Paper 
Andreoni James, 1989. Giving with impure Altruism: Applications to Charity and Ricardian Equivalence, The Journal of Political Economy, Volume 97 Issue 6 (Dec. 1989), $1447-1458$

Antonakis John, Bendahan Samuel, Jacquart Philippe, and Lalive Rafael, 2010; On making causal claims: A review and recommendations. The Leadership Quarterly 21 (2010) 1086-1120. journal homepage: www. e lsevi e r.com/locate/leaqua

Arnott, Richard. 1987. Economic theory and housing, in E. S. MILLS (Ed.) Handbook of Regional Urban Economics. Vol. 2 Urban Economics, pp. 959-988. Amsterdam: Elsevier Science Publishers.

Bageine, Shem. 2010. Interview in the New Vision Newspaper, 6 October 2010 by David Ssempijja of the New Vision

Baldé, Yero, The Impact of Remittances and Foreign Aid on Savings/Investment in Sub-Saharan Africa (SSA) (January 2011). African Development Review, Forthcoming. Available at SSRN: http://ssrn.com/abstract=1756730

Ball, M. 2003. Markets and Structure of the House-building Industry: An International Perspective, Urban Studies 40 (5-6) pp.897-916.

Banerjee, B., 1984, the Probability, Size, and Uses of Remittances From Urban to Rural Areas in India, Journal of Development Economics 16, 293-311.

Bank of Uganda 2009. 'Quarterly Economic Report'. September. Kampala: BoU.

Bank of Uganda, 2009. Balance of payments statistics. www.bou.or.ug/ bouwebsite/ opencms/ bou/rates_statistics/statistics/bop_statistics.html.

Barnum, H.N. and Sabot, R.H. 1977. "Education, Employment Probabilities and Rural- Urban Migration in Tanzania." Oxford Bulletin of Economics and Statistics 39: 109-26.

Basok, T. 2003, Mexican Seasonal Migration to Canada and Development: A Community-based comparison. International Migration, 41: 3-26. doi: 10.1111/14682435.00233

Becker Gary S, 1974. A Theory of Social Interactions, the Journal of Political Economy, Volume 82, Issue 6 (Nov. - Dec., 1974), 1063-1093

Bendixen Associates, 2006. MIF commissioned Bendixen and Associates, one of the leading independent polling and research firms in the United States, to conduct the surveys. Bendixen and Associates interviewed 2,511 Latin American immigrants in 2006 by telephone in Spanish.

Bernheim, B. Douglas and Stark, Oded. 1988. "Altruism within the Family Reconsidered: Do Nice Guys Finish Last?" The American Economic Review 5: 10341045. 
Bernheim, B. Douglas., Shleifer, Andrei, and Summers, Lawrence H. 1985. “The Strategic Bequest Motive." The Journal of Political Economy 93: 1045-1076.

Bhagwati, Jagdish N. and Srinivasan, T. N. 1974. On re-analysing the Harris-Todaro Model: Policy Rankings in the Case of Sector-Specific Sticky Wages. The American Economic Review (AER), 64(3), 502 - 08

Bongaarts John 2001 Household size and composition in the developing world in the 1990s, Population Studies, Vol. 55, Issue No. 3

Boyd, M. 1989. "Family and personal networks in international migration: recent developments and new agendas". International Migration Review 23: 638-70.

Briere, de La B., Sadoulet E., Janvery A. De, and Lambert S., (2003), "The Roles of Destination, Gender and Household Composition in Explaining Remittances: An Analysis for the Dominican Sierra", Journal of Development Economics, Vol. 68, 309-328.

Buckenberger, Corina 2010. Housing qualities in suburban Auckland the suburban 'pavlova' paradise? School of Environment, the University of Auckland. The online version of this article can be found at: http://www.fbe.unsw.edu.au/cf/apnhr/

Carling, Jorgen. 2005. "Migrant Remittances and Development Cooperation." PRIO Report 1/2005, Global Economic Perspectives Page 113.

Carter, Steven John, 2007. House prices, housing tenure, and happiness: Three essays in applied Econometrics University of California, Irvine, 2009, 120 pages; AAT 3353927

Chami, Ralph., Fullenkamp, Connel, and Jahjah, Samir. 2003. "Are Immigrant Remittance Flows a Source of Capital for Development." International Monetary Fund Working Paper 03/198.

Chami Ralph, Barajas Adolfo, Cosimano Thomas, Fullenkamp Connel, Gapen Michael, and Montiel Peter,(2008). Macroeconomic Consequences of Remittances. International Monetary Fund, Washington DC, Occasional Paper 259

Cirman, A. 2006. Housing tenure Preferences in the Post-privatisation period: The case of Slovenia', Housing Studies, 21 (1) pp 113-134

Clark, W. A. V., M. C. Deurloo, and F. M. Dieleman, 1996. Entry to Home ownership in Germany: Some Comparisons with the United States," Urban Studies, 34, 7

Clark, W.A.V., Dieleman, F.M. and Deurloo, M.C. 1984. Housing consumption and residential mobility, Annals of the Association of American Geographers, 74, pp. 2943

Cohen, Michael, October 2007, Thinking Outside the Bubble: The Urban Crises of Land, Labor, and Capital, International Affairs Working Paper 2007-05 
Connell, J and Brown, R.P.C. 1995. "Migrations and Remittances in the South Pacific: Towards New Perspectives." Asian and Pacific Migration Journal 4: 1-33

Cox, Donald., Eser, Zekeriya., and Jimenez, Emmanuel. 1998. "Motives for Private Transfers over the Life Cycle: An Analytical Framework and Evidence for Peru." Journal of Development Economics 55: 57-80.

Curran, Sara R., Filiz Garip, Chang Y. Chung and Kanchana Tangchonlatip. 2005. Gendered migrant social capital: Evidence from Thailand, Social Forces 84 (1): 225255.

Daily Monitor, 2012. Uganda's 2012 Remittance Outlook Points to Decline, Business Outlook on 19 th December 2012, Page 2. http://www.monitor.co.ug/Business/Uganda-s-2012-remittance-outlook-poin...

Daniere, A. (1994). Estimating the willingness-to-pay for housing attributes: An application to Cairo and Manila. Regional Science and Urban Economics, 24, 577599.

de Haas, Hein, 2003. The social and cultural impacts of international migration on Moroccan sending communities: a review. Paper to be published in Morocco and the Netherlands

de Haas, Hein, 2007. Migration and Development: A Theoretical Perspective Paper presented at the conference on 'Trans-nationalization and Development(s): Towards a North-South Perspective', Center for Interdisciplinary Research, Bielefeld, Germany, May 31 - June 01, 2007 COMCAD Arbeitspapiere - Working Paper No. 29

de Haas, Hein, 2008. The complex role of migration in shifting rural livelihoods: The case of a Moroccan oasis. Naerssen, T. van, E. Spaan and A. Zoomers (eds.): Global Migration and Development. New York/London: Routledge

de Haas, Hein, 2010. Migration and Development: A Theoretical Perspective. International Migration Review, 44: 227-264. doi: 10.1111/j.1747-7379.2009.00804.x

Diko J. \& A.G. Tipple (1992) “Migrants Build at Home: Long Distance Housing Development by Ghanaians in London" Cities (Nov. 1992) 288-294.

Djajić, Slobodan. 1986. "International Migration, Remittances and Welfare in a Dependent Economy." Journal of Development Economics 21: 229-234.

Doyle, Morgan. 2006. Sending Money Home: Remittances and Housing in Latin America and the Caribbean. PowerPoint presentation shown at Earth Center, Columbia University. Inter-American Development Bank. www.earthinstitute.columbia.edu/cgsd/remittances/documents/Doyle.pdf 
Durand, Jorge, William Kandel, Emilio A. Parrado, Douglas S. Massey. 1996. "International Migration and Development in Mexican Communities" Demography 33(2): $249-264$

Durand, Jorge, Douglas S. Massey, and Emilio A. Parrado, 1999. The New Era of Mexican Migration to the United States. The Journal of American History 86.260 pars.

<http://www.historycooperative.org/cgibin/justtop.cgi?act=justtop\&url=http://www. historycooperative.org/ journals/jah/86.2/durand.html>.

Durlauf, Steven N. and Young, H. Peyton (eds.) 2001. Social Dynamics: Economic Learning and Social Evolution. The MIT Press: London. ISBN 0262041863

Dynarski, M. and Sheffrin, S., 1985. Housing purchases and transitory income: a study with panel data. Review of Economics and Statistics 67, 195-204

Edwards, Alejandra C. and Ureta, Manuelita. 2003. "International Migration, Remittances, and Schooling: Evidence from El Salvador." Journal of Development Economics 72: 429-461

Ellis, Frank. 1998. "Household Strategies and Rural Livelihood Diversification." The Journal of Development Studies 35: 1-38.

Elseoud M. Sayed Abou, 2014. Do Workers' Remittances Matter for the Egyptian Economy? IJAOR Vol. 4, No. 1, 13-38, Winter 2014 (Serial \#11)

Endo Isaku, Namaaji Jane and Kulathunga Anoma, 2010. World Bank Working Paper No. 201. Uganda's Remittance Corridors from United Kingdom, United States, and South Africa: Challenges to Linking Remittances to the Use of Formal Services, Washington DC

Fafchamps, Marcel. 1992 "Solidarity Networks in Pre-Industrial Societies: Rational Peasants with a Moral Economy." Economic Development and Cultural Change 41: 147-74.

Fafchamps, Marcel and Lund, Susan. 2003. "Risk-Sharing Networks in Rural Philippines." Journal of Development Economics 71: 261-287.

Fiadzo Emmanuel. 2004. Estimating the Determinants of Housing Quality: The Case of Ghana. Joint Center for Housing Studies, Harvard University, June 2004, W046

Fajnzylber, P., and J. H. Lopez, 2007, "Close to Home: The Development Impact of Remittances in Latin America," mimeo (Washington: World Bank).

Funkhouser, Edward. 1995. "Remittances from International Migration: A Comparison of El Salvador and Nicaragua." The Review of Economics and Statistics 77: 137-146. 
Galster, G. (2003): Investigating behavioral impacts of poor neighbourhoods: Towards new data and analytic strategies, Housing Studies 18 (3), 893 - 914.

Garip, Filiz. 2008. Social capital and migration: How do similar resources lead to divergent outcomes? Demography 45 (3): 591-617.

Gau George W. 1987, Efficient Real Estate Markets: Paradox or Paradigm? Real Estate Economics, Volume 15, Issue 2, June 1987, Pages: 1-12, Gau

Gibler, K., and Megbolugbe, I. (1992), "Differentiating between First-Time and Repeat Buyers of New Homes", paper presented at the 8th Annual ARES Meeting, San Diego.

Giddings Stephen W. 2009. The Land Market in Kampala, Uganda and its Effect on Settlement Patterns, The International Housing Coalition (IHC), www.Intlhc.org

Glytsos Nicholas P, 1996. The Role of Migrant Remittances in Development: Evidence from Mediterranean Countries. International Migration http://onlinelibrary.wiley.com/doi/10.1111/imig.2002.40.issue-1/issuetoc

Goodman J.L. 1977. "Causes and Indicators of Housing Quality," Social Indicators Research 5: 195-210.

Grieco, Elizabeth M. (1998) "The Effects of Migration on the Establishment of Networks: Caste Disintegration and Reformation Among the Indians of Fiji". International Migration Review, volume 32, number 3, pp. 704-736.

Grieco, E. M. 2003. The Remittance Behavior of Immigrant Households: Micronesians in Hawaii and Guam. New York: LFB Scholarly Publishing LLC

Grieco, E. M 2004. Will Remittances Continue Through Time? A New Answer to an Old Question. International Journal on Multicultural Societies (IJMS), Vol. 6, No. 2, 2004:243- 252 ISSN 1817-4574, www.unesco.org/shs/ijms/vol6 /issue2/art3 C UNESCO

Guarnizo L.E., Portes, A. and Haller, W. (2003) ' Assimilation and transnationalism: determinants of transnational political action among contemporary migrants,' American Journal of Sociology, (May).

Gurak, D. T. and Caces, F. 1992. "Migration networks and the shaping of migration systems". In: M. M. Kritz, L. L. Lim and H. Zlotnik, eds., International Migration Systems: A Global Approach, 150-76. New York: Oxford University Press.

Haan, Arjan de. \& Yaqub, Shahin, 2009. Migration and poverty: linkages, knowledge gaps and policy implications / Arjan de Haan and Shahin Yaqub United Nations Research Institute for Social Development, Geneva 
Haines, Lindsey, 2010. Cross-City Inequalities: Determinants of Rental Housing Quality in Bloomington, IL, Res Publica - Journal of Undergraduate Research: Vol. 15 Available at: http://digitalcommons.iwu.edu/respublica/vol15/iss1/6

Hanson, Gordon H. 2002. "Emigration and Educational Attainment in Mexico." Working Paper

Harris, John and Michael Todaro. 1970. "Migration, Unemployment, and Development: A Two-Sector Analysis." American Economic Review 60: 126-142.

Harris, John, and Sabot, R. 1976. Urban unemployment in LDC's: Towards a more general search model. Paper presented at Research Workshop on Rural-Urban Labor Market Interactions, International Bank for Reconstruction and Development, Washington, D.C.

Haurin, D. and Gill, L., 1987. Effects of income variability on the demand for owneroccupied housing. Journal of Urban Economics 22, pp. 136-150

Haurin, D., 1991. Income variability, homeownership, and housing demand. Journal of Housing Economics 1, 60-74

Henderson J and Ioannides Y. 1983. A Model of Housing Tenure Choice," American Economic Review, 73, No. 1, March, 98-113.

Henderson, J and Y. Ioannides 1986. Tenure Choice and the Demand for Housing, Economica 53, 231-246

Henderson, J and Y. Ioannides 1989. Dynamic Aspects of Consumer Decisions in Housing Markets, Journal of Urban Economics 26:2 212-230

Herrin William E., John R. Knight and Arsene M. Balihuta 2008. Migration and Wealth Accumulation in Uganda. The Journal of Real Estate Finance and Economics. Coverage Volume 1 / 1988 - Volume 42 / 2011 DOI 10.1007/s11146-008-9111-9

Hoddinott, John. 1994. "A Model of Migration and Remittances Applied to Western Kenya." Oxford Economic Papers 46: 459-76

IFAD (International Fund for Agriculture and Development). 2009. Sending Money Home to Africa. Rome.

Ilahi Nadeem, 1999. Return Migration and Occupational Change, Review of Development Economics Volume 3, Issue 2, June 1999, Pages: 170-186

Ilahi, Nadeem and Jafarey, Saqib. 1999. "Guest worker Migration, Remittances and the Extended Family: Evidence from Pakistan." Journal of Development Economics 58: 458-512. 
Itzigsohn, J. and Saucedo, S. G. 2002. Immigrant Incorporation and Sociocultural Transnationalism. International Migration Review, 36: 766-798. doi: 10.1111/j.17477379.2002.tb00104.x

Jiboye Adesoji David, 2010. Evaluating the Pattern of Residential Quality In Nigeria: The Case Of Osogbo Township UDC 728.1:711.4 - 112(669A/Z)(045)=111 Series: Architecture and Civil Engineering Vol. 8, No 3, 2010, pp. 307 - 316 DOI: 10.2298/FUACE1003307J

Jorgensen, Danny L. 1989. Participant Observation: A Methodology for Human Studies, Newbury Park, CA: Sage Publications.

Julca Alex, 2012 Can Immigrant Remittances Support Development Finance? Original scientific paper Panoeconomicus, 2013, 3, Special Issue, pp. 365-380

Kabki, M., Mazzucato, V., and Appiah, E., 2003, "Wo Benane A Eye Bebree". The Economic Impact Of Remittances Of Holland Based Ghanaian Migrants On Rural Ashanti, Brighton, Centre For Migration Research, University Of Sussex.

Kalema Willam S and Kayiira Duncan , 2008. Access too Housing Finance in Africa: Exploring the Issues. No. 4: Overview of the Housing Finance Sector in Uganda, Commissioned by Finmark Trust with support from Habitat for Humanity

Kandel and Massey 2002 Kandel, William and Douglas S. Massey 2002. The Culture of Mexican Migration: A Theoretical and Empirical Analysis, Social Forces 80 9811004.

Kapur Devesh. 2005, Remittances: the New Development Mantra, in Maimbo and Ratha, 2005, United Nations Development Organisation.

Katz, Eliakim and Stark, Oded, 1986. "On the shadow wage of urban jobs in lessdeveloped countries," Journal of Urban Economics, Elsevier, vol. 20(2),

Kauko, T. 2003. Planning Processes, Development Potential and House Prices: Contesting Positive and Normative Argumentation Housing, Theory and Society 20 (3) pp.113-126.

Kendig, H.L. 1990. A life course perspective on housing attainment, in: D. MYERS (Ed.) Housing Demography, pp. 133-156. Madison, WI: University of Wisconsin Press.

King Peter, 1996. The limits of housing policy: a philosophical investigation. London, Middlesex University Press.

King (2009) Understanding Housing Finance - Meeting Needs and Making Choices, p.3, on Amazon.com

Knowles, J. and R. Anker, 1981. An Analysis of Income Transfers in a Developing Country, Journal of Development Economics 8, 205-226. 
Knox, P. 1995. Urban Social Geography: An Introduction (Harlow, Longman).

Korn E.L. and Graubard B.I. (2003) Estimating variance components using survey data, Journal of the Royal Statistical Society, B, 65, 175-190

LaLonde Robert J and Topel Robert H, 1997 Economic Impact of International Migration and the Economic Performance of Migrants Chapter 14 in Handbook of Population and Family Economics. Edited by M.R. Rosenzweig and 0. Stark, Elsevier Science B.V., 1997

Lartey Emmanuel, 2010. Remittances, Investment and Growth in Sub-Saharan Africa, California State University, Fullerton

Lawrence, R. J. 1995. Housing Quality: An Agenda for Research. Urban Studies, 32(10), 1655-1664.

Leece, D. 2003. Behavioural Finance and Urban Sustainability. Future Thinking paper (London, RICS Foundation).

Levitt, Peggy and Ninna Nyberg, S Brensen, 2004. 'The Transnational Turn in Migration Studies', Global Migration Perspectives No. 6 http://www.gcim.org/gmp/Global\% 20 Migration\%20Perspectives\%20No\%206.pdf

Lin, J. Y., Wang, G., and Zhao, Y. (2004). Regional inequality and labor transfers in China. Economic Development and Cultural Change, 52(3):587-603.

Liu C H, Hartzell D J, Greig W, and Grissom T V, 1990 Integration of the Real Estate Market and the Stock Market: Some Preliminary Evidence, Journal of Real Estate Finance and Economics.

Lindley, A. (2007). Protracted displacement and remittances: the view from Eastleigh, Nairobi. UNHCR New Issues in Refugee Research No. 143. Geneva, UNHCR.

Linneman P (1986). A New Look at the Home Ownership Decision. Housing Finance Review, Fall/Winter, 1986

Lucas, Robert E.B. 1985. "Migration amongst the Botswana." The Economic Journal 95: 358-82

Lucas, Robert E.B. 1987. "Emigration to South Africa's Mines." The American Economic Review 77: 313-330.

Lucas Robert E.B. 2006. Migration and Economic Development in Africa: A Review of Evidence Journal of African Economic first published online October 25, 2006

Lucas, Robert E.B. and Stark, Oded. 1985. "Motivations to Remit: Evidence from Botswana." The Journal of Political Economy 93: 901-918. 
Lutz-Strulik, H. and Vale,R. 2002. Preservation of Architectural Heritage through Adaptive Reuse and Its Value for a Sustainable Environment. Paper presented at the Southern Crossings - Whaka whitiwhiti au Tonga Sixth Australasian Urban History Planning History Conference, Auckland, 13-16 February 2002.

Lynch, Philip (1971). The Evolution of a Policy. Canberra, Department of Immigration.

Mabogunje, A.L., Hardoy, J.E., \& Misra, R.P. 1978. Shelter Provision in Developing Countries, New York: John Wiley,

Maloney, Conor. 2004. Private Housing Estate Development and the Restructuring of Residential Geography in Accra. MA Thesis, London School of Economics

Malpezzi, S. 2003. Hedonic Pricing Models: a Selective and Applied In: O'Sullivan and Gibb (Eds) Housing Economics and Public Policy (Oxford, Blackwell Sciences/RICS Foundation

Massey Doreen B. and Catalano Alejandrina, 1978 Capital and land: Landownership by capital in Great Britain, Book (ISBN 0713161086 )

Massey, Douglas S. 1988. "Economic Development and International Migration in Comparative Perspective." Population and Development Review 14(3): 383-413.

Massey, Douglas S. 1990. Social structure, Household Strategies, and the Cumulative Causation of Migration, Population Index 56 (1): 3-26.

Massey, Douglas S, Rafael Alarcón, Jorge Durand, Humberto González. 1987. Return to Aztlan: The Social Process of International Migration from Western Mexico. Berkeley, CA: University of California Press

Massey, D. S., Arango, J., Hugo, G., Kouaouci, A., Pellegrino, A. and TaylorJ. E. 1993. "Theories of international migration: a review and appraisal". Population and Development Review 19: 431-66.

Mazzucato, V. 2008. The double engagement: Trans-nationalism and integration Ghanaian migrants' lives between Ghana and the Netherlands. Journal of Ethnic and Migration Studies 34 (2)

Mazzucato, V. (2008) Transnational reciprocity: Ghanaian migrants and the care of their parents back home. In E. Alber, S. Van der Geest, W. Geissler and S. Whyte (eds.) Generations in Africa:Connections and Conflicts, pp. 111-133. Münster: LIT Verlag.

McKenzie David and Mistiaen Johan. 2007, Surveying Migrant Households: A Comparison of Census-Based, Snowball, And Intercept Point Surveys\#. Development Research Group, World Bank June, 2007 
McKenzie, David J., and Hillel Rapoport. 2004. "Network Effects and the Dynamics of Migration and Inequality: Theory and Evidence from Mexico." Bureau for Research in Economic Analysis of Development (BREAD) Working Paper, no. 063. Cambridge, MA.

Meen, G. 2003 Housing, Random Walks, Complexity and the Macroeconomy. In: O'Sullivan and Gibb (Eds) Housing Economics and Public Policy (Oxford, Blackwell Sciences/RICS Foundation).

Meen, D. and Meen, G. 2003. Social Behaviour as a Basis for Modelling the Urban Housing Market: A Review, Urban Studies 40 (5-6) pp.917-935.

Menjivar, C., Davanzo, J., Greenwell, L. \& Burciaga-Valdez, R. 1998 'Remittance behavior among Salvadoran and Filipino Immigrants in Los Angeles'. International Migration Review, 32, no. 1, pp. 97-126.

Mishra, Prachi. 2005. "Macroeconomic Impact of Remittances in the Caribbean." International Monetary Fund, Washington, DC

Ministry of Finance, Planning and Economic Development, (MoFPED). 2009. 'Background to the Budget 2009/2010: Enhancing Strategic Interventions to Improving Business, and Revitalise Production to Achieve Prosperity for All'. Kampala:

Mohapatra Sanket \& Ratha Dilip, 2011. "Remittance Markets in Africa," World Bank Publications, The World Bank, number 2292, January

Morris E. and Winter M. 1997, Housing, family and society, 2nd Edition, St. Paul Minn: Department of Design, Housing and Apparel, University of Minnestota (originally published by John Willy and Sons, New York, 1978)

Morris E. W, Woods, M.E and Jacobson A. L. 1972. The measurement of housing quality. Land Economic 48(4), 383-387

Morrow-Jones, H. A. 1988. The housing lifecycle and the transition from renting to owning a home in the United States: a multi-state analysis, Environment and Planning A, 20, pp. 1165-1184

Myers D. 1985. Wives earnings and the rising cost of home ownership. Social science Quarterly 66: 319-329

Ndubueze, J. O. (2009) Urban housing affordability and housing policy dilemmas in Nigeria. Birmingham: University of Birmingham (http://etheses.bham.ac.uk/298/).

New Vision Newspaper, 9th 2010, http://www.newvision.co.ug/PA/8/220/728283 21/02/2011

Orozco M. 2002. Worker Remittances: the human face of globalization. Working Paper commissioned by the Multilateral Investment Fund of the Inter- American 
Development Bank, October 10, 2002.

www.thedialogue.org/publications/country studies/remittances /worker_remit.pdf

Orozco, M., 2005: Diasporas, development and transnational integration: Ghanaians in the U.S., U.K. and Germany, Institute for the Study of International Migration and Inter-American Dialogue.

Osili Una Okonkwo (2006), Remittances and savings from international migration: Theory and evidence using a matched sample. Journal of Development Economics 83 (2007) 446-465. www.elsevier.com/locate/econbase

Ozden Caglar and Schiff Maurice (Eds.) 2006. International Migration, Remittances, and the Brain Drain New York: Palgrave Macmillan and World Bank, xiv + 274 p

Page, John, and Plaza Sonia. 2006. "Migration Remittances and Development: A Review of Global Evidence." Journal of African Economies 15 (Suppl. 2): 245-336.

Parrado, Emilio A, "Economic restructuring and intra-generational class mobility in Mexico.", Social Forces (2004)

Pelletier, A. and Rocher, E. (2008), « Les transferts de revenus des migrants : quel impact sur le développement économique et financier des pays $\mathrm{d}^{\prime}$ Afrique subsaharienne? », Bulletin de la Banque de France , $N^{\circ} 173$.

Pellow, D. 2003, New Spaces in Accra: transnational houses. City \& Society, 15: 5986. doi: 10.1525/city.2003.15.1.59

Plaut, S. E. 1987. The timing of housing tenure transition, Journal of Urban Economics, Volume 21, Issue 3, 21, pp. 312-322

Plaza, Sonia, Mario Navarrete, and Dilip Ratha, 2011. Migration and Remittances Household Surveys: Methodological Issues and New Findings from Sub-Saharan Africa, 2011. Washington, D.C.: World Bank. (Africa Migration Project, Migration and Remittances Unit, World Bank).

Poirine, Bernard. 1997. "A Theory of Remittances as an Implicit Family Loan Arrangement." World Development 25: 589-611.

Porell, F.W. 1985 “One Man's Ceiling is Another Man's Floor: Landlord/Manager Residency and Housing Condition," Land Economics 61, no. 2: 106-117.

Portes, A. 1995. "Economic sociology and the sociology of immigration: a conceptual overview". In: Alejandro Portes, the Economic Sociology of Immigration: Essays on Networks, Ethnicity and Entrepreneurship, 248-79. New York: Russell Sage Foundation.

Portes, A. 1998. "Social capital: its origins and applications in modern sociology". Annual Review of Sociology 24: 1-24. 
Quibria, M.G. 1997 “International Migration, Remittances and Income Distribution in the Source Country: A Synthesis." Bulletin of Economic Research 49: 29-46.

Rapoport, H. (2002): Migration, credit constraints and self-employment: A simple model of occupational choice, inequality and growth, Economics Bulletin, 15, 7: 1-5

Ratha D. 2007. Leveraging Remittances for Development. || Policy Brief, Migration Policy Institute, Washington DC.

Ratha, Dilip. 2010. "Diaspora Bonds for Development Financing during the Crisis." October 26, People Move Blog, World Bank, Washington, DC. http:// blogs.worldbank.org/peoplemove/diaspora-bonds-for-developmentfinancingduring-a crisis

Ratha D, Mohapatra S and Scheja, 2011. Impact of Migration on Economic and Social Development : a Review of Evidence and Emerging Issues. The World Bank Development Prospects Group Migration and Remittances Unit \& Poverty Reduction and Economic Management Network, February 2011

Ratha Dilip, 2011. Leveraging Migration for Africa, Remittances, Skills and Investments. www. Chathamhouse.org.uk

Ratha Dilip, Mohapatra Sanket, Ozden Caglar, Plaza Sonia, Shaw William, and Shimeles Abebe, 2011. Leveraging Migration for Africa: Remittances, Skills and Investments. Washington, D.C.: World Bank. (Africa Migration Project, Migration and Remittances Unit, World Bank)

Rapoport, A. 2001 'Theory, Culture and Housing', Housing, Theory and Society, 17, pp 145-165

Regmi Gopal \& Tisdell Clem, 2002. Remitting behaviour of Nepalese rural-to-urban migrants: implications for theory and policy, The Journal of Development Studies, Taylor and Francis Journals, vol. 38(3), pages 76-94, February

Rempel, Henry and Lobdell, Richard A. 1978. The Role of Urban-to-Rural Remittances in Rural Development. Journal of Development Studies 14: 324-41.

Richter, Kerry, Philip Guest, Wathinee Boonchalaksi, Nittaya Piriyathamwong, Nimfa B. Ogena. 1997. Migration and the Rural Family: Sources of Support and Strain in a Mobile Society. Nakhon Pathom, Thailand: Institute for Population and Social Research

Rosen Jeffrey Scott, 2007. Remittances, Investment and Portfolio allocation: Analysis of remittance usage and risk tolerance in rural Pakistan, $\mathrm{PhD}$ thesis. Graduate School of the Ohio State University 
Rozelle, Scott T., Taylor, J. Edward., and DeBrauw, Alan. 1999. "Migration, Remittances, and Agricultural Productivity in China." The American Economic Review 89: 287-91.

Rudel, T. K. 1987. Housing price inflation, family growth, and the move from rented to owner-occupied housing, Urban Studies, 24, pp. 258-267.

Sayer, R.A. (2000) Realism and Social Science. London: Sage.

Seidel, John and Klaus Udo Kelle, 1995. "Different Functions of Coding in the Analysis of Data." in K.U.Kelle ed., Computer Aided Qualitative Data Analysis: Theory, Methods, and Practice. Thousand Oaks, CA: Sage Publications.

Selman S, Morris E.W, Winter M. and Murphy A. D. 1994. Changes in the quality of building materials in Oaxaca De Juarez. Proceedings for the Ninth Annual Conference on the Sociology of housing. Saint Paul, Minn, Department of Design, Housing and Apparel, University of Minnesota 199-216.

Sinning, M. 2006. "Home-Ownership and Economic Performance of Immigrants in Germany." RWI Discussion Papers No. 45.

Skeldon, R. 2004. More than remittances: other aspects of the relationship between migration and development. United Nations, Population Division, New York.

Retrieved 4 February 2005

from:www.un.org/esa/population/publications/thirdcoord2004/Skeldon_Paper.pdf

Smith, L. and Mazzucato, V. 2003. Houses, businesses and urban livelihoods: The influence of Ghanaian migrants on local economic activities in Accra, Ghana. Presented at the International Workshop on Migration and Poverty in West Africa. Sussex

Sommerville, P and Chan, C. 2001. Human dignity and the 'third way': the case of housing policy, paper presented at the Housing Studies Association conference on 'Housing Imaginations: new concepts, new theories, new researchers, University of Cardiff, Cardiff, 4-5 September 2001.

Sorensen N N and Olwig K F. 2002. Work and Migration: Life and livelihoods in a globalizing world. London: Routledge.

Ssewanyana Sarah and Bategeka Lawrence, 2010. Global Financial Crisis Discussion series, Paper 21: Uganda Phase 2. ODI, UK

Stalker, Peter. 2000 Workers without frontiers: the impact of globalization on international migration / Peter Stalker Lynne Rienner Publishers, Boulder, Colo.; London

Stark, Oded. 1980. "On the Role of Urban-to-Rural Remittances in Rural Development." Journal of Development Studies 16: 369-74 
Stark Oded. 1991, The migration of labor : Stark, (Basil Blackwell, Oxford, 1991) pp. $\mathrm{x}+406<\mathrm{A}$ HREF="http://ideas.repec.org/s/eee/regeco.html">Regional Science and Urban Economics $</ A>$,Elsevier, vol. 23(3), pages 453-457, July.

Stark, Oded. 1995. Altruism and Beyond. Cambridge University Press.

Stark ,Oded. 1996. "Discontinuity and the Theory of International Migration," Kyklos, Vol. 37, 1984. (Reprinted in Robin Cohen (ed.), Theories of Migration. Cheltenham: Elgar, 1996.)

Stark, Oded and Levhari, David. 1982. "On Migration and Risk in Less Developed Countries." Economic Development and Cultural Change 31: 191-96.

Stark, O., and R. E. B. Lucas. 1988. "Migration, Remittances, and the Family." Economic Development and Cultural Change 36 (3, April): 465-81.

Stark, Oded, Helmenstein, Christian., and Prskawetz, Alexia. 1997. “A Brain Gain with a Brain Drain." Economics Letters 55: 227-34.

Stark, Oded and Lucas, Robert E.B. 1988. "Migration, Remittances, and the Family." Economic Development and Cultural Change 36: 465-81.

StataCorp, 2009. Stata Statistical Software: Release 11. College Station, TX: StataCorp LP.

Sternlieb, George . 1966. The Tenement Landlord. NewBRuniswick, N.J: Rutgers Universisty Press.

Stiglitz, Joseph E. 1974. "Alternative Theories of Wage Determination and Unemployment in LDC's: The Labor Turnover Model." The Quarterly Journal of Economics 88: 194-227

Strassman, W.P. (1980b), "Housing improvement in an opportune setting: Cartagena, Colombia", Land Economics.

Taylor, J. Edward. 1999. "The New Economics of Labour Migration and the role of remittances in the migration process." International Migration, Vol. 37, No. 1, pp. 63-88

Tilly, C. and Brown, C. H. 1967. "On uprooting, kinship, and the auspices of migration" Journal of Comparative Sociology 8: 141-64.

Todaro, M. P. 1969. "A Model of Labor Migration and Urban Unemployment in Less Developed Countries." American Economic Review 59 (1): 138-48.

Todaro, M. P. 1976. Rural-urban migration, unemployment and job probabilities: Recent theoretical and empirical research. In Economic factors in population growth, ed. Ansley J. Coale, pp. 367-86. Proceedings of an International Economics Association conference at Valescure, France. London: Macmillan. 
Todaro, Michael P. and Harris, John R. (1970), "Migration, Unemployment and Development: A Two-Sector Analysis", American Economic Review 60 (1): 126-142, JSTOR 1807860

Tomes, Nigel. 1981. "The Family, Inheritance, and the Intergenerational Transmission of Inequality." The Journal of Political Economy 89: 928-958.

Uganda Bureau of Statistics, 2006, Uganda National Household Survey 2005/2006, Version 1.0 of the public use dataset (August 2008), provided by the National, Data Archive' www.ubos.org

Uganda Bureau of Statistics, 2007. Survey on Remittances to Uganda, Version 1.0 of the public use dataset (February 2009), provided by the Uganda National Data Archive. www.ubos.org

Uganda Bureau of Statistics, 2010 Uganda National Household Survey 2009/2010 overview of findinga at public workshop provided by the Uganda National Data Archive. www.ubos.org

United Nations Development Program (UNDP). 2005. Trends in Total Migrant Stock: The 2005 Revision. Population Division. New York.

UNHS, 2005/2006: Uganda National Household Survey, 2005/2006: Socio-economic module. Volume 3 of Uganda National Household Survey, 2005/2006: Report, Uganda Bureau of Statistics

Vertovec, Stephen. 2004. Trends and Impacts of Migrant Trans-nationalism University of Oxford: Compas Working Paper No. 3 World Bank. 2009. Migration and Development Brief 11. November.

Wallace Alison, 2004 Understanding Local Housing Markets? Examining Approaches to Housing Market Analysis. Working Paper 62004 ISBN: 1-903825-15-6 ESRC/ODPM Postgraduate Research Programme

Winters, Paul, Alain de Janvry, and Elisabeth Sadoulet. 2001. "Family and Community Networks in Mexico-US Migration." Journal of Human Resources 36(1):159-84.

World Bank, 1993. Mali: Assessment of Living Conditions. Washington DC.

World Bank. 2009. Migration and Development Brief 11. November. Washington, D.C. www.worldbank.org/prospects/migration and remittances

Woodruff, C. and R. Zenteno (2001): Remittances and micro-enterprises in Mexico, Mimeo.,University of California at San Diego

Yang, D. 2004. "International Migration, Human Capital, and Entrepreneurship: Evidence from Philippine Migrants' Exchange Rate Shocks", Mimeo. Ford School of Public Policy, University of Michigan. 
Yeboah Ian E.A., 2000. Structural Adjustment and Emerging Urban Form in Accra, Ghana. Africa Today, Vol. 47, No. 2, pp. 61-89.

Yeboah Ian E.A., 2003. Demographic and Housing Aspects of Structural Adjustment and Emerging Urban Form in Accra, Ghana. Africa Today, Vol. 50, No. 1, pp. 106119.

Zucker, L. G. 1988. Where do institutional patterns come from? Organizations as actors in social systems. In L. G. Zucker (Ed.), Institutional patterns and organization: Culture and environment (pp. 23-49). Cambridge, MA: Ballinger. 


\section{Samenvatting scriptie}

Geldzendingen ("remittances") zijn steeds vaker een belangrijke bron van buitenlands kapitaal geworden, die de instroom van buitenlandse hulp en ander privékapitaal naar vele landen in Afrika overschrijden. Geldzendingen zijn nu een erkende bron van extra inkomsten voor gezinnen, gezien het feit dat ze privégeld zijn waarvan het gebruik niet enkel afhangt van één gebruiker maar eerder van twee gebruikers, de gezinnen en de migranten zelf, zonder enige tussenpersoon. Theoretisch vormen geldzendingen een van de verklarende factoren waarom migranten verbonden blijven met hun thuisland, wat adequaat beschreven wordt door transnationalistische theoretici. De vraag naar huisvesting in Oeganda is veel groter dan het aanbod en de woningnood zal naar schatting bijna 8 miljoen eenheden bereiken in 2020. Een aanzienlijk deel van de geldzendingen, ongeveer 25 procent wordt geabsorbeerd door huisvesting, die een van de belangrijkste begunstigde sectoren in Oeganda is. Geconfronteerd met deze groei proberen sommige regeringen het gebruik van zulke instromen te reguleren door beleid, echter zonder succes. Voor de huisvestingssector is het echter mogelijk om prikkels te creëren voor het gericht gebruik van geldzendingen voor de bevordering van de woonzekerheid en de kwaliteit van de huisvesting. Uit de bevindingen van deze scriptie uit een gepoolde dwarsdoorsnede-analyse van steekproefgegevens van de Uganda National Household Survey 2005/2006 (UNHS III) en 2009/2010 (UNHS IV) blijkt dat ten gevolge van beduidende positieve correlaties tussen geldzendingen en de attributen van woonzekerheid (eigendoms- en huurhuizen) en huisvestingskwaliteit (toegang tot nutsvoorzieningen en de fysieke toestand van de huisvesting) geldzendingen kunnen geconditioneerd worden. Kruistabel- en correlatiematrices bevestigen de onafhankelijkheid van geldzendingen en hun invloed als een verklarende variabele voor de veranderingen in de woonzekerheid en huisvestingskwaliteit. De logistieke regressieresultaten geven hogere kansen voor huishoudens die geldzendingen ontvangen om hun woonzekerheid te bevorderen en verbeteringen aan de kwaliteit van hun huis te financieren voor zowel de nutsvoorzieningen als de fysieke omstandigheden dan voor huishoudens zonder ontvangst van geldzendingen. De conclusie is dat geldzendingen kunnen dienen als een instrument voor betere huisvestingszekerheid en -kwaliteit voor huishoudens. 


\section{MGSoG Dissertation Series}

Ilire Agimi

New Governance under Limited Statehood

The Case of Local Government Reform in Kosovo

MGSoG Dissertation Series, nr 39 (2014)

Kristine Farla

Empirical Studies on Institutions, Policies and Economic Development

MGSoG Dissertation Series, nr 38 (2013)

Marina Petrovic

Social Assistance and Activation in the Pursuit of Happiness:

Shedding New Light on Old Policy Solutions to Social Exclusion

MGSoG Dissertation Series, nr 37 (2013)

Laura Torvinen

Assessing Governance Assessments; The Case of Mozambique

Governance Assessments in the Context of Aid Effectiveness Discourse

MGSoG Dissertation Series, nr 36 (2013)

Biniam Egu Bedasso

Institutional Change in the Long Shadow of Elites

Essays on Institutions, Human Capital and Ethnicity in Developing Countries

MGSoG Dissertation Series, nr 35 (2013)

Sepideh Yousefzadeh Faal Deghati

Childhoods Embargoed

Constructing and Reconstructing Multidimensional Child Poverty in Iran 1984-2009

MGSoG Dissertation Series, nr 34 (2013)

Robert Bauchmüller

Investing in Early Childhood Care and Education:

The Impact of Quality on Inequality

MGSoG Dissertation Series, nr 33 (2013)

Martin Rehm

Unified Yet Separated

Empirical Study on the Impact of Hierarchical Positions within Communities of Learning

MGSoG Dissertation Series, nr 32 (2013) 
Dorcas Mbuvi

Utility Reforms and Performance of the Urban Water Sector in Africa

MGSoG Dissertation Series, nr 31 (2012)

Lina Salanauskaite

Distributional Impacts of Public Policies:

Essays in Ex-Ante and Ex-Post Evaluation

MGSoG Dissertation Series, nr 30 (2012)

\section{Esther Schüring}

To Condition or not - is that the Question?

An Analysis of the Effectiveness of Ex-Ante and Ex-Post Conditionality in Social Cash

Transfer Programs

MGSoG Dissertation Series, nr 29 (2012)

Joe Abah

Strong Organisations in Weak States

Atypical Public Sector Performance in Dysfunctional Environments

MGSoG Dissertation Series, nr 28 (2012)

Zina Samih Nimeh

Social Citizenship Rights: Inequality and Exclusion

MGSoG Dissertation Series, nr 27 (2012)

Lenka Eisenhamerová

Legitimacy of 'Humanitarian Military Intervention'

MGSoG Dissertation Series, nr 26 (2011)

Sonila Tomini

Informal Payments for Health Care Services in Albania

MGSoG Dissertation Series, nr 25 (2011)

Jinjing Li

Dynamic Microsimulation in Public Policy Evaluation

MGSoG Dissertation Series, nr 24 (2011)

Aziz Atamanov

Rural Nonfarm Employment and International Migration as Alternatives to Agricultural

Employment:

The Case of Kyrgyztan

MGSoG Dissertation Series, nr 23 (2011) 
Frieda Vandeninden

Poverty Alleviation: Aid and Social Pensions

MGSoG Dissertation Series, nr 22 (2011)

Juliana Nyasha Tirivayi

The Welfare Effects of Integrating AIDS Treatment with Food Transfers:

Evidence from Zambia

MGSoG Dissertation Series, nr 21 (2011)

Agnieska Ewa Sowa

Who's Left Behind? Social Dimensions of Health Transition and Utilization of Medical Care in Poland

MGSoG Dissertation Series, nr 20 (2011)

Emmanaouil Sfakianakis

The Role of Private Actors in the Provision of Public Goods with Applications to Infrastructure and Financial Stability

MGSoG Dissertation Series, nr 19 (2011)

Siu Hing Lo

White Collars Green Sleeves

An Interonganizational Compariso of Deteminants of Energie-Related Behaviors among Office Workers

MGSoG Dissertation Series, nr 18 (2011)

Treena $\mathrm{Wu}$

Constraints to Human Capital Investment in Developing Countries:

Using the Asian Financial Crisis in Indonesia as a Natural Experiment

MGSoG Dissertation Series, nr 17 (2011)

Henry Espinoza Peña

Impact Evaluation of a Job-Training Programme for Disadvantaged Youths:

The Case of Projoven

MGSoG Dissertation Series, nr 16 (2011)

Florian Tomini

Between Family and Friends

Understanding the Interdependency of Private Transfers

MGSoG Dissertation Series, nr 15 (2010) 


\section{Michał Polalowski}

The Institutional Transformation of Social Policy in East Central Europe:

Poland and Hungary in comparative and historical perspective

MGSoG Dissertation Series, nr 14 (2010)

\section{Maha Ahmed}

Defining, Measuring and Adressing Vulnerability:

The Case of Post Conflict Environments

MGSoG Dissertation Series, nr 13 (2010)

Pascal Beckers

Local Space and Economic Success

The role of spatial segregation of migrants in the Netherlands

MGSoG Dissertation Series, nr 12 (2010)

Victor Cebotari

Complicting Demands in Ethnically Diverse Societies

Ethnopolitical Contention and Identity Values in Europe

MGSoG Dissertation Series, nr 11 (2010)

\section{Dennis Gyllensporre}

Competing and Complementary Perspectives on the EU as a Crisis Management Actor:

An Examination of the Common Security and Defence Policy through the Lenses of Idealism

and Realism

MGSoG Dissertation Series, nr 10 (2010)

Judit Vall Castello

Business Cycle and Policy Effects on Labour Market Transitions of Older and Disabled Workers in Spain

MGSoG Dissertation Series, nr. 9 (2010)

Keetie Roelen

False Positives or Hidden Dimentions: the definition and measurement of child poverty MGSoG Dissertation Series, nr. 8 (2010)

Denisa Maria Sologon

Earning Dynamics in Europe

MGSoG Dissertation Series, nr. 7 (2010)

Melissa Siegel

Money and Mobility: Migration and Remittances

MGSoG Dissertation Series, nr. 6 (2010) 
Jessica S. Hagen-Zanker

Modest Expectations: Causes and effects of migration on migrant households in source countries

MGSoG Dissertation Series, nr. 5 (2010)

Mirtha R. Muniz Castillo

Human Development and Autonomy in Project Aid: Experiences from four bilateral projects in Nigaragua and El Salvador

MGSoG Dissertation Series, nr. 4 (2009)

Christiane Arndt

Governance Indicators

MGSoG Dissertation Series, nr. 3 (2009)

Britta Augsburg

Microfinance - Greater Good or Lesser Evil?

MGSoG Dissertation Series, nr. 2 (2009)

Geranda Notten

Measuring and Managing Poverty Risks

MGSoG Dissertation Series, nr. 1 (2008) 